Projeção multidimensional aplicada a visualização de resultados de busca textual 
SERVIÇO DE PÓS-GRADUAÇÃO DO ICMC-USP

Data de Depósito:

Assinatura:

\title{
Projeção multidimensional aplicada a visualização de resultados de busca textual
}

\author{
Erick Mauricio Gómez Nieto
}

Orientador: Prof. Dr. Luis Gustavo Nonato

Dissertação apresentada ao Instituto de Ciências Matemáticas e de Computação - ICMC-USP, como parte dos requisitos para obtenção do título de Mestre em Ciências - Ciências de Computação e Matemática Computacional. VERSÃO REVISADA.

USP - São Carlos

Outubro/2012 
Ficha catalográfica elaborada pela Biblioteca Prof. Achille Bassi e Seção Técnica de Informática, ICMC/USP, com os dados fornecidos pelo(a) autor(a)

G633p Nezieto, Erick Mauricio
Projeção multidimensional aplicada a visualização
de resultados de busca textual / Erick Mauricio Gómez
Nieto; orientador Luis Gustavo Nonato. -- São
Carlos, 2012 .
73 p.
Dissertação (Mestrado - Programa de Pós-Graduação en
Ciências de Computação e Matemática Computacional) --
Instituto de Ciências Matemáticas e de Computação,
Universidade de São Paulo, 2012.
1. Visualização de informação. 2. Mineração de
dados. 3. Projeção Multidimensional. 4. Visualização
de buscas na web. I. Nonato, Luis Gustavo, orient.
II. Título.



Dedicatória

Dedico este trabalho a:

Delia, Willy e Alberto no céu;

e Maria e Katty, as minhas luzes neste mundo. 


\section{Agradecimentos}

Ao Prof. Dr. Luis Gustavo Nonato, pela excelente orientação fornecida, pelo incentivo, pelo exemplo, apoio e parceria na realização deste projeto. Sem aquele nível de exigência não teria jamais alcançado nossos objetivos.

À Profa. Dra. Maria Cristina Ferreira de Oliveira pela colaboração, ideias, sugestões e orientação adicional durante meu mestrado. E principalmente, por me mostrar o significado da vida acadêmica como professor.

Aos Profs. Drs. Rosane Minghim e Fernando Paulovich por me ensinar os conhecimentos necessários de visualização durante e após a disciplicina. Agora, eu posso ajudar à gente a entender seu "brave new information world"(F.P.).

Aos amigos do Grupo de Processamento Visual e Geométrico (VGPG): Wallace Casaca $(W)$, Danilo Motta (Danilo), Paulo Joia (PJ), Luiz Fernando de Souza (Luiz), Douglas Cedrim (Cedrim), Afonso Paiva (Afopa), Paulo Pagliosa (PP) e Mario Lizier (Mario), a primeira geração deste grupo de pesquisa. Também, aos amigos do Laboratório de Matemática Aplicada e Computação Cientifica (LMACC), e do Grupo de Visualização e Computação Gráfica (VICG). Seu apoio e exemplo sempre foi muito importante para mim.

Aos meus pais, Maria e Willy, pelo exemplo e apoio incondicional, e a minha irmã Katty (que me pediu para colocar o nome dela aqui).

Ao Alex Cuadros-Vargas, Eduardo Tejada e César Beltrán, pela confiança depositada em mim antes, durante e depois do meu mestrado.

À Frizzi pelo incomparável carinho e apoio durante todo este tempo.

Ao Brian Johnson, Angus Young, John Frusciante, Yngwie Malmsteen, Mr. Mojo Risin, Gavin Rossdale, Paco de Lucia, Andrés Segovia, Eddie Van Halen, Jimmy Page, Robby Krieger, Orianthi, J. Hendrix e Alice Cooper, pela motivação durante as duras jornadas de trabalho, e a inspiração necessária para concluir esta dissertação.

Ao Instituto de Ciências Matemáticas e de Computação (ICMC), pela oportunidade de realização do curso de mestrado. Aos funcionários e professores sempre dispostos na prestação de seus serviços e pela colaboração.

À Coordenação de Aperfeiçoamento de Pessoal Nível Superior (CAPES), pelo apoio financeiro concedido que viabilizou a realização deste trabalho, processo DS-7251876/M1. 
GOMEZ-NIETO, Erick. Projeção multidimensional aplicada a visualização de resultados de busca textual. 2012. Dissertação (Mestrado) - Instituto de Ciências Matemáticas e de Computação, Universidade de São Paulo, São Carlos, 2012.

Usuários da Internet estão muito familiarizados que resultados de uma consulta sejam exibidos como uma lista ordenada de snippets. Cada snippet possui conteúdo textual que mostra um resumo do documento referido (ou página web) e um link para o mesmo. Esta representação tem muitas vantagens como, por exemplo, proporcionar uma navegação fácil e simples de interpretar. No entanto, qualquer usuário que usa motores de busca poderia reportar possivelmente alguma experiência de decepção com este modelo. Todavia, ela tem limitações em situações particulares, como o não fornecimento de uma visão geral da coleção de documentos recuperados. Além disso, dependendo da natureza da consulta - por exemplo, pode ser muito geral, ou ambígua, ou mal expressa - a informação desejada pode ser mal classificada, ou os resultados podem contemplar temas variados. Várias tarefas de busca seriam mais fáceis se fosse devolvida aos usuários uma visão geral dos documentos organizados de modo a refletir a forma como são relacionados, em relação ao conteúdo.

Propomos uma técnica de visualização para exibir os resultados de consultas web que visa superar tais limitações. Ela combina a capacidade de preservação de vizinhança das projeções multidimensionais com a conhecida representação baseada em snippets. Essa visualização emprega uma projeção multidimensional para derivar layouts bidimensionais dos resultados da pesquisa, que preservam as relações de similaridade de texto, ou vizinhança. A similaridade é calculada mediante a aplicação da similaridade do cosseno sobre uma representação "bag-of-words" vetorial de coleções construídas a partir dos snippets. Se os snippets são exibidos diretamente de acordo com o layout derivado, eles se sobrepõem consideravelmente, produzindo uma visualização pobre. Nós superamos 
esse problema definindo uma energia funcional que considera tanto a sobreposição entre os snippets e a preservação da estrutura de vizinhanças como foi dada no layout da projeção. Minimizando esta energia funcional é fornecida uma representação bidimensional com preservação das vizinhanças dos snippets textuais com sobreposição mínima. A visualização transmite tanto uma visão global dos resultados da consulta como os agrupamentos visuais que refletem documentos relacionados, como é ilustrado em vários dos exemplos apresentados.

Palavras-chave: Visualização de informação; Mineração de dados; Projeção multidimensional; Visualização de buscas na Web. 
GOMEZ-NIETO, Erick. Multidimensional projection applied to textual search results visualization. 2012. Dissertation (Master) - Institute of Mathematics and Computer Science, University of São Paulo, São Carlos, 2012.

Internet users are very familiar with the results of a search query displayed as a ranked list of snippets. Each textual snippet shows a content summary of the referred document (or web page) and a link to it. This display has many advantages, e.g., it affords easy navigation and is straightforward to interpret. Nonetheless, any user of search engines could possibly report some experience of disappointment with this metaphor. Indeed, it has limitations in particular situations, as it fails to provide an overview of the document collection retrieved. Moreover, depending on the nature of the query - e.g., it may be too general, or ambiguous, or ill expressed - the desired information may be poorly ranked, or results may contemplate varied topics. Several search tasks would be easier if users were shown an overview of the returned documents, organized so as to reflect how related they are, content-wise.

We propose a visualization technique to display the results of web queries aimed at overcoming such limitations. It combines the neighborhood preservation capability of multidimensional projections with the familiar snippet-based representation by employing a multidimensional projection to derive two-dimensional layouts of the query search results that preserve text similarity relations, or neighborhoods. Similarity is computed by applying the cosine similarity over a "bag-of-words" vector representation of collection built from the snippets. If the snippets are displayed directly according to the derived layout they will overlap considerably, producing a poor visualization. We overcome this problem by defining an energy functional that considers both the overlapping amongst snippets and the preservation of the neighborhood structure as given in 
the projected layout. Minimizing this energy functional provides a neighborhood preserving two-dimensional arrangement of the textual snippets with minimum overlap. The resulting visualization conveys both a global view of the query results and visual groupings that reflect related results, as illustrated in several examples shown.

Keywords: Information Visualization; Visual Data Mining; Multidimensional projection; Web search visualization. 
Lista de Figuras $\quad$ xi

\begin{tabular}{ll} 
Lista de Tabelas & xv \\
\hline
\end{tabular}

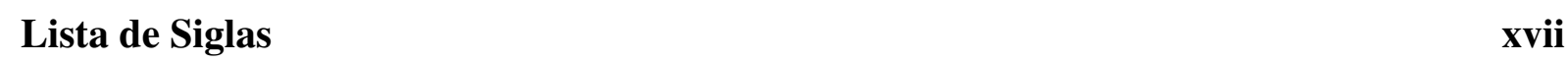

Lista de Algoritmos $\quad$ xix

\begin{tabular}{|lll}
\hline 1 & Introdução & 1
\end{tabular}

1.1 Contexto e Motivação . . . . . . . . . . . . . . . . . . . . . . . 1

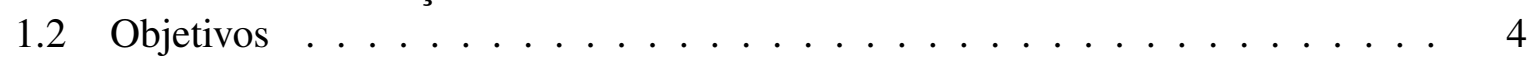

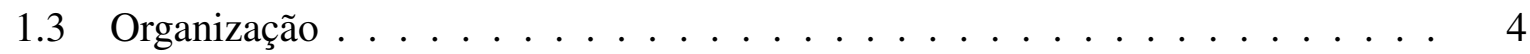

\begin{tabular}{|ll|}
\hline 2 & Metáforas Visuais a partir de Projeções Multidimensionais e de Resultados em \\
\hline \hline Buscas Web & $\mathbf{7}$
\end{tabular}

2.1 Considerações Inicias . . . . . . . . . . . . . . . . . . . . . . . . 7

2.2 Metáforas Visuais a partir de Projeções Multidimensionais . . . . . . . . . . . 10

$2.2 .1 \quad$ ProjCloud (2012) $\ldots \ldots \ldots \ldots$. . . . . . . . . . . . . . 10

2.2.2 Nuvens de palavras com preservação semântica usando Seam Carving

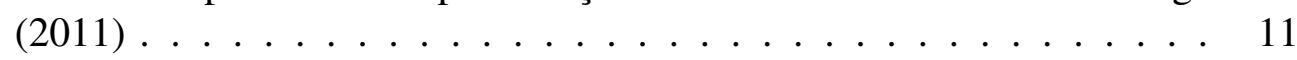

$2.2 .3 \quad$ CSMP (2011) . . . . . . . . . . . . . . . . . 12

2.2 .4 Nuvens dinâmicas com preservação de contexto (2010) . . . . . . . . . . 14

2.2 .5 GraphSplatting (2003) . . . . . . . . . . . . . . . . . . . 16

2.3 Visualização de Resultados de Buscas na Web . . . . . . . . . . . . . . . . . 17

2.3 .1 Técnicas baseadas em listas aumentadas . . . . . . . . . . . . . . . . . . 17

2.3 .2 Técnicas baseadas em imagens . . . . . . . . . . . . . . . . . . . . . 18

2.3.3 Técnicas baseadas em plotagem . . . . . . . . . . . . . . . . . . 19

2.4 Considerações Finais $\ldots \ldots \ldots \ldots$ 
$\begin{array}{llr}3 & \text { ProjSnippet } & 25\end{array}$

3.1 Pré-Processamento . . . . . . . . . . . . . . . . . . . 25

3.2 Projeção Multidimensional . . . . . . . . . . . . . . . . . . . 27

3.3 O Funcional de Energia . . . . . . . . . . . . . . . . . . . . . . 28

$3.3 .1 \quad$ A energia de sobreposição $E_{O}$. . . . . . . . . . . . . . . . . . . 29

3.3.2 A energia de vizinhança $E_{N} \ldots \ldots \ldots \ldots$. . . . . . . . 30

3.4 Aspectos Computacionais e Outros Detalhes . . . . . . . . . . . . . . . . . 32

3.4 .1 Reduzindo espaços vazios . . . . . . . . . . . . . . . . . . . 33

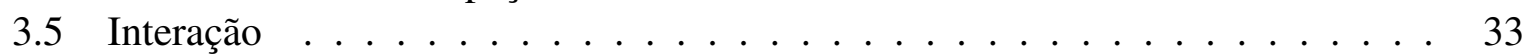

3.6 Resultados . . . . . . . . . . . . . . . . . . . . . . . . . . . . . . . . . . . . . . .

$3.6 .1 \quad$ O efeito do parâmetro $\alpha$ (alfa) $\ldots \ldots \ldots \ldots$

4 Estudo Comparativo: Avaliação e Resultados 41

4.1 Heurísticas para a Remoção de Sobreposição . . . . . . . . . . . . . . . . . . 41

4.1 .1 VPSC . . . . . . . . . . . . . . . . . 41

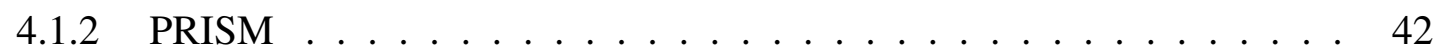

4.1 .3 Wordle/ManiWordle . . . . . . . . . . . . . . . . 43

4.1 .4 Voronoi . . . . . . . . . . . . . . . . . . . . . . . . . . . . 44

4.2 Métodos de Avaliação Quantitativa . . . . . . . . . . . . . . . . . . . . 45

4.2 .1 Medida de distância Euclidiana . . . . . . . . . . . . . . . . 45

4.2 .2 Similaridade no layout . . . . . . . . . . . . . . . . . . . . . . . . . . . . . . . . . 45

4.2 .3 Incremento no tamanho . . . . . . . . . . . . . . . . . . . . . 46

4.2 .4 Preservação de vizinhança . . . . . . . . . . . . . . . . . . 46

4.3 Comparações e Resultados . . . . . . . . . . . . . . . . . . . . . . . . . . . . 47

$4.3 .1 \quad$ Conjunto de dados 1: "pyrotechnics supplies" . . . . . . . . . . . . . . . 47

4.3 .2 Conjunto de dados 2: "scrapbooking supplies" . . . . . . . . . . . . . . . . . . 48

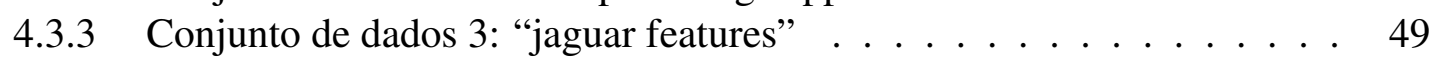

4.3 .4 Conjunto de dados $4:$ "wave applications" . . . . . . . . . . . . . . 50

4.3 .5 Conjunto de dados 5: "batman" . . . . . . . . . . . . . . . 50

5 Conclusões 63

5.1 Contribuições . . . . . . . . . . . . . . . . . . 63

5.2 Limitações . . . . . . . . . . . . . . . . . . . . . . . . . . . . . . 64

5.3 Trabalhos Futuros . . . . . . . . . . . . . . . . . . . . . 65

\begin{tabular}{ll}
\hline Referências Bibliográficas & 67
\end{tabular} 


\section{Lista de Figuras}

2.1 Projeção de um conjunto de 1357 notícias (coletadas das agências de noticias Reuters, $A P, B B C$ e $C N N$ ), usando ProjClus e $\mathbf{L S P}$, dividido em 9 classes diferentes baseando-se nos tópicos que são narrados. . . . . . . . . . . . . . 8

2.2 Composição de um snippet web textual. Extraído de uma consulta feita em

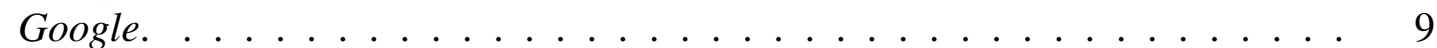

2.3 Visualização de uma coleção de documentos gerados automaticamente por ProjCloud a partir de uma coleção de artigos científicos em 4 diferentes áreas de conhecimento (extraído de Paulovich et al.(2012)). . . . . . . . . . . . . . . 11

2.4 (a-c) nuvens de palavras com preservação semântica dos resumos dos artigos do IEEE Vis/InfoVis 1999, 2005 e 2010. (d-f) nuvens de palavras com preservação semântica dos resumos dos artigos do EuroVis 1999, 2005 e 2010 (extraído de (Wu et al., 2011)). . . . . . . . . . . . . . . . . . 12

2.5 Ilustração para Seam Carving: (a) um layout de uma nuvem de palavras espalhadas com um campo de importância Gaussiana; (b) layout particionado pelas caixas delimitadoras das palavras; (c) uma costura (seam) ótima (em azul), um caminho de regiões conectadas de direita para esquerda é selecionado; (d) a costura poda para obter outro com uma largura idêntica (amarelo); (e) o layout da nuvem de palavras depois da eliminação da costura amarela em (d). (f) uma nuvem de palavras compacta e com preservação semântica depois da otimização de Seam Carving (extraído de Wu et al.(2011)). . . . . . . . . . . . . . . . . . 13

2.6 Projeções obtidas com a CSMP para os conjuntos de dados com 3-classes e 4classes, respectivamente. Diferentes cores de moldura representam diferentes classes. ................................. 14

2.7 Uma visão geral do sistema para a geração de nuvens dinâmicas de palavras. (a-e) apresentam cinco nuvens de palavras para momentos de tempo diferentes. (f) O gráfico mostra um gráfico de tendência sobre a significância, cuja curva de significância é extraída a partir de uma coleção de documentos em momentos de tempo diferentes (extraído de (Cui et al., 2010)). . . . . . . . . . . . . . . 15

2.8 Visualização de um campo splat. A imagem da esquerda mostra o layout com 40 vértices. As imagens do centro e da direita mostram o campo com valores $\sigma$ variados (extraído de van Liere e de Leeuw (2003)] . . . . . . . . . . . . . . . 17 
2.9 Algumas das técnicas de visualização de resultados em buscas web baseadas em listas aumentadas. . . . . . . . . . . . . . . . . . . . 21

2.10 Algumas das técnicas de visualização de resultados em buscas web baseadas em imagens. . . . . . . . . . . . . . . . . . . 22

2.11 Algumas das técnicas de visualização de resultados em buscas web baseadas

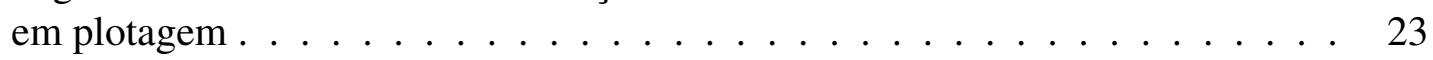

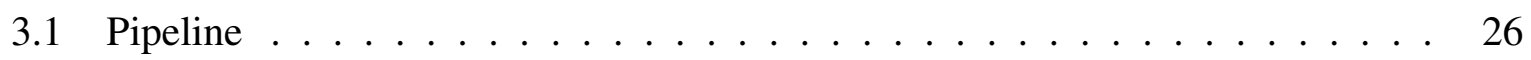

3.2 Interface gráfica para o pre-processamento e a projeção multidimensional em ProjSnippet. No lado esquerdo da janela são mostrados os parâmetros ajustáveis no processo. No lado direito, os resultados recuperados da consulta são mostrados para uma simples inspeção do conteúdo. . . . . . . . . . . . . 28

3.3 O mesmo conjunto de dados projetado no espaço visual baseado em pontos (usando PEx (Paulovich et al., 2007)) e em snippets (usando ProjSnippet). . . . 29

3.4 a) Layout sem otimização; b) Energia de sobreposição $E_{O}$ só; c) ambas energias $E_{O}$ e $E_{N}$ combinadas $(\alpha=0.5) . \ldots \ldots \ldots \ldots \ldots \ldots$

3.5 Reduzindo os espaços sem uso com o mecanismo carving. . . . . . . . . . . . 34

3.6 Exploração interativa do ProjSnippet: (a) Janela de visualização mostrando alguns resultados da pesquisa, (b) quando o cursor do mouse é posicionado sobre um dos snippets, ele é ressaltado aumentando suas dimensões a fim de fornecer uma melhor leitura, (c) depois de alguns segundos uma pré-visualização do conteúdo da página web é mostrada embaixo do snippet. . . . . . . . . . . . . 35

3.7 Comparação entre a saída de Google e ProjSnippet. . . . . . . . . . . . . . . 36

3.8 Procurando "scrapbooking supplies" (a) and "pyrothecnique supplies" (b) em

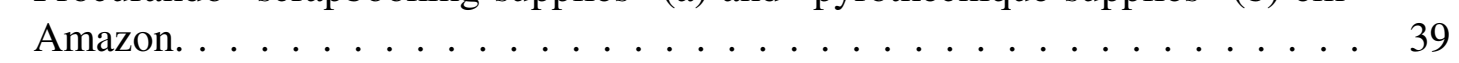

3.9 Procurando "wave applications" em Bing. . . . . . . . . . . . . . . . . . . . 40

3.10 Efeito da variação do parâmetro $\alpha . \ldots \ldots$. . . . . . . . . . . 40

4.1 Exemplo de solução ótima usando o algoritmo VPSC. Os nós são ordenados de forma ascendente (a), onde cada um é computado (b,c) para produzir um layout livre de sobreposições de modo a respeitar as restrições de separação inicialmente impostas (extraído de Dwyer et al.(2005)). . . . . . . . . . . . 42

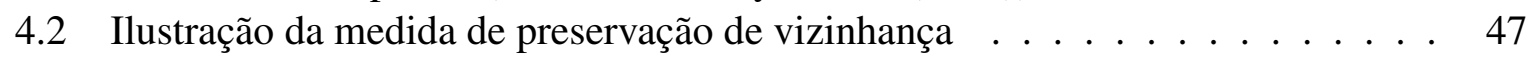

4.3 Layouts obtidos pelos métodos aqui comparados (conjunto de dados "pyrotechnics supplies"). . . . . . . . . . . . . . . . 52

4.4 Resultados obtidos pelas métricas quantitativas aplicadas às técnicas de remoção de sobreposição aqui avaliadas (conjunto de dados "pyrotechnics supplies"). 53

4.5 Projeção multidimensional e tabela de distâncias sobre os resultados obtidos para o conjunto de dados "pyrotechnics supplies". . . . . . . . . . . . . . 53

4.6 Layouts obtidos pelos métodos aqui comparados (conjunto de dados "scrapbo-

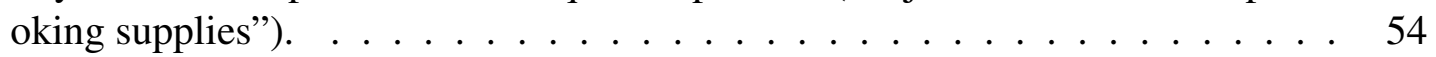

4.7 Resultados obtidos pelas métricas quantitativas aplicadas às técnicas de remoção de sobreposição aqui avaliadas ("scrapbooking supplies"). . . . . . . . . . . 55

4.8 Projeção multidimensional e tabela de distâncias sobre os resultados obtidos para o conjunto de dados "scrapbooking supplies". . . . . . . . . . . . . 55 
4.9 Layouts obtidos pelos métodos comparados (conjunto de dados "jaguar features"). 56

4.10 Resultados obtidos pelas métricas quantitativas aplicadas às técnicas de remoção de sobreposição aqui avaliadas (conjunto de dados "jaguar features"). . . . . 57

4.11 Projeção multidimensional e tabela de distâncias sobre os resultados obtidos para o conjunto de dados "jaguar features". . . . . . . . . . . . . . . 57

4.12 Layouts obtidos pelos métodos aqui comparados (conjunto de dados "wave ap-

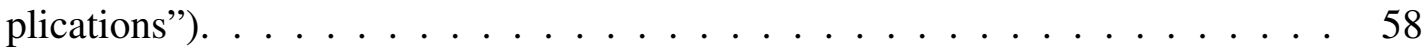

4.13 Resultados obtidos pelas métricas quantitativas aplicadas às técnicas de remoção de sobreposição aqui avaliadas (conjunto de dados "wave applications"). . . 59

4.14 Projeção multidimensional e tabela de distâncias sobre os resultados obtidos para o conjunto de dados "wave applications". . . . . . . . . . . . . . . 59

4.15 Layouts obtidos pelos métodos comparados (conjunto de dados "batman"). . . 60

4.16 Resultados obtidos pelas métricas quantitativas aplicadas às técnicas de remoção de sobreposição aqui avaliadas (conjunto de dados "batman"). . . . . . . . . 61

4.17 Projeção multidimensional e tabela de distâncias sobre os resultados obtidos para o conjunto de dados "batman". . . . . . . . . . . . . . . 61

5.1 Resultados preliminares de uma abordagem baseada inteiramente no operador Seam Carving. São mostrados 37 vídeos resultantes da pesquisa do termo "sibgrapi" no motor de busca de Youtube. As cores ilustram os diferentes grupos reconhecidos após a aplicação de um algoritmo de clustering. A primeira vista pode-se notar que a semelhança entre os resultados de cada grupo fica bastante

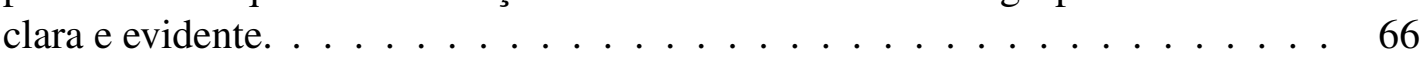



Lista de Tabelas

ב

3.1 Resultados da otimização. . . . . . . . . . . . . . . . . 38 



\section{Lista de Siglas}

CSMP Class-Specific Multidimensional Projection

HTML HyperText Markup Language

InfoVis Information Visualization

IR Information Retrieval

KDD Knowledge Discovery in Databases

LAMP Local Affine Multidimensional Projection

LSP Least Square Projection

ManiWordle Manipulating Wordle

MDS Multidimensional Scaling

PEx Projection Explorer

PRISM Proximity Stress Model

ProjClus Projection by Clustering

VDM Visual Data Mining

VPSC Variable Placement with Separation Constraints

XML eXtensible Markup Language 


\section{Lista de Algoritmos}

1 Geração do layout (Wordle) $\ldots \ldots \ldots$. . . . . . . . . . . . . . . 43

2 Remoção de sobreposição baseada em Voronoi . . . . . . . . . . . . . . . . . . 44 



\subsection{Contexto e Motivação}

O volume de informação atualmente disponível para consulta sofreu um incremento dramático nos últimos anos. A grande quantidade de informação existente demanda novos mecanismos e ferramentas computacionais para processar e analisar dados. Dentre as metodologias emergentes para suporte à interpretação de dados massivos a Mineração de Dados e a Visualização de Informação tem recebido grande destaque.

A mineração de dados pode ser definida como o processo de extração de informação a partir de bases de dados, a qual representa parte de um processo completo denominado Knowledge Discovery in Databases (KDD) (Fayyad et al., 1996) que refere-se à conversão de dados não processados em informação útil. A aplicação de tais algoritmos sobre recursos web é denominada Web Data Mining. A mineração Web (Liu, 2006) pode ser categorizada em 3 tipos principais:

- Mineração da Estrutura Web que usa teoria de grafos para analisar os nós e as estruturas de conetividade de um sitio na web. Baseado no tipo de estrutura web podemos dividirlos em métodos que extraem padrões por meio de seus hiperlinks ${ }^{1}$, e os que analisam a

\footnotetext{
1é um componente estrutural que conecta à página web com uma localização diferente
} 
estrutura do documento através de um esquema hierárquico, para descrever o uso de tags $\mathrm{HTML}^{2}$ e XML ${ }^{3}$.

- Mineração do Conteúdo Web que consiste na análise de textos, imagens ou outros componentes presentes no documento HTML. Dentre os usos principais podemos mencionar a categorização automática das paginas HTML e indexação do conteúdo.

- Mineração dos Registros de Navegação Web, ou também conhecidos comologs, baseados na descoberta de padrões de navegação que podem ajudar a melhorar a navegabilidade entre os sítios publicados. Assim, foi possível o desenvolvimento do conceito "Busca personalizada" que permite o uso de um contexto próprio na busca de documentos na Internet, gerando resultados de acordo com as preferencias comuns do usuário. Um exemplo desse tipo é o modelo criado pelo Google.

A Visualização de Informação (InfoVis) torna-se um recurso computacional importante para gerar representações gráficas que auxiliam visualmente a análise e o reconhecimento de padrões nos dados. Assim, o objetivo da InfoVis é traduzir a informação abstrata em uma forma visual que forneça uma nova visão sobre essa informação (Hearst, 2009). Diferentes autores descrevem diretrizes para a geração de visualizações para a exploração de informação, tais como $\mathrm{Few}$ (2009) e Tufte (1986). Essas diretrizes baseiam-se nos princípios da percepção humana, dentre os quais Few (2006) ressalta os seguintes pela sua importância:

- Preattentiveness (Treisman, 1985), é um termo que refere-se as propriedades visuais que um humano pode perceber em menos de 250 milissegundos (devido a que focar novamente a visão depois de mudar o foco de observação leva aproximadamente 200 milissegundos (Ware, 2004)) sem ter que varrer o campo visual atentamente. Assim, esta propriedade explica por que uma pequena quantidade de realce de cores facilita a exploração de dados.

- Propriedades uteis para fazer comparações quantitativas. Bertin (1983) por exemplo, define um vocabulário gráfico que consiste em marcadores (pontos, linhas, áreas), variáveis visuais (color, tamanho, forma, orientação, escala), e uma posição relativa para cada marca no espaço.

- Princípios da Gestals ou psicologia da forma. Basicamente é composta pelos sete fundamentos básicos da Gestalt: Continuidade, Segregação, Unidade, Pregnância, Fechamento, Semelhança e Proximidade. Alguns dos princípios mais considerados na criação

\footnotetext{
${ }^{2}$ HyperText Markup Language

${ }^{3}$ eXtensible Markup Language
} 
de visualizações são os dois mencionados no final: a semelhança reflete a tendencia de ver objetos que têm os mesmos atributos visuais e tornam-se parte do mesmo grupo, enquanto que a proximidade significa que os objetos que são situados espacialmente próximos são percebidos como pertencendo ao mesmo grupo.

A área que combina as linhas de pesquisa Mineração e Visualização de Informação é a denominada Mineração Visual de dados (VDM) (Wong, 1999). Esta fusão oferece muitas possibilidades e benefícios, pois tem a capacidade de apresentar visualmente resultados da mineração de dados, combinados com a flexibilidade, criatividade e conhecimento geral do usuário. Desta forma, a exploração visual de dados pode lidar com dados heterogêneos intuitivo, evitando muitas vezes o uso de complexos algoritmos (Keim, 2002).

A busca de informação na internet é uma tarefa de rotina para milhões de usuários. O procedimento típico consiste em fornecer consultas textuais a um motor de busca, o qual devolve uma lista ordenada de snippets textuais, contendo um resumo do conteúdo e um link ao documento referido (ou página web). Uma lista ordenada de snippets é bastante simples, fácil de interpretar e que acaba por ser eficaz em algumas tarefas de busca, como localizar uma determinada página ou documento (Teevan et al., 2009). Não obstante, também têm limitações que provavelmente prejudicam a experiência do usuário na análise e exploração dos resultados em alguns casos. Na verdade, uma lista ordenada não fornecer uma visão geral da coleção de documentos recuperados, o que torna difícil descobrir como os documentos estão relacionados. Por exemplo, se um usuário procura os termos "jaguar" e "features" no motor de busca do Google, a primeira página retornou uma lista de snippets com pelo menos quatro temas distintos, a saber, o animal, a marca do carro, um fã-clube de carros antigos Jaguar, e uma consola de jogos de vídeo. Certamente, o usuário pode adicionar palavras-chave para refinar a pesquisa, no entanto, se ele pretende obter uma visão global sobre um determinado assunto, não há outra opção senão a navegar através das páginas da lista e agrupar mentalmente os snippets de acordo com o seu tema.

Ferramentas de visualização de informação proporcionam aos usuários mecanismos mais flexíveis para inspecionar e navegar entre os resultados das consultas textuais. Alguns métodos existentes preservam o paradigma de lista ordenada de snippets, melhorando-o com recursos visuais como pictogramas coloridos ou nuvens de palavras, tentando transmitir mais informações sobre os conteúdos dos documentos devolvidos. Apesar de interessante e potencialmente útil, os recursos visuais ainda não incluem informações sobre a estrutura da vizinhança dos documentos, isto é, que documentos compartilhar conteúdo semelhante e quantos temas diferentes aparecem nos resultados da pesquisa. Outras classes de métodos diferentes ao paradigma de lista ordenada apresentam alternativas como thumbnails e redução de dimensionalidade que 
favorecem uma melhor compreensão do conteúdo dos documentos e a identificação de agrupamentos de documentos similares. Esses métodos, no entanto, tendem a ser visualmente mais complicados, exigindo maior esforço ao usuário que está tentando localizar e examinar documentos específicos. Além disso, os métodos atuais têm um alto custo computacional (como na criação da visualização que exige que o conteúdo completo de cada documento seja processado previamente) e portanto não são facilmente acopláveis em motores de busca convencionais.

\subsection{Objetivos}

Esse projeto de mestrado tem como objetivo geral o desenvolver metáforas visuais a partir de dados recuperados por mecanismos de buscas, de forma a melhorar a qualidade e eficiência na análise da informação, fornecendo uma maior capacidade de exploração visual dos dados em comparação com outros métodos usados na atualidade.

São objetivos específicos desse projeto:

- Desenvolver um processo de mineração/visualização interativa de resultados recuperados a partir de buscas textuais em motores de pesquisa web.

- Aproveitar a eficiência das técnicas de projeção multidimensional para usar como base na visualização, e assim manter uma relação semântica entre os resultados a fim de apresenta-los agrupados por conteúdo, o que facilita o entendimento e a exploração.

- Gerar um layout adequado que mostre o total dos resultados recuperados na consulta fornecendo um entendimento global da busca e ressaltando características especificas como nível de importância na consulta e agrupamento por tópicos de interesse.

\subsection{Organização}

Esta dissertação está organizada da seguinte maneira:

- No capitulo 2 é apresentada una revisão bibliografia sobre as técnicas que propõem metáforas visuais a partir de projeções multidimensionais com o fim de explorar conjuntos de dados. Neste capitulo também é apresentada uma revisão dos métodos de visualização de buscas na web, a fim de identificar as limitações em comparação com este trabalho de mestrado;

Os demais Capítulos detalham as principais contribuições desta dissertação. 
- No capitulo3 a primeira técnica de visualização, nomeada ProjSnippet é apresentada. Ela busca a visualização de um maior número de resultados de uma busca web fornecendo a mistura da capacidade de preservação de vizinhança da projeção multidimensional com a representação familiar baseada em snippets usando um funcional de energia, em um layout livre de sobreposição entre os resultados.

- No capitulo 4, um estudo comparativo entre ProjSnippet e outras técnicas no contexto de heurísticas para a remoção de sobreposição é apresentado.

- Por fim, o capitulo 5 apresenta as conclusões desse projeto de mestrado, ressaltando as contribuiçõos e limitações, além da discussão de trabalhos futuros. 


\section{Metáforas Visuais a partir de Projeções Multidimensionais e de Resultados em Buscas}

\subsection{Considerações Inicias}

$\mathrm{Na}$ atualidade existe uma crescente tendência ao uso de técnicas de projeção multidimensional como um dos passos intermediários na visualização de dados. Essencialmente, a idéia é mapear dados de alta dimensão em um espaço onde a percepção humana consiga identificar naturalmente as diferenças e similaridades entre os dados, preservando informação de distância entre as instâncias projetadas a fim de revelar estruturas e agrupamentos existentes no espaço original. Em geral, estamos falando de um espaço visual $m$-dimensional, com $m=\{1,2,3\}$, onde o reconhecimento de padrões é intuitivo.

Formalmente uma técnica de projeção multidimensional pode ser definida como:

Definição 2.1 . Projeção Multidimensional (Tejada et al., 2003) Seja um conjunto de objetos em $\mathfrak{R}^{m}$ e $\partial: \mathfrak{R}^{m} \times \mathfrak{R}^{m} \rightarrow \mathfrak{R}$ uma medida de proximidade entre objetos. Seja $Y$ um conjunto de pontos em $\mathfrak{R}^{p}, p=\{1,2,3\}$ e $d: \mathfrak{R}^{p} \times \mathfrak{R}^{p} \rightarrow \mathfrak{R}$ uma medida de proximidade em $\mathfrak{R}^{p}$. Uma 


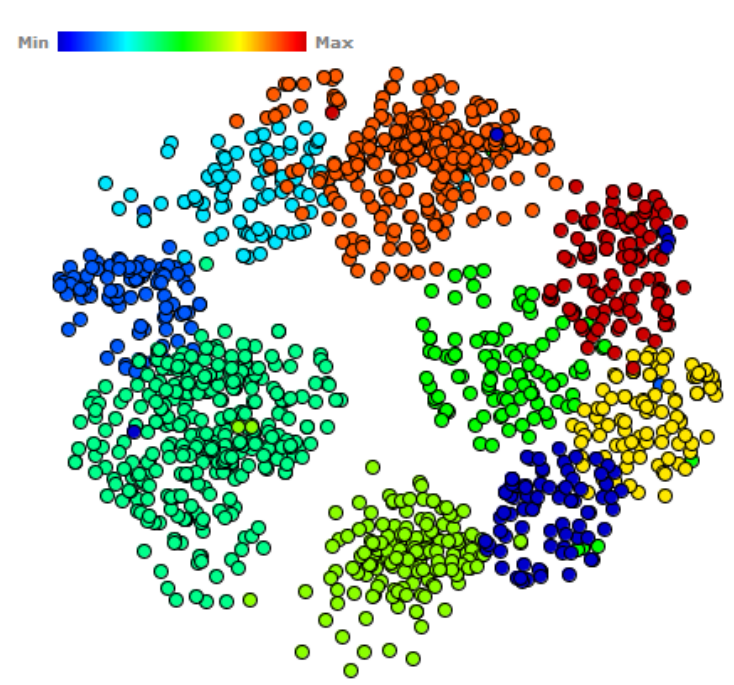

(a) usando ProjClus

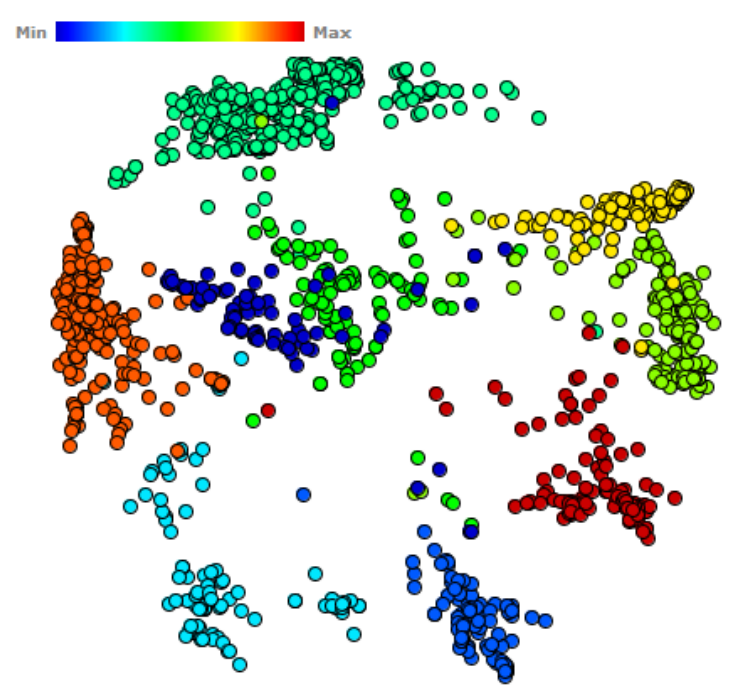

(b) usando LSP

Figura 2.1: Projeção de um conjunto de 1357 notícias (coletadas das agências de noticias Reuters, $A P, B B C$ e $C N N$ ), usando ProjClus e $\boldsymbol{L S P}$, dividido em 9 classes diferentes baseando-se nos tópicos que são narrados.

projeção multi-dimensional é uma função $f: X \rightarrow Y$ que visa tornar $\partial\left(x_{i}, x_{j}\right)-d\left(f\left(x_{i}\right), f\left(x_{j}\right)\right)$ o mais próximo possível de zero, $\forall x_{i}, x_{j} \in X$.

O resultado da aplicação de alguma técnica de projeção multi-dimensional é uma nuvem de pontos na reta (1-dimensional), no plano (2-dimensional) ou no espaço (3-dimensional), dependendo do espaço visual escolhido. Em geral, o espaço visual utilizado neste trabalho será bidimensional. A Figura 2.1 mostra como uma projeção apoia nas tarefas de identificação e interpretação de dados multi-dimensionais. Essas projeções foram geradas usando um subconjunto do conjunto de dados classificado NEWS2011 ${ }^{1}$ que contém notícias coletadas a partir dos RSS feed $s^{2}$ dos provedores de notícias na Internet - Reuters, AP, BBC e CNN durante 28 dias entre os meses de junho e julho do 2011. O subconjunto tem um total de 1357 documentos divididos em 9 classes: Afghanistan (89 documentos, conflitos em Afeganistão), E.coli_Europe (93 documentos, Surto de epidemia de E. coli na Europa), Greek_debt (91 documentos, Crise econômica da Grécia), hacking_scandal_London (336 documentos, Escândalo pelo hacking de telefone em Londres), Lybia (110 documentos, Conflitos na Líbia), Norway (166 documentos, Atentado na Noruega - explosão de uma bomba e tiroteios num

\footnotetext{
${ }^{1}$ Disponível em http://infoserver.lcad.icmc.usp.br/infovis2/DataSets

${ }^{2}$ RSS (Rich Site Summary) é um formato para entregar regularmente mudanças no conteúdo da web. Muitos sites relacionado com notícias, e outros editores on-line distribuem seu conteúdo como um feed RSS para quem quiser. Fonte: http://www.whatisrss.com/
} 


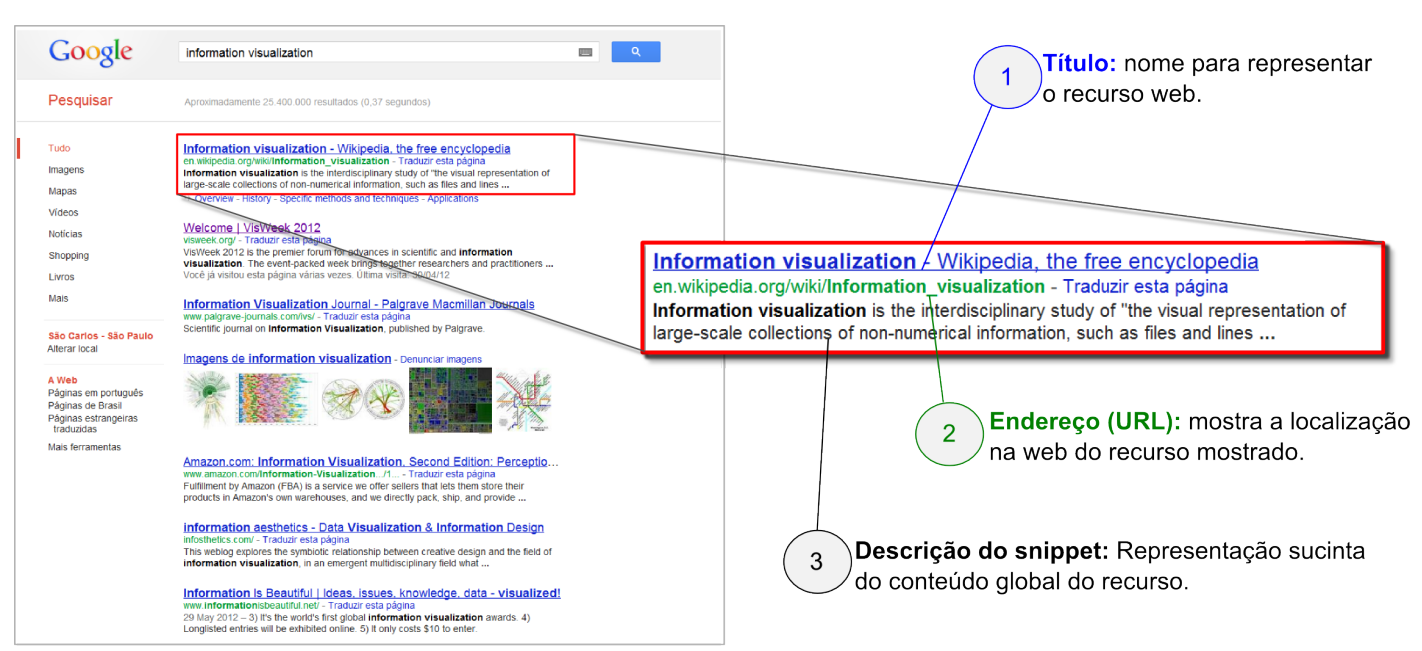

Figura 2.2: Composição de um snippet web textual. Extraído de uma consulta feita em Google.

acampamento), Syria (102 documentos, Conflitos na Síria), USA_crisis (261 documentos, Crise econômica dos Estados Unidos) e Yemen (109 documentos, Conflitos governamentais no Iêmen), mapeados usando as técnicas de projeção ProjClus (Paulovich e Minghim, 2006) e Least-Square Projection (LSP) (Paulovich et al., 2008a) disponíveis na ferramenta Projection Explorer (PEx) (Paulovich et al., 2007). Note-se que cada ponto foi colorido de acordo com a classe que pertence, assim o resultado mostra que os pontos da mesma classe (que tem relação semântica entre eles) foram projetados próximos no espaço visual.

As representações visuais (ou visualizações) de consultas web apresentam um grande desafio para visualização de informação. Como nos casos típicos de Information Retrieval (IR), que devolvem documentos sobre uma consulta específica, buscas na web resultam em documentos que são web pages. As buscas na web são feitas usando um motor de pesquisa, onde os mais usados (e.g. Google, Yahoo!, Bing) devolvem os resultados sobre tais consultas seguindo um paradigma baseado em uma lista 1-dimensional. Cada um dos items que são recuperados pelo motor de busca é uma representação sumarizada do conteúdo total da web page, denominado snippet. A Figura 2.2 mostra a composição tradicional de um snippet textual, onde essencialmente um título, uma descrição sucinta e o endereço web do resultado são suficientes para o usuário obter uma idéia do conteúdo completo da web page recuperada pelo motor de pesquisa (Google neste caso).

Existem também outros tipos de motores de pesquisa na web que buscam encontrar diversos tipos de recursos web (documentos, imagens, vídeos, etc). No caso especifico de vídeos temos sites dedicados ao armazenamento, busca, difusão e demais atividades interativas que 
envolvem vídeos na web, tais como Youtube ${ }^{3}$, VideoSurf ${ }^{4}$ ou DailyMotion ${ }^{5}$. Nesse contexto, a visualização dos resultados recuperados em uma busca nestes sites devolve em forma de lista 1-dimensional de snippets textuais que adicionam uma imagem (ou frame) do vídeo a fim de fornecer visualmente uma melhor compreensão do conteúdo.

Nas seguintes seções deste capítulo será apresentado um levantamento bibliográfico de técnicas que propõem novas metáforas sobre a amostragem de dados usando projeções multidimensionais, e uma revisão de abordagens que visam mudar o paradigma de visualização fornecido pelo principais motores de pesquisa na atualidade, descrevendo os aspectos positivos e negativos de cada uma.

\subsection{Metáforas Visuais a partir de Projeções Multidimen- sionais}

\subsubsection{ProjCloud (2012)}

Paulovich et al. (2012) propõem uma técnica para a visualização de coleções de documentos usando nuvens de palavras para ressaltar os termos mais usados em um conjunto, e projeções multidimensionais para preservar a semântica entre documentos. Em geral, o processo de wordification está composto por: (i) mapeamento dos documentos no espaço visual usando a Least Square Projection (LSP) (Paulovich et al., 2008a), (ii) definição dos grupos de palavras que constituíram as nuvens (o usuário pode definir um polígono sobre a projeção para limitar o tamanho e a forma da região que a nuvem vai usar, ou de forma automática, a técnica aplica um algoritmo de clustering (Bisecting K-Means (Steinbach et al., 2000)) para obter os grupos e computar o polígono contentor) (iii) definição do tamanho das palavras chaves com base na relevância e a área do polígono contentor, (iv) posicionamento das palavras dentro dos polígonos usando um esquema de otimização. A Figura 2.3 mostra a visualização de uma coleção de documentos usando ProjCloud, o mesmo conjunto de dados foi separado em 4 e 9 grupos respectivamente.

A combinação do uso de projeções multidimensionais e nuvens de palavras fornece maior facilidade para o usuário na exploração, pois ele pode interagir com a coleção de documentos no espaço visual, permitindo um analises global e local da coleção. Entre as principais limitações, existe forte dependência entre o número de pontos no agrupamento e a área do polígono

\footnotetext{
${ }^{3}$ http://www.youtube.com

${ }^{4} \mathrm{http} / / / \mathrm{www}$.videosurf.com

${ }^{5} \mathrm{http}: / /$ www.dailymotion.com
} 


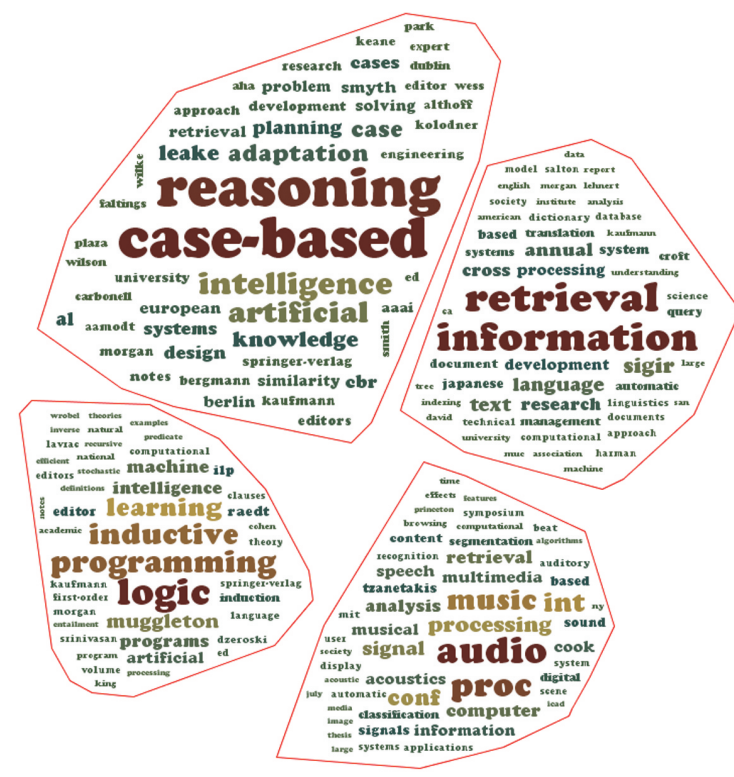

(a) 4 grupos

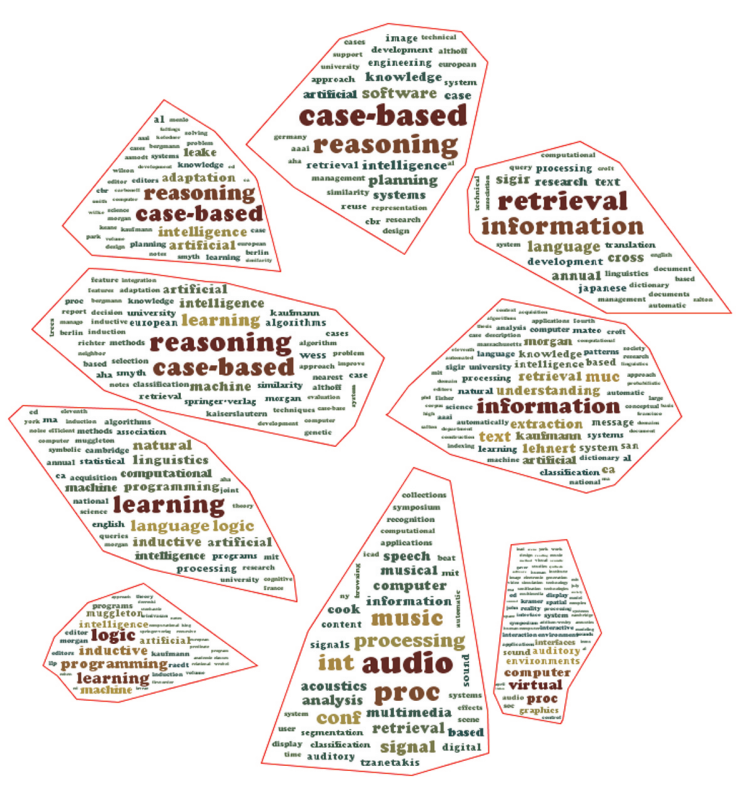

(b) 9 grupos

Figura 2.3: Visualização de uma coleção de documentos gerados automaticamente por ProjCloud a partir de uma coleção de artigos científicos em 4 diferentes áreas de conhecimento (extraído de Paulovich et al. (2012)).

contentor, isto é se alguns pontos são concentrados em uma região específica do espaço visual e a área do polígono contentor é pequena, o resultado do posicionamento das palavras é prejudicado, tornando-se difícil a leitura. Por fim, pode-se notar a necessidade de evitar os espaços sem uso (vazios) entre os grupos, o qual implica um melhor aproveitamento do espaço visual.

\subsubsection{Nuvens de palavras com preservação semântica usando Seam Carving (2011)}

Wu et al. (2011) apresentam um método para visualizar nuvens de palavras preservando as relações semânticas entre elas usando Seam Carving (Avidan e Shamir, 2007), um operador amplamente conhecido na área do processamento de imagens (PI), para o redimensionamento de imagens. A técnica contém três componentes principais: (i) pré-processamento, extrai todas as palavras-chave da coleção de documentos, posteriormente são calculadas todas as distâncias entre essas palavras a fim de construir uma matriz de dissimilaridade para finalmente mapear as instâncias no espaço bidimensional usando Multidimensional Scaling (MDS) (Cox e Cox, 1994). Um algoritmo de força-dirigida é aplicado para eliminar as palavras sobrepostas, obtendo desta maneira um layout inicial. O (ii) desenho da nuvem de palavras é feito atra- 


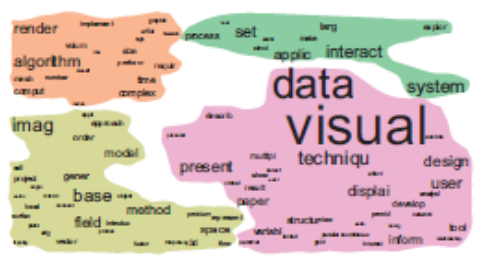

(a)

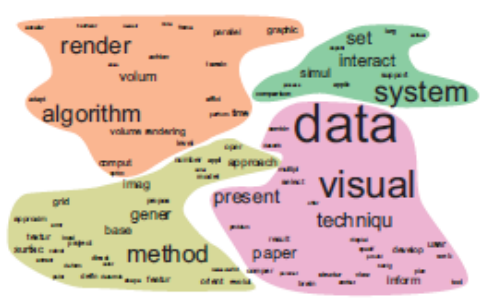

(d)

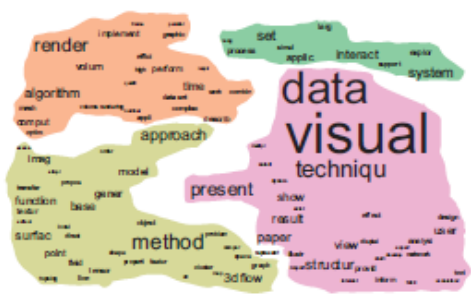

(b)

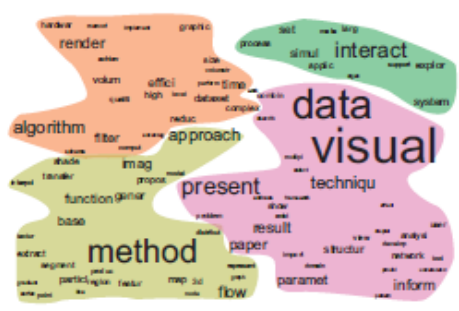

(e)

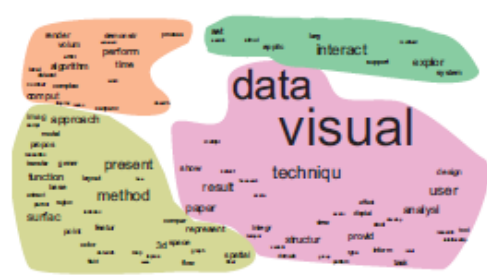

(c)

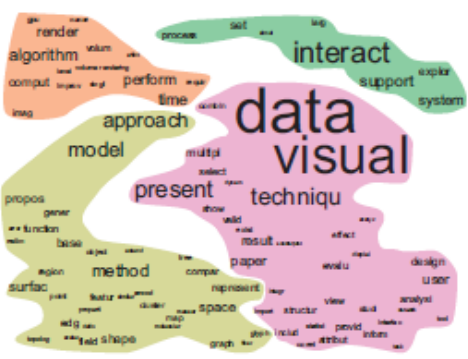

(f)

Figura 2.4: (a-c) nuvens de palavras com preservação semântica dos resumos dos artigos do IEEE Vis/InfoVis 1999, 2005 e 2010. (d-f) nuvens de palavras com preservação semântica dos resumos dos artigos do EuroVis 1999, 2005 e 2010 (extraído de (Wu et al., 2011)).

vés da eliminação de palavras irrelevantes do layout inicial, depois desta operação o resultado é uma nuvem de palavras espalhadas com múltiplos espaços vazios. Para compactar a nuvem preservando as posições relativas das palavras mais importantes, o operador Seam Carving é aplicado. Por ultimo, (iii) Bubble Sets (Collins et al., 2009) são aplicados para visualizar melhor as relações semânticas, apresentando as nuvens no estilo planilha, fornecendo a opção de comparar visualmente diferentes nuvens, como mostra notar na Figura 2.4 .

O principal aporte desta abordagem é o uso do operador Seam Carving modificado para nuvens de palavras, com a finalidade de eliminar espaços vazios no contexto de visualização de texto. Basicamente, usa-se uma função de energia para estimar a importância de cada região (ou pixels no caso de imagens) e decidir quais regiões deveram ser removidas. A Figura 2.5 ilustra o uso de Seam Carving no processo de optimização de espaço com preservação semântica.

\subsubsection{CSMP (2011)}

Baseado na flexibilidade oferecida pela técnica de projeção multidimensional Least Square Projection (LSP) (Paulovich et al., 2008a), a técnica chamada Class-Specific Multidimensional Projection (CSMP) (Joia et al., 2011b), busca recuperar imagens e visualizar o resultado da recuperação de forma intuitiva. Em contraste com outras técnicas de projeção multidimensional, a CSMP usa uma família de métricas ao invés de uma única para projetar os dados. 


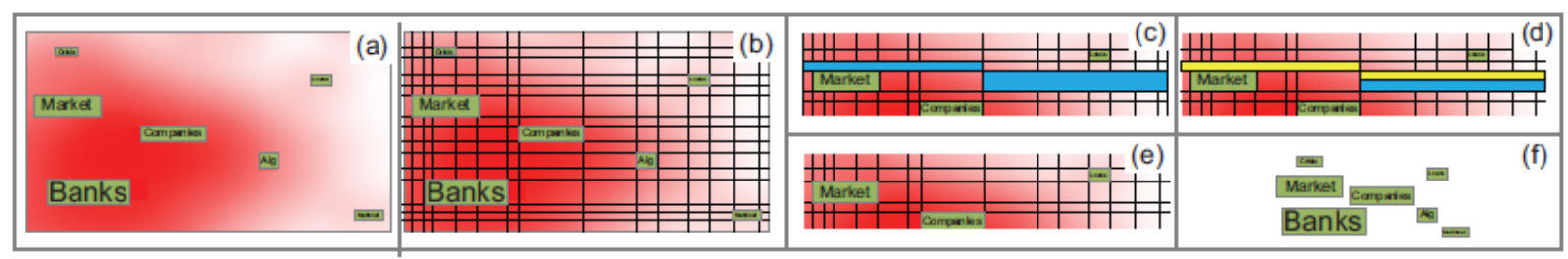

Figura 2.5: Ilustração para Seam Carving: (a) um layout de uma nuvem de palavras espalhadas com um campo de importância Gaussiana; (b) layout particionado pelas caixas delimitadoras das palavras; (c) uma costura (seam) ótima (em azul), um caminho de regiões conectadas de direita para esquerda é selecionado; (d) a costura poda para obter outro com uma largura idêntica (amarelo); (e) o layout da nuvem de palavras depois da eliminação da costura amarela em (d). (f) uma nuvem de palavras compacta e com preservação semântica depois da otimização de Seam Carving (extraído de Wu et al. (2011)).

As principais contribuições deste trabalho podem ser sumarizadas como: (i) A definição de métricas para classes específicas a fim de medir a similaridade entre imagens. (ii) A criação de uma nova técnica de projeção multidimensional que usa métricas específicas para cada classe, permitindo realizar consultas com base em seu conteúdo. (iii) Um sistema capaz de executar múltiplas consultas em bancos de dados de imagens, a partir de imagens de diferentes classes.

O método proposto pode ser descrito através de cinco passos:

1. Extração de características, para a construção do espaço de características. Os extratores Wavelet (Kumar e Esther, 2011), Gabor (Arivazhagan et al., 2006), Tamura (Deselaers et al. 2008), momentos de primeira ordem (Theodoridis e Koutroumbas, 2009) e momentos de cor (Maheshwary e Srivastav, 2008) são utilizados. O número de características extraídas é aproximadamente 220, onde muitas delas não são representativas. Então, um algoritmo extrai as características mais relevantes utilizando o SSFS (Gütlein et al., 2009), dando como resultado apenas um subconjunto com $15 \%$ do total de características.

2. A seleção de imagens para a consulta. O usuário fornece uma ou mais imagens para começar a pesquisa.

3. Construção da família de métricas específicas por classe, usando o Logistic Model Tree (LMT) (Landwehr et al., 2005) para a seleção de características.

4. Preparação da matriz de projeção. A família de métricas específica é usada para o cálculo da similaridade entre as instâncias.

5. Projeção multidimensional, propriamente dita. Os dados são projetados no espaço visual. 


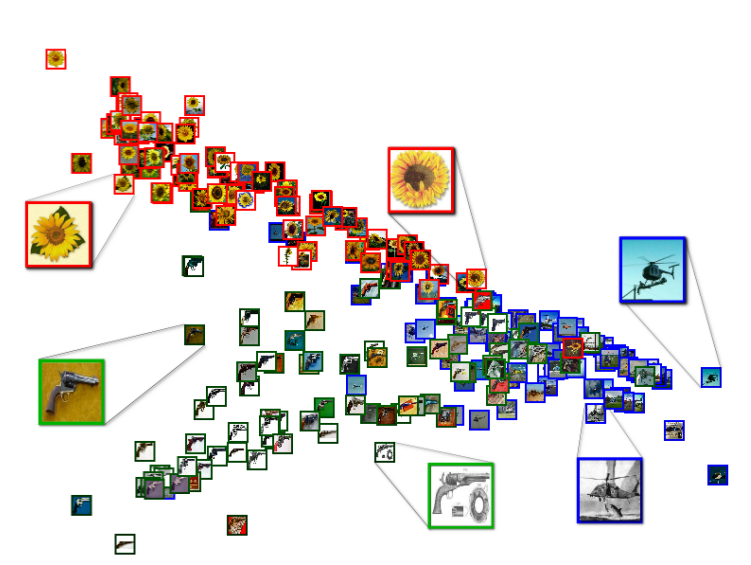

(a) Projeção do conjunto de dados com 3-classes.

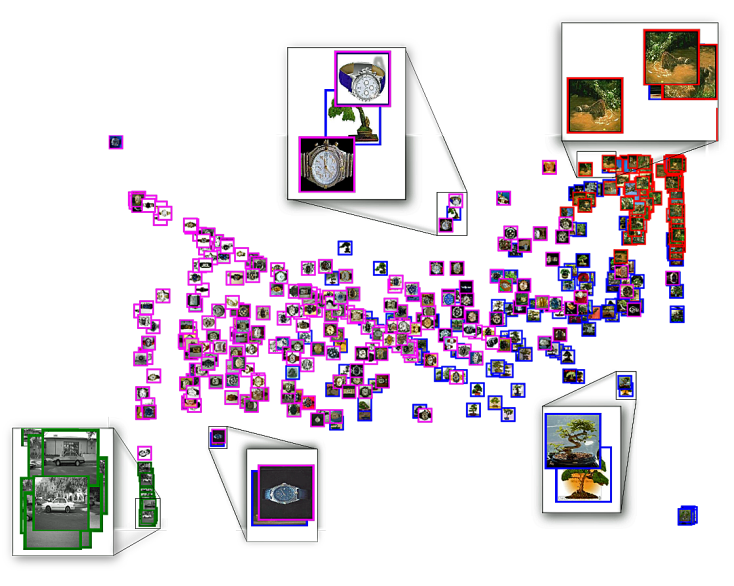

(b) Projeção do conjunto de dados com 4-classes.

Figura 2.6: Projeções obtidas com a CSMP para os conjuntos de dados com 3-classes e 4-classes, respectivamente. Diferentes cores de moldura representam diferentes classes.

A Figura 2.6 mostra o mapeamento das imagens no espaço visual. Em lugar de usar pontos para representar o banco de dados de imagens, foram usadas representações das mesmas imagens em menor escala (conhecidas como thumbnails), fornecendo maior conhecimento sobre o domínio de dados na exploração. Por outro lado, aparece um problema de sobreposição de dados, que impede a visualização global do conjunto de dados.

\subsubsection{Nuvens dinâmicas com preservação de contexto (2010)}

Cui et al. (2010) propõem uma técnica para visualizar coleções dinâmicas de documentos eliminando os espaços vazios, por meio do uso de projeções multidimensionais e a otimização do layout através de um algoritmo de força-dirigida. A técnica ainda preserva as relações de coerência semântica entre as palavras, seguindo três critérios: co-ocorrência, importância e similaridade no significado.

- Critério de importância: com esse critério, a disposição das palavras no plano é definida pela importância, consequentemente, palavras com tamanho de fonte similar ficam próximas na visualização. Nesse contexto, um vetor de importâncias $V_{m}=\left\{v_{1}, v_{2}, \cdots, v_{i}\right\}$ com $i$ sendo o número de instantes de tempo da visualização, é gerado para cada palavra do conjunto. O elemento $v_{j}$ desse vetor representa o valor de importância (tamanho da fonte) da palavra no instante de tempo $j$.

- Critério de co-ocorrência: utilizando esse critério, as palavras que são propensas a aparecer ou desaparecer de forma simultânea ficam próximas no plano de visualiza- 


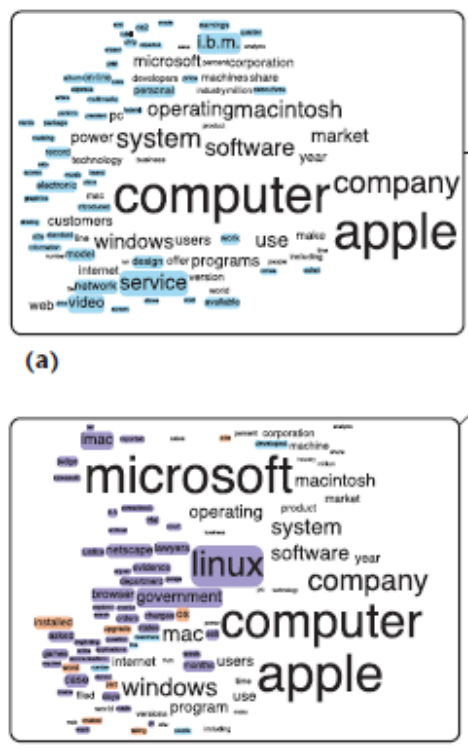

(b)

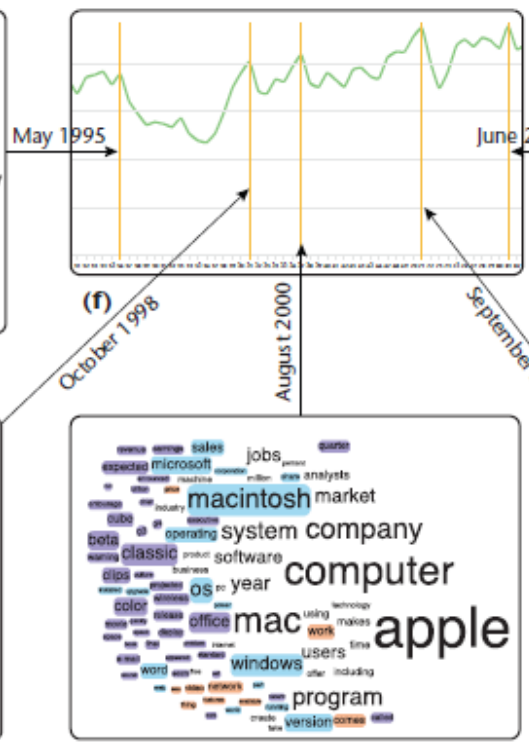

(c)

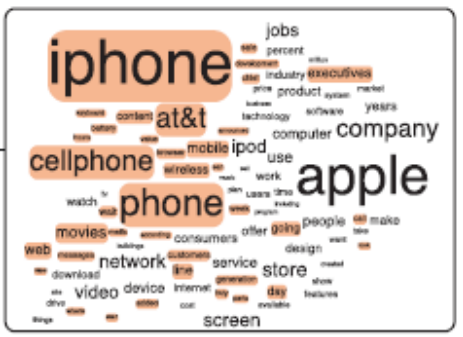

(e)

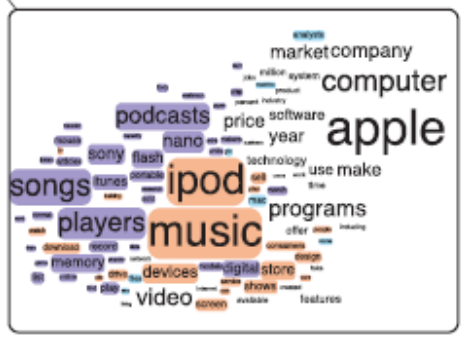

(d)

Figura 2.7: Uma visão geral do sistema para a geração de nuvens dinâmicas de palavras. (a-e) apresentam cinco nuvens de palavras para momentos de tempo diferentes. (f) $\mathrm{O}$ gráfico mostra um gráfico de tendência sobre a significância, cuja curva de significância é extraída a partir de uma coleção de documentos em momentos de tempo diferentes (extraído de (Cui et al., 2010)).

ção. O vetor de co-ocorrência gerado para cada palavra da coleção é definido como $V_{a}=\left\{v_{1}, v_{2}, \cdots, v_{i}\right\}$ com $i$ sendo o número de instantes de tempo da visualização no qual o elemento $v_{j}$ será 1 se a palavra é visível no instante de tempo $j$, caso contrário, o valor do elemento $v_{j}$ será 0 .

- Critério de similaridade: utilizando esse critério, as palavras com significado semântico $^{6}$ similar serão posicionadas próximas no plano da visualização. Neste caso, para uma palavra $p$, seu vetor de similaridades estará definido por $V_{s}=\left\{v_{1}, v_{2}, \cdots, v_{i}\right\}$ com $i$ sendo o tamanho do conjunto de palavras importantes.

A Figura 2.7 apresenta um exemplo de visualização gerada com esta técnica. As cinco subfiguras descrevem nuvens de etiquetas (tag clouds) de uma coleção de documentos sobre a empresa Apple, correspondente a cinco faixas de tempo diferentes (e.g. a Figura 2.7(a) representa os documentos correspondentes ao mês de Maio de 1995, e a Figura 2.7(b) ao mês de Outubro do 1998). Com a finalidade de analisar a evolução das palavras na coleção a Figura 2.7(f) mostra um gráfico de significância a partir de nuvens de etiquetas com diferentes datas.

\footnotetext{
${ }^{6} \mathrm{O}$ termo semântico refere-se aos aspectos de significado, sentido ou interpretação do significado de uma palavra.
} 
Cada tag cloud gerada pelo sistema é composto pelas palavras mais representativas da coleção. Para extrair essas palavras é necessário efetuar algumas operações: (i) Primeiro, as palavras comuns e pouco importantes (conhecidas como stopwords) são removidas da coleção. (ii) Em seguida, o algoritmo de lematização ${ }^{7}$ de Porter (Porter, 1997) é utilizado para reduzir as palavras restantes a seus radicais. (iii) A seguir é gerado um histograma de frequência das palavras restantes, sendo que aquelas palavras cujas frequências ultrapassarem o valor de um limiar, definido pelo usuário, serão incluídas no conjunto de palavras importantes. Após a extração do conjunto de palavras importantes, o algoritmo posiciona as palavras em um plano $2 \mathrm{D}$, agrupando-as segundo um dos critérios de coerência semântica anteriormente descritos. A seguir, uma triangulação de Delaunay é aplicada sobre as posições das palavras no plano, obtendo uma malha de triângulos. A malha pode ser estruturada como um grafo, que permitirá a flexibilidade necessária para mover as posições das palavras guardando as relações semânticas entre elas. Para otimizar a utilização do espaço de visualização, os autores utilizam um modelo de força-dirigida adaptado, assim espaços vazios são removidos e a topologia do grafo é mantida.

O agrupamento semântico das palavras, além de melhorar a legibilidade da nuvem, permite que novas representações mantenham uma estrutura similar à anterior, assim o usuário não perderá a familiaridade com a nuvem. Uma das limitações desta abordagem, é que o sistema não pode entregar um layout compacto se o layout inicial não é irregular (quando a maioria das palavras são colocadas em uma linha reta por exemplo).

\subsubsection{GraphSplatting (2003)}

van Liere e de Leeuw (2003) propõe uma técnica de visualização para nuvens de pontos e grafos como um campo escalar, onde o resultado pode ser mostrado como um mapa de alturas, mapa de cores ou um conjunto de contornos. Neste contexto, cada vértice apresenta uma densidade que contribui com o campo (denominado campo splat) segundo uma função gaussiana (splatting gaussiana), ao invés de apresentar os pontos isolados como na maioria de visualizações baseadas em projeções multidimensionais. A densidade dos pontos, é influenciada pelo grau de suavidade (largura $\sigma$ da função gaussiana ). Na figura 2.8 pode-se notar a sensibilidade do parâmetro $\sigma$ : enquanto o valor de $\sigma$ for pequeno, o resultado será mais detalhado. Para o mapeamento de pontos multidimensionais no espaço visual (2-Dimensões nesse caso), o autor utiliza Multidimensional Scaling (MDS) (Cox e Cox, 1994).

Uma das principais contribuições dessa técnica é o fato que não é necessário a criação de clustering para a identificação de pontos similares no espaço visual. A Figura 2.8 mostra um

\footnotetext{
${ }^{7}$ Conversão de un conjunto de palavras em seus radicais.
} 


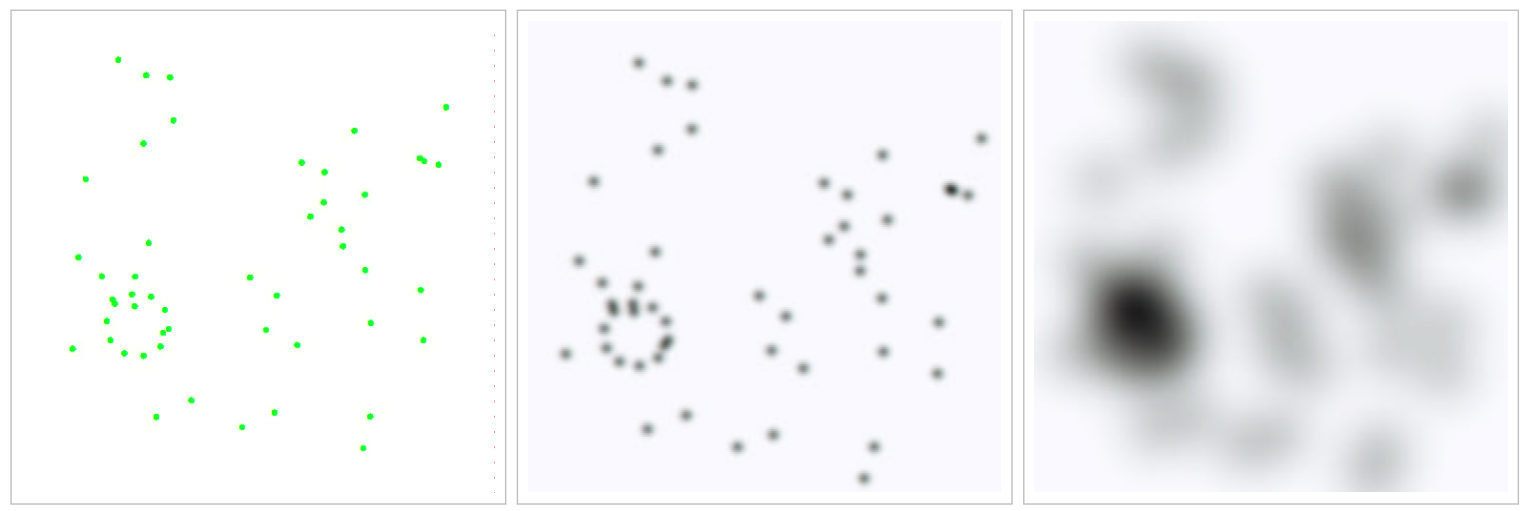

Figura 2.8: Visualização de um campo splat. A imagem da esquerda mostra o layout com 40 vértices. As imagens do centro e da direita mostram o campo com valores $\sigma$ variados (extraído de van Liere e de Leeuw (2003))

campo onde grupos de pontos são facilmente reconhecíveis. Como parte da interação com o usuário, é importante ressaltar o uso do zoom como ferramenta importante na exploração do campo escalar, o parâmetro $\sigma$ é decrementado proporcionalmente para manter uma razão constante na região de interesse.

\subsection{Visualização de Resultados de Buscas na Web}

No contexto de buscas textuais, as técnicas de visualização podem ser classificadas em dois grandes grupos: (i) os métodos que buscam resultados a partir de uma consulta livre, os quais apresentam ferramentas visuais para apoio ao processo de consulta, e (ii) métodos que visualizam resultados a partir de uma consulta previamente definida. Com o proposito de contextualizar melhor o problema que esse trabalho aborda, vamos nos focar no último grupo. Os tópicos que não serão discutidos nessa seção, podem ser encontrados na pesquisa abrangente feita por Yao et al. (2010). O livro de Hearst (2009) também descreve importantes contribuições sobre os métodos visuais em apoio de buscas em geral.

Com base no paradigma usado, podemos organizar as técnicas para visualizar buscas textuais nas seguintes três categorias:

\subsubsection{Técnicas baseadas em listas aumentadas}

Técnicas baseadas em listas aumentadas essencialmente usam como representação visual uma lista simples unidimensional, mas aumentada com recursos visuais para ajudar na interpretação do conteúdo (por exemplo, ressaltar palavras chave ou colorir os diferentes componentes). O 
exemplo mais comum desse tipo de representação é a utilizada pelo Google. Outra representação amplamente conhecida é TileBars (Hearst, 1995) e suas variantes (Reiterer et al., 2000), (Reiterer et al., 2005) que exibe uma barra colorida próximo de cada resultado, transmitindo visualmente informações como o comprimento do documento ou a frequência dos termos da consulta no documento (como mostram as Figuras 2.9(a) 2.9(c)|2.9(d)). Hotmap (Hoeber e Yang, 2006a) é uma versão simplificada de TileBars, onde só um quadrado é mostrado por cada termo da consulta, colorindo os quadrados como um mapa de calor de acordo com a frequência dos termos no documento. A exploração interativa é fornecida por meio do re-ordenamento dinâmico dos documentos baseado na frequência dos termos da consulta, permitindo em todo momento uma visão geral da lista de resultados (Figura 2.9(b)). PubClouds (Kuo et al., 2007) faz uso de diferentes mecanismos, os quais basicamente enriquecem a visualização por meio de tag clouds construídas sobre documentos abstratos devolvidos a partir de uma consulta no banco dados PubMed. A tag cloud permite selecionar um tópico específico na nuvem para filtrar a lista retornada (Figura 2.9(e)). WordBars (Hoeber e Yang, 2006b) fornece uma visão geral dos resultados da busca baseado no histograma de frequências, e também permite o refinamento dos resultados através do reordenamento interativo, selecionando algum dos termos devolvidos como novo critério de filtragem (Figura 2.9(f)].

As técnicas descritas anteriormente mostram um desempenho notável em alguns casos específicos, mas em geral a maioria deles precisam acessar o conteúdo completo dos documentos para obter uma classificação coerente, o que limita eficiência das mesmas como métodos para visualização de buscas na web. Além disso, devido ao paradigma de lista sequencial que eles usam, não é possível mostrar uma relação semântica entre os resultados, dificultando a tarefa de exploração.

\subsubsection{Técnicas baseadas em imagens}

Pesquisadores têm notado que embora as representações textuais sejam mais compactas e muito mais rápidas de coletar, o conteúdo das mesmas não é tão facilmente assimilado em comparação com imagens. Segundo Woodruff et al. (2001), podemos entender a essência de uma imagem em 110ms ou menos, o mesmo tempo que levamos para ler duas palavras ou menos. Técnicas baseadas em imagens essencialmente substituem um resultado textual por uma imagem (thumbnails) que sumariza visualmente o conteúdo da busca. Algumas dessas abordagens incorporam o uso de thumbnails como apoio ao histórico dos buscadores web (Hightower et al. 1998), (Jhaveri e Räihä, 2005) (Figura 2.10(a)). Algumas outras apresentam textualmente melhorias visuais no corpo dos documentos (Woodruff et al., 2001) (Figura 2.10(b)), ou fazem uma mistura de texto e imagem a partir dos resultados (Teevan et al., 2009) (Figura 2.10(c)). Jiao et 
al. (2010) apresenta uma técnica que mistura a extração de keywords e imagens obtidas usando as keywords. Essa técnica também precisa de acessar ao conteúdo completo dos documentos e a efetividade na busca de novos resultados é discutível, sendo mais apropriado na tarefa de refinamento de buscas. Novamente, nenhuma das abordagens citadas anteriormente apresentam os dados preservando similaridade entre eles.

\subsubsection{Técnicas baseadas em plotagem}

Técnicas baseadas em plotagem usam um gráfico bidimensional para o apresentar dos dados com o proposito de substituir ou complementar as listas de resultados. As técnicas existentes variam substanciavelmente no recurso visual empregado para apoiar a busca. Nguyen e Zhang (2006), por exemplo, apresenta um sistema de visualização interativa chamado WebSearchViz, que adota uma forma análoga ao sistema solar onde a consulta feita pelo usuário é posicionada no centro da representação, e ao redor dele estão os resultados da busca orbitando de acordo à similaridade com a consulta, como pode-se notar na Figura 2.11(f), Spoerri (2004), como mostra a Figura 2.11(b), organiza os resultados recuperados da consulta como uma espiral onde os documentos com melhor ranking (baseado na quantidade de motores de busca que devolveram ele) são localizados mais perto do centro, enquanto que os íconos atribuídos em cada resultado identificam em quantos e em quais motores de busca foram encontrados. Nizamee e Shojib (2010) utiliza scatter plot para complementar o amostragem dos snippets textuais, mapeando os dados baseados no tipo de recurso web e no ano de publicação; a interatividade é fornecida através da filtragem de dados por categoria, como apresenta a Figura 2.11(d), VisGets (Dörk et al., 2008) combina diferentes widgets para busca e visualização de RSS feeds, permitindo múltiplas facetas visuais que permitem a visualização geográfica e temporal do conteúdo, como mostra a Figura 2.11(c), Apesar da efetividade obtida em casos específicos, as abordagens anteriores não possibilitam o reconhecimento ou identificação de grupos ou documentos similares. Esse é o ponto central da visualização apresentada pelo PEx-Web (Paulovich et al., 2008b) que apoia a interpretação de coleções de resultados web, criando uma representação visual a partir de documentos recuperados. Testes realizados mostram que o PEx-Web propicia uma redução no tempo de análises dos resultados de uma busca web. A Figura 2.11(e) mostra a representação visual que fornece a ferramenta. Sallaberry et al. (2010) propõe um mecanismo de visualização em múltiplos níveis, onde a representação é baseada em grafos e alguns componentes de visualização de informação, fornecendo a identificação de grupos e similaridade entre documentos. Assim, um esquema de clusters (que representam os tópicos em comum dos documentos recuperados) e bridges (palavras que relacionam dois clusters) é adotado, como pode-se notar na Figura 2.11(a), O uso de projeção multidimensional e layouts baseados em grafos são bas- 
tante efetivos para a exploração pelo conteúdo, no entanto exibir os resultados sumarizados de maneira favorável no contexto de buscas web é uma tarefa atendida pelos métodos descritos anteriormente.

\subsection{Considerações Finais}

Nesse capitulo foram descritas algumas metáforas visuais que usam projeção multidimensional. Elas mostram a eficácia de usar essa abordagem com a finalidade de gerar um mapa de dados relacionados pelas suas características. Também foi apresentada uma revisão bibliografia dos métodos para visualizar resultados a partir de buscas, focada em pesquisas na Web.

O próximo capítulo apresenta a técnica de visualização desenvolvida no projeto de mestrado. Tal técnica visa resolver os problemas apresentados pelas técnicas aqui expostas, propondo um novo layout para a exploração visual de dados baseado no uso de projeção multidimensional e otimização do espaço visual. 


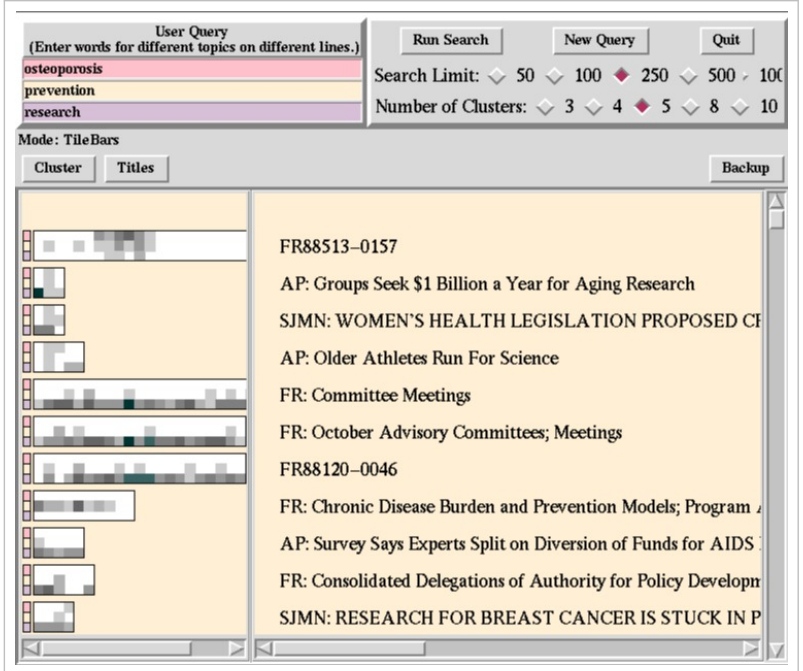

(a) TileBars (Hearst, 1995)

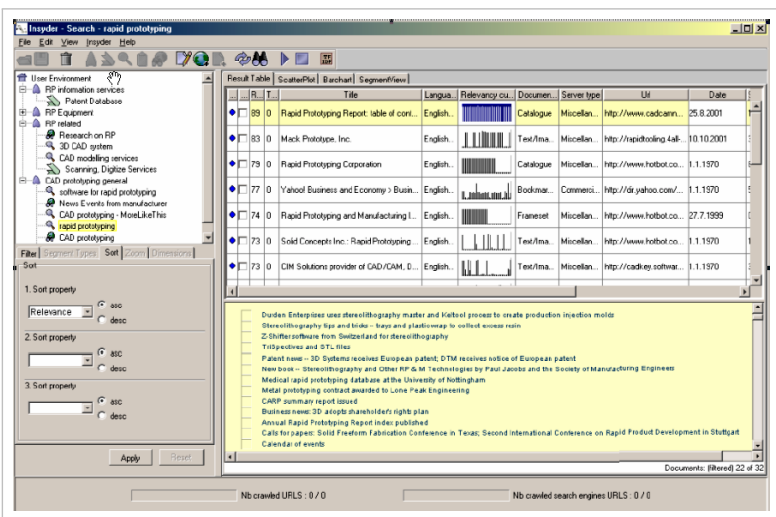

(c) Uma melhora de TileBars (Reiterer et al. 2000)

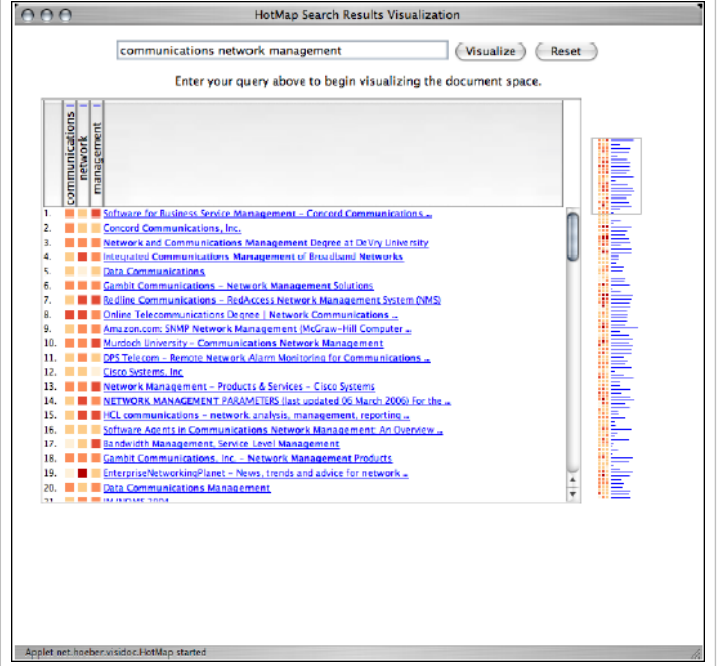

(b) HotMap (Hoeber e Yang, 2006a)

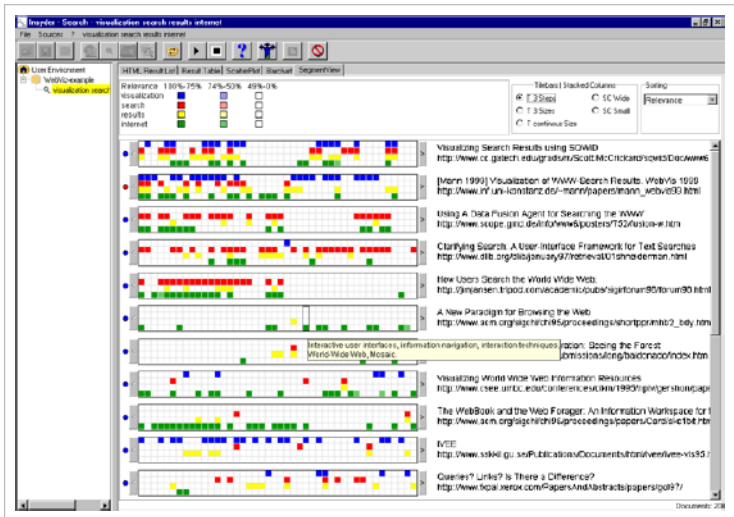

(d) TileBars colorido (Reiterer et al. 2005)

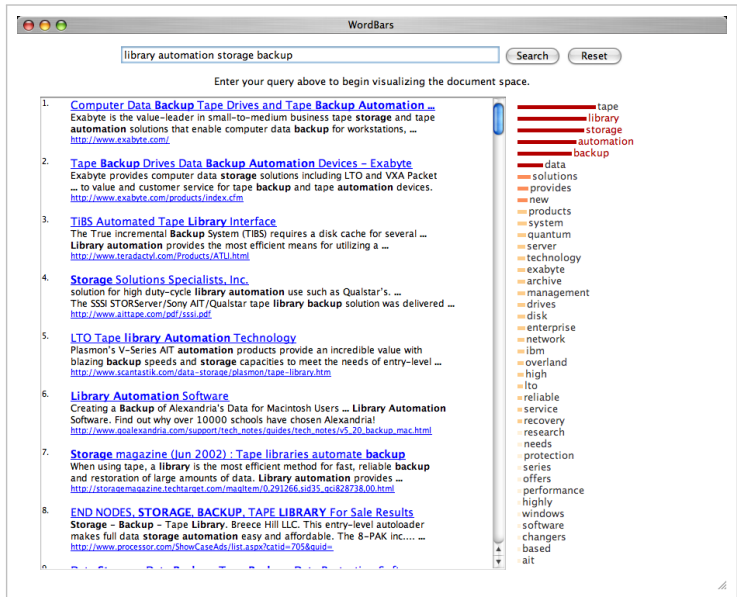

(f) WordBars (Hoeber e Yang, 2006b)

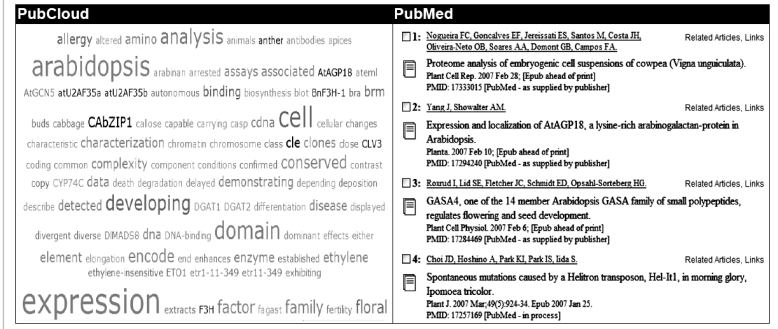

(e) PubCloud (Kuo et al., 2007)

Figura 2.9: Algumas das técnicas de visualização de resultados em buscas web baseadas em listas aumentadas. 

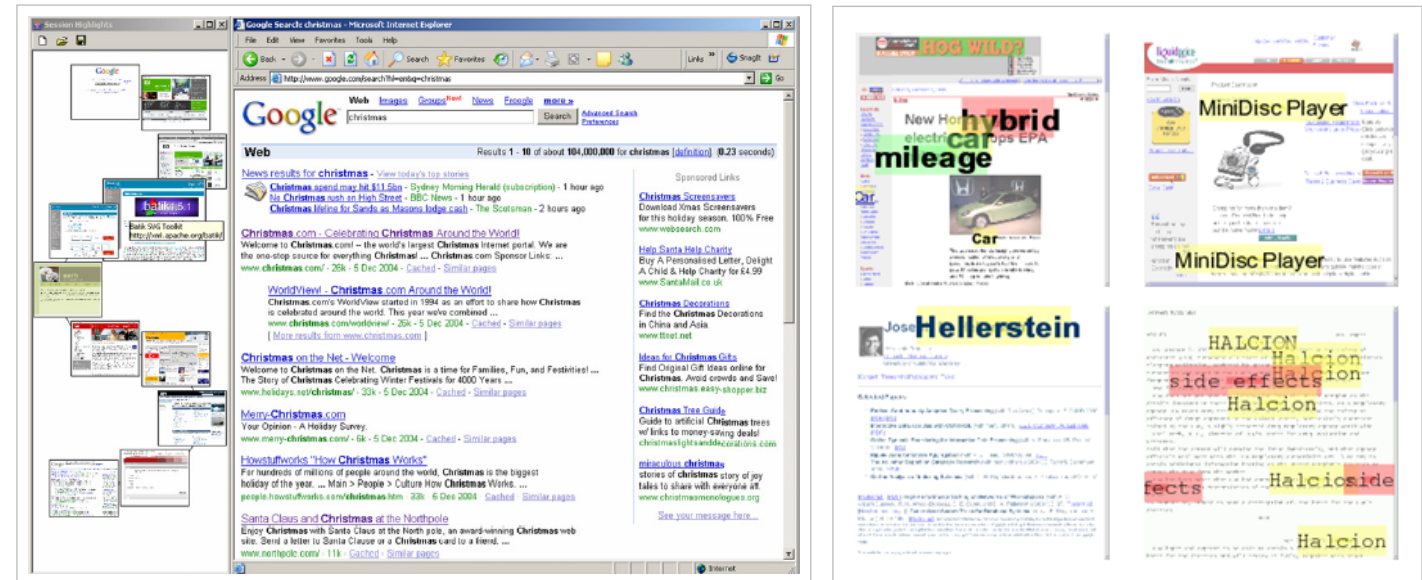

(a) Histórico de um navegador web mostrando thumbnails (b) Thumbnails textualmente melhorados. selecionados pelo usuário. Extraído de (Jhaveri e Räihä, Extraído de (Woodruff et al. 2001) 2005).

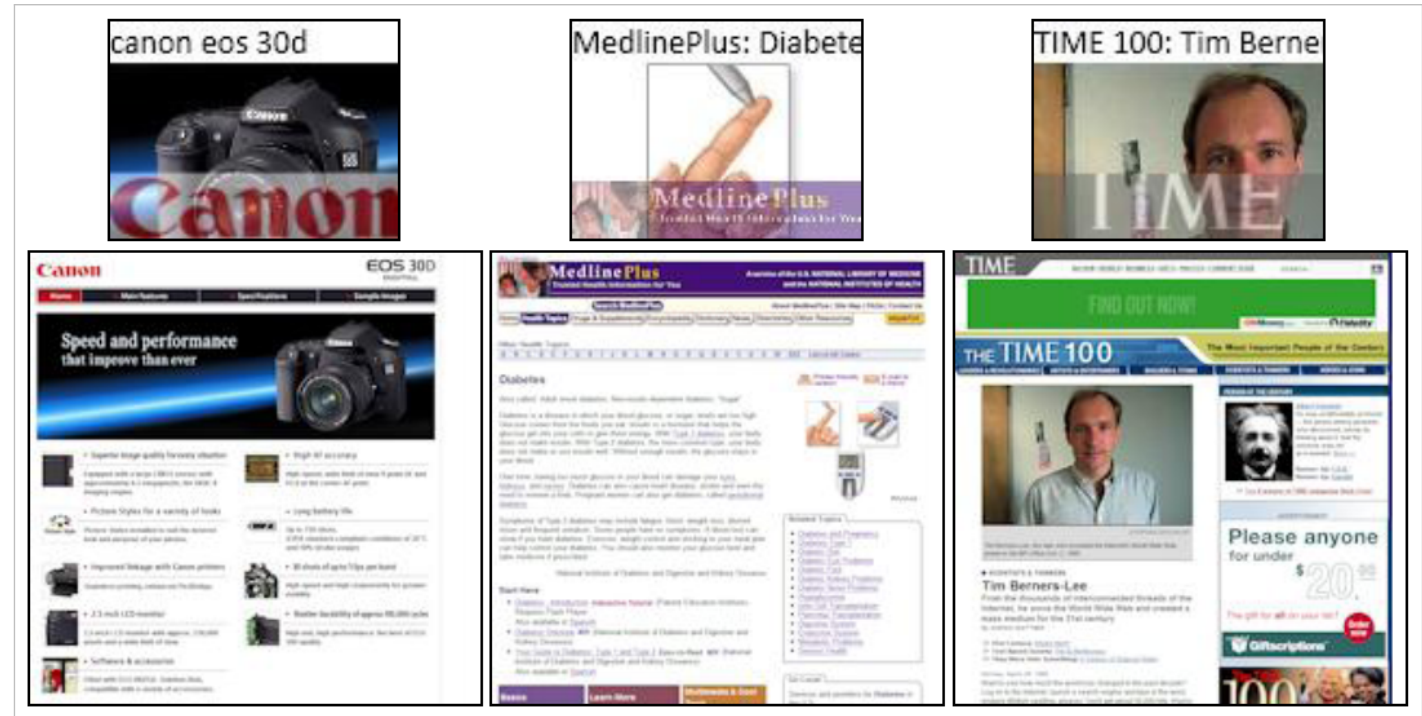

(c) Alguns exemplos de web pages (abaixo) e os visual snippets (acima) construídos a partir delas. Extraído de (Teevan et al. 2009)

Figura 2.10: Algumas das técnicas de visualização de resultados em buscas web baseadas em imagens. 


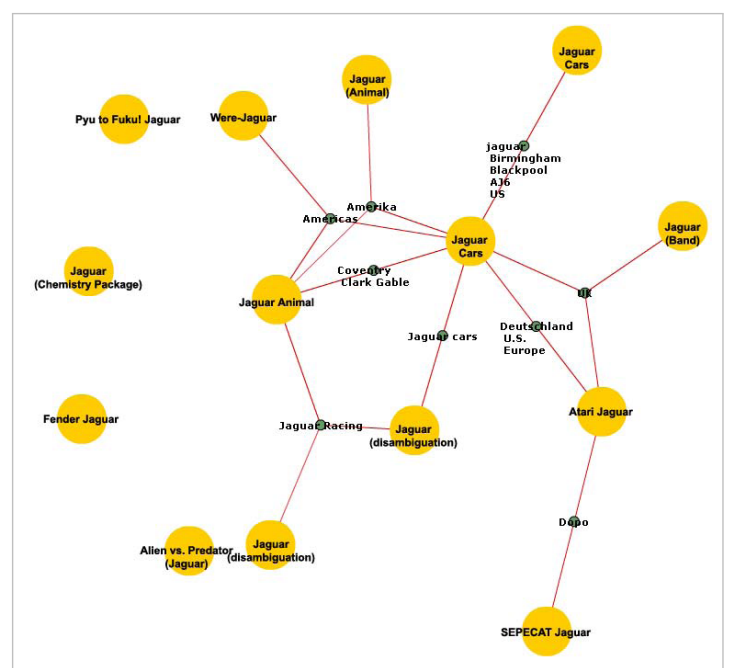

(a) Usando clusters e bridges (Sallaberry et al. 2010).

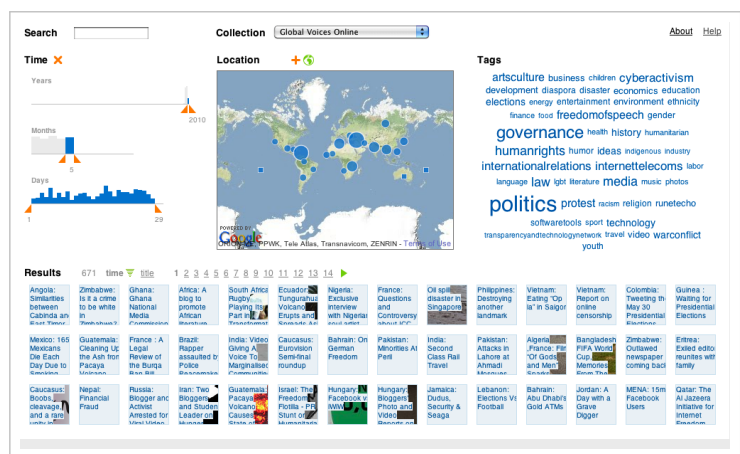

(c) VisGets (Dörk et al. 2008).

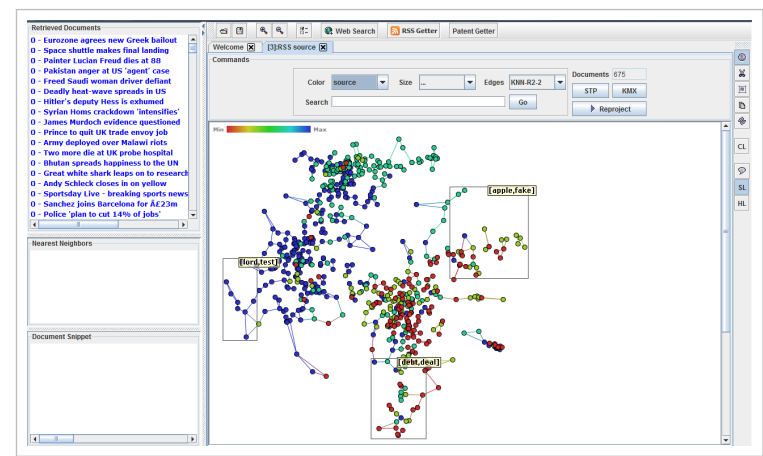

(e) PEx-Web (Paulovich et al., 2008b).

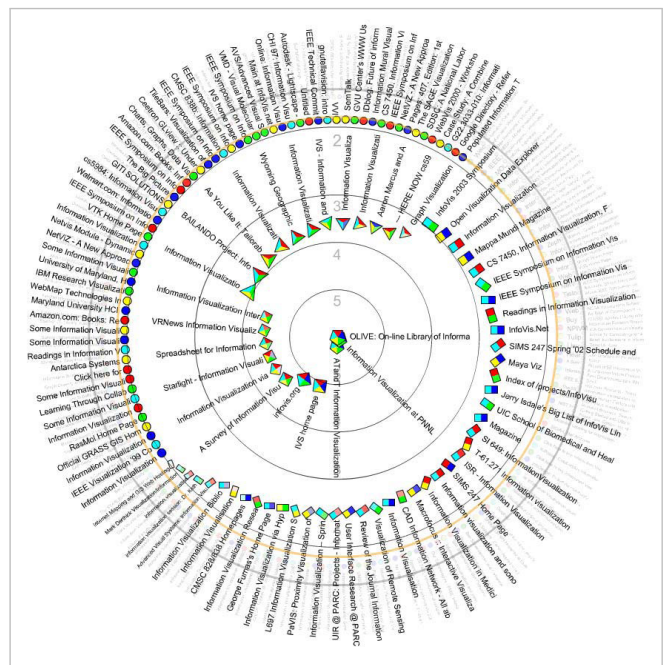

(b) RankSpiral (Spoerri, 2004).

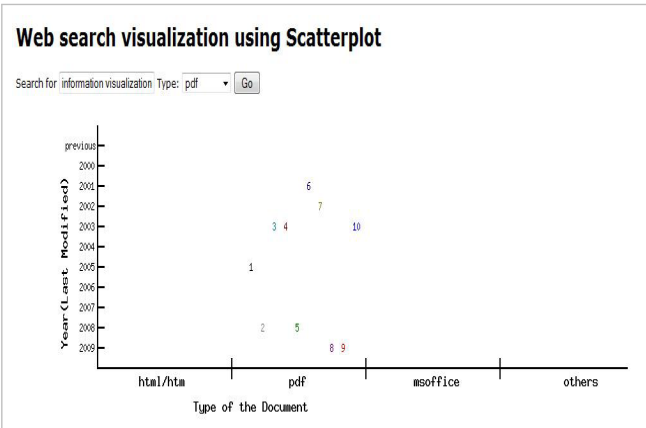

(d) Scatterplot (Nizamee e Shojib, 2010).

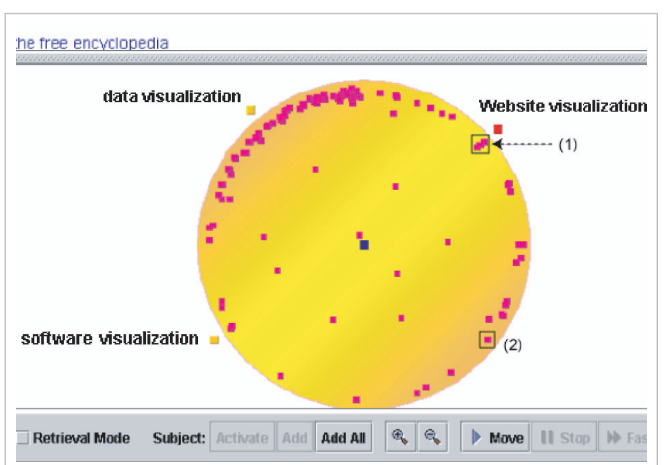

(f) WebSearchViz (Nguyen e Zhang, 2006).

Figura 2.11: Algumas das técnicas de visualização de resultados em buscas web baseadas em plotagem 
CAPÍTULO 2. METÁFORAS VISUAIS A PARTIR DE PROJEÇÕES MULTIDIMENSIONAIS 


\begin{tabular}{l|c|}
\hline Capítulo \\
\hline 3
\end{tabular}

\section{ProjSnippet}

ProjSnippet é uma abordagem para visualizar resultados de buscas web que combina a preservação de vizinhança fornecida pela projeção multidimensional com a simplicidade da representação baseada em snippets, produzindo um layout bi-dimensional. O layout é obtido a partir de um funcional de energia que considera tanto a relação de vizinhança entre snippets como a sobreposição deles no espaço visual.

A proposta envolve três passos principais, como mostra a Figura 3.1; (i) pré-processamento dos resultados da busca, (ii) projeção multidimensional e (iii) otimização baseada no funcional de energia.

\subsection{Pré-Processamento}

O primeiro passo processa os resultados recuperados a partir de um motor de pesquisa (tal como: Google ${ }^{1}$ Bing $^{2}$ ou o motor de busca fornecido por Amazon.com ${ }^{3}$ ) extraindo vetores de frequência de termos ${ }^{4}$, com a finalidade de obter características representativas de dados.

\footnotetext{
${ }^{1}$ www.google.com

${ }^{2}$ www.bing.com

${ }^{3}$ www.amazon.com

${ }^{4}$ ver (Salton et al. 1975) para informação detalhada da representação bag-of-word
} 

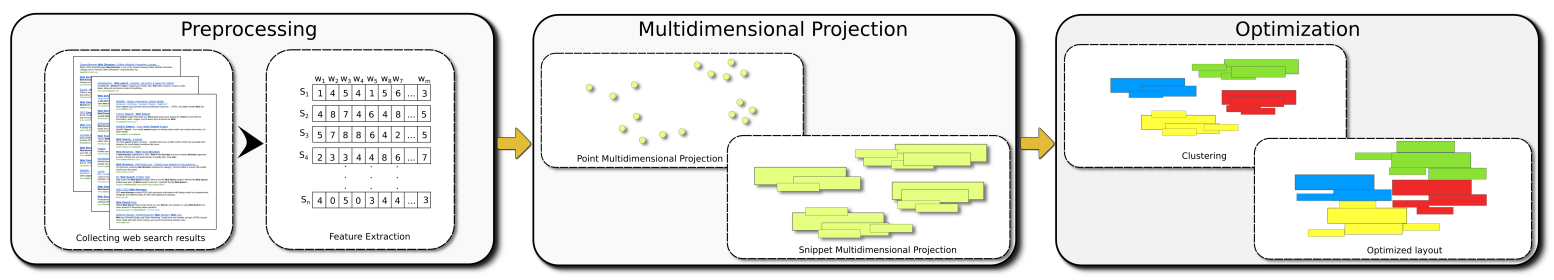

Figura 3.1: Pipeline

A fim de obter características representativas dos snippets recuperados, alguns operadores bem conhecidos de processamento de texto são aplicados:

- Remoção de stopwords: remoção de palavras que não contribuem representativamente para a compreensão do conteúdo. Tipicamente, artigos e preposições (por exemplo on, in, $a$, an, the para a língua inglesa).

- Lematização: (Stemming ou conflation) é outra função para ajudar a combinar um termo de consulta com a análise morfológica (Chakrabarti. 2002), i.e. (dependendo da língua) algumas partes da expressão, tempo, gênero e número. Essencialmente a tarefa é reduzir as variantes de termos ao seu radical. O radical é a parte invariável de uma palavra, obtida após a remoção de seus prefixos e sufixos. A seguir, alguns exemplos de redução aos radicais (em parênteses) de alguns termos muito usados na web:

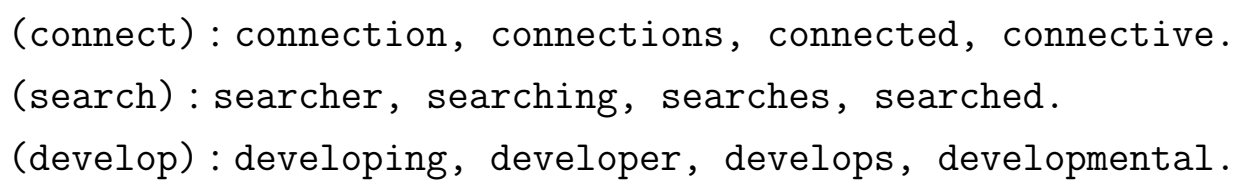

Na maioria dos métodos de lematização combinam o uso de análise morfológica, como o amplamente conhecido algoritmo de Porter (Porter, 1997) para a língua inglesa, com a pesquisa em um dicionário (e.g., FrameNet (Baker et al., 1998) and WordNet (Fellbaum, 1998)).

Tipicamente, um termo lematizado pode aumentar o número de respostas com (às vezes) documentos irrelevantes. Especificamente, no caso de buscas web, não é uma tarefa fácil de decidir se é melhor ou não aplicar lematização, por exemplo o uso de uma variedade de abreviaturas e nomes cunhados nos sectores comerciais podem dirigir a resposta em um sentido que o usuário não está requerendo.

- Definindo corte de Luhn ( $\mathrm{Luhn}$, 1958): A medida do significado das palavras é baseada na frequência em que elas aparecem. O uso de palavras com frequência muito alta ou muito baixa algumas vezes pode introduzir ruido no processo. Para evitar o problema, 
dois "limites de confiança" são estabelecidos, cortando palavras com alta e baixa frequência, sujeito a alguns fatores como número de palavras na consulta, ou a quantidade de respostas esperadas.

Após o processamento anterior, o fator de ponderação term frequency-inverse document frequency (tf-idf) é calculado para cada snippet, proporcionando uma métrica onde os termos que aparecem em poucos documentos são favorecidos. O cálculo da primeira componente inverse document frequency (idf) é definida por:

$$
i d f\left(t_{j}\right)=\log \frac{N}{d\left(t_{j}\right)}
$$

onde $N$ é o número de documentos e $d\left(t_{j}\right)$ é o número de documentos que contem $t_{j}$. Assim, tf-idf para o termo $j$ no documento $i$ é calculado pela Equação 3.2 .

$$
\operatorname{tfidf}\left(t_{j}, d_{i}\right)=t f\left(t_{j}, d_{i}\right) \times i d f\left(t_{j}\right)
$$

onde $t f\left(t_{j}, d_{i}\right)$ é a frequência do $j$-ésimo termo no $i$-ésimo documento.

\subsection{Projeção Multidimensional}

Após o pré-processamento cada snippet é interpretado como um dado de alta dimensão e como tal pode ser mapeado em um espaço visual através de uma técnica de projeção multidimensional. A fim de realizar o mapeamento, usamos a técnica Least Squares Projection (Paulovich et al., 2008a) devido a sua precisão na preservação de distancia. Outras técnicas de projeção multidimensional com as mesmas características também podem ser usadas ${ }^{5}$. O uso da projeção multidimensional preserva a estrutura da vizinhança do conjunto original de dados, assegurando que os pontos que têm relação semântica serão projetados próximos no espaço visual. A Figura 3.2 mostra a janela de pré-processamento e projeção multidimensional de ProjSnippet. Os parâmetros dos operadores descritos anteriormente podem ser modificados interativamente.

Depois da projeção, o conteúdo de cada snippet é incorporado dentro de um retângulo onde o canto inferior-esquerdo corresponde à coordenada resultante da projeção do snippet no espaço visual. A Figura 3.3 exemplifica o processo da construção de snippets a partir dos pontos resultantes da projeção multidimensional. A altura e largura de cada retângulo são determinadas pela ordem na lista de dados recuperados, assim o maior tamanho de snippet é atribuído

\footnotetext{
${ }^{5}$ Uma revisão do atual estado do arte pode ser encontrado em (Joia et al. 2011a)
} 


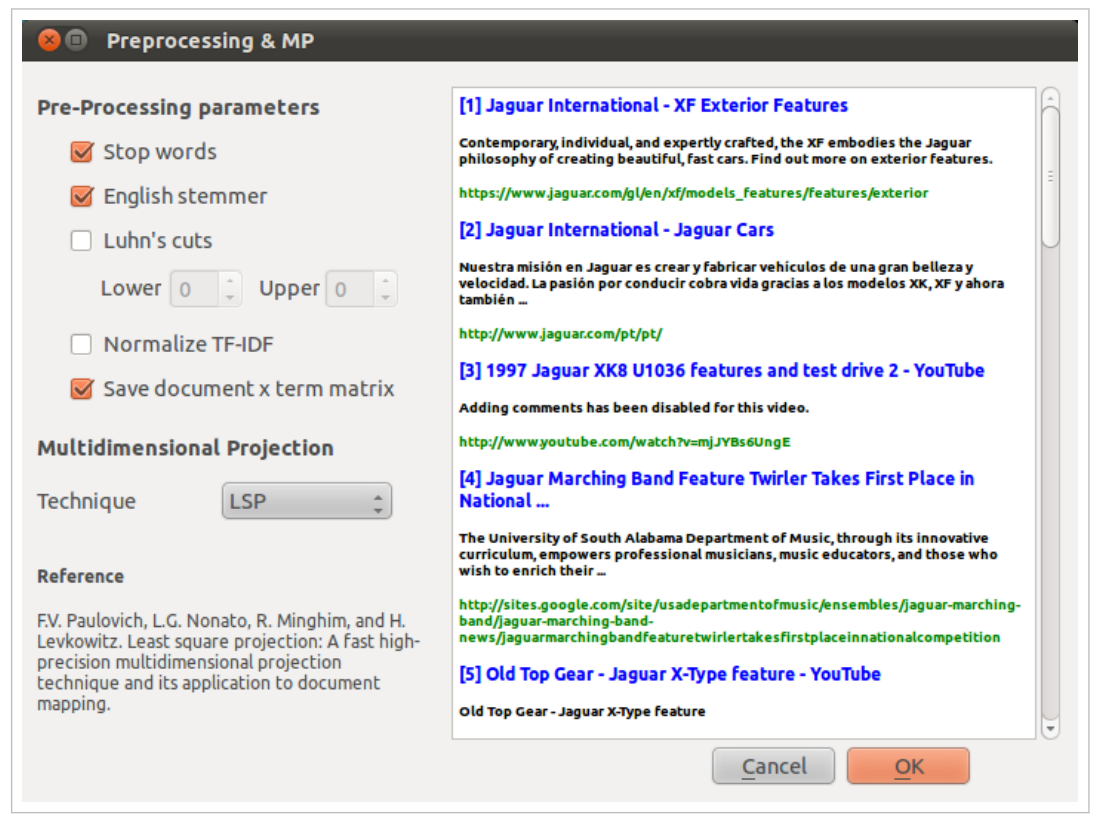

Figura 3.2: Interface gráfica para o pre-processamento e a projeção multidimensional em ProjSnippet. No lado esquerdo da janela são mostrados os parâmetros ajustáveis no processo.

No lado direito, os resultados recuperados da consulta são mostrados para uma simples inspeção do conteúdo.

aos snippets melhor posicionados na lista. Posteriormente, o algoritmo k-means ++ Arthur e Vassilvitskii, 2007) é aplicado no espaço visual (usando distancia Euclidiana como métrica), a fim de identificar os grupos de snippets semanticamente relacionados. Assim, cada grupo identificado é ressaltado na representação visual usando uma mesma cor na moldura é no fundo dos retângulos para os snippets do mesmo grupo.

O problema com a definição dos retângulos é que o conjunto de snippets representados no espaço visual ficam consideravelmente sobrepostos, impedindo a identificação do conteúdo e a percepção da estrutura de vizinhança entre os documentos. O passo final do processo é a otimização do posicionamento dos snippets de modo a evitar a sobreposição, preservando porém as vizinhanças fornecidas pela projeção. A otimização é guiada por um funcional de energia, descrito na seção a seguir.

\subsection{O Funcional de Energia}

$O$ funcional da energia $E$ compreende dois componentes, um deles quantifica a sobreposição dos snippets, denotado por $E_{O}$, e o segundo componente mede as relações de vizinhança resul- 


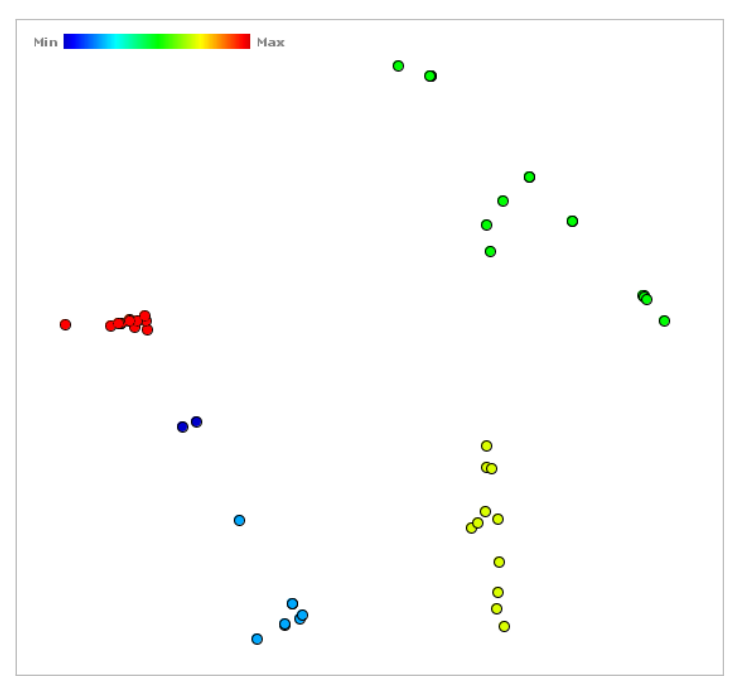

(a) Point-based

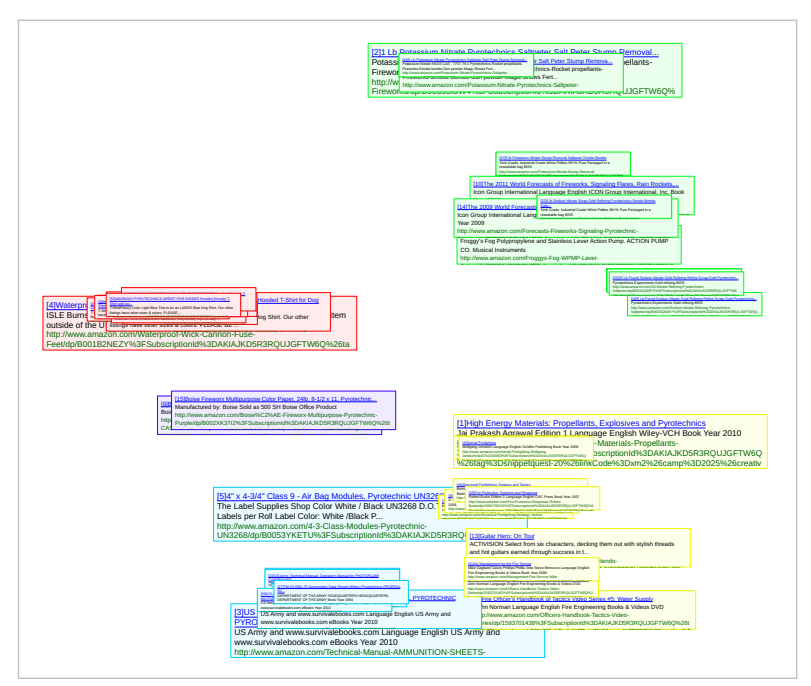

(b) Snippet-based

Figura 3.3: O mesmo conjunto de dados projetado no espaço visual baseado em pontos (usando PEx (Paulovich et al., 2007)) e em snippets (usando ProjSnippet).

tantes da projeção multidimensional, denotado por $E_{N}$. Em termos matemáticos, a energia $E$ pode ser escrita como:

$$
E=(1-\alpha) E_{O}+\alpha E_{N}
$$

onde o parâmetro $\alpha \in[0,1]$ equilibra a contribuição relativa de ambos $E_{O}$ e $E_{N}$ no total da energia.

A energia $E$, assim como $E_{O}$ e $E_{N}$, são funções das coordenadas do canto inferior-esquerdo dos retângulos que contém os snippets. As variáveis independentes das equações serão omitidas para simplificar a notação.

\subsubsection{A energia de sobreposição $E_{O}$}

Com o objetivo de aumentar a visibilidade e legibilidade geral da visualização, a energia $E_{O}$ deve ser definida de forma a minimizar a sobreposição/interseção dos snippets. Isto é alcançado com uma função que mede a distância entre os cantos esquerdos dos retângulos.

Esta função é suave, atinge seu mínimo valor quando não existe sobreposição e toma valores mais elevados quando a sobreposição dos retângulos é maior. Suavidade é uma propriedade importante aqui, já que permite o uso de métodos de otimização simples e eficientes, que são obrigatórios para a geração rápida da visualização final. 
Sejam $\vec{x}, \vec{y} \in \mathbf{R}^{n}$ os vetores contendo as coordenadas do canto inferior-esquerdo de cada retângulo e $\vec{v}, \vec{h} \in \mathbf{R}^{n}$ os vetores cujos componentes são as dimensões verticais e horizontais de cada retângulo.

Considere as seguintes funções auxiliares:

$$
[x]_{+}= \begin{cases}x & x \geq 0 \\ 0 & x<0\end{cases}
$$

e

$$
O_{i, j}(\vec{x}, \vec{h})=\left\{\begin{array}{ll}
\frac{1}{h_{j}^{4}}\left[h_{j}^{2}-\left(x_{i}-x_{j}\right)^{2}\right]_{+}^{2} & x_{i} \geq x_{j} \\
\frac{1}{h_{i}^{4}}\left[h_{i}^{2}-\left(x_{i}-x_{j}\right)^{2}\right]_{+}^{2} & x_{i}<x_{j}
\end{array} .\right.
$$

onde $x_{i}, h_{i}$ e $x_{j}, h_{j}$ denota a coordenada $x$ do canto inferior-esquerdo e o comprimento dos retângulos $i$ e $j$, respectivamente. Note-se que $O_{i, j}(\vec{x}, \vec{h})$ é zero quando não existe sobreposição horizontal dos retângulos $i$ e $j$, alcançando seu máximo valor 1 quando a coordenada $x$ do canto esquerdo de ambos retângulos coincidem. A função $O_{i, j}$ trabalha similarmente se a coordenada $y$ e alturas são usadas como argumentos, i.e., $O_{i, j}(\vec{y}, \vec{v})$.

A partir das definições anteriores, calculamos $E_{O}$ por:

$$
E_{O}=\frac{2}{n(n-1)} \sum_{i=1}^{n} \sum_{j=i+1}^{n}\left[O_{i, j}(\vec{x}, \vec{h}) O_{i, j}(\vec{y}, \vec{v})\right] .
$$

onde $n$ é o número de pontos projetados. A definição de $O_{i, j}$ garante claramente que $E_{O}$ é continuamente diferenciável e varia no intervalo $[0,1]$.

\subsubsection{A energia de vizinhança $E_{N}$}

A minimização de $E_{O}$ espalha os snippets textuais no espaço visual de modo a evitar que retângulos se sobreponham. No entanto, este processo de minimização é susceptível a estragar a estrutura de vizinhança estabelecida pela projeção multidimensional, colocando snippets semelhantes distantes na visualização final.

$O$ termo de energia $E_{N}$ é introduzido para equilibrar o efeito da energia de sobreposição durante a otimização. Na prática, a energia $E_{N}$ é definida a partir do grafo dos $k$ vizinhos mais próximos construído a partir da projeção (vetores de características dos snippets). Nossa implementação usou dez vizinhos $(k=10)$. Os componentes desconectados resultantes da construção do grafo $G$ são conectados adicionando a $G$ a menor aresta ligando as componentes, garantindo que $G$ se torne conectado. 


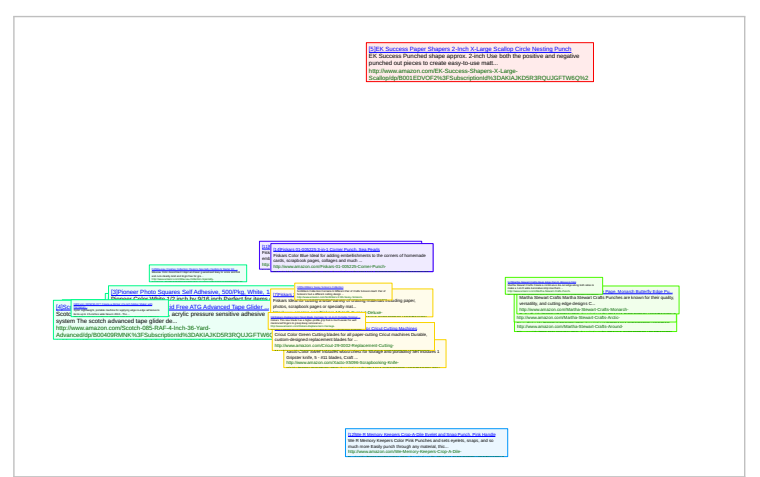

(a) Sem otimização

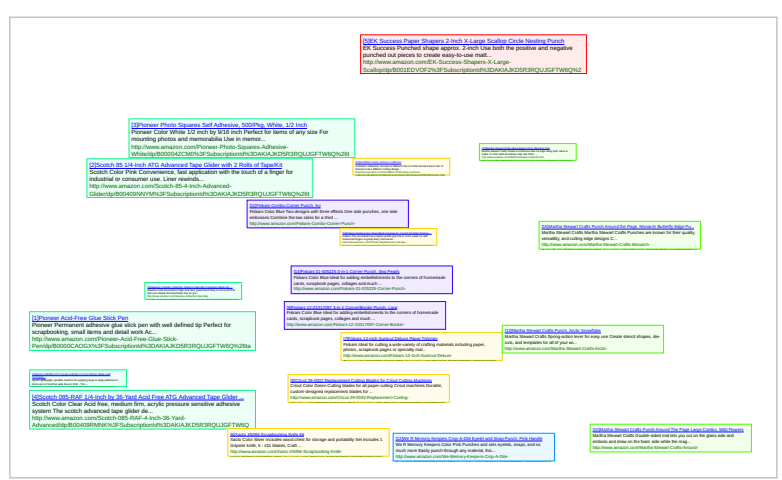

(b) Somente $E_{O}$

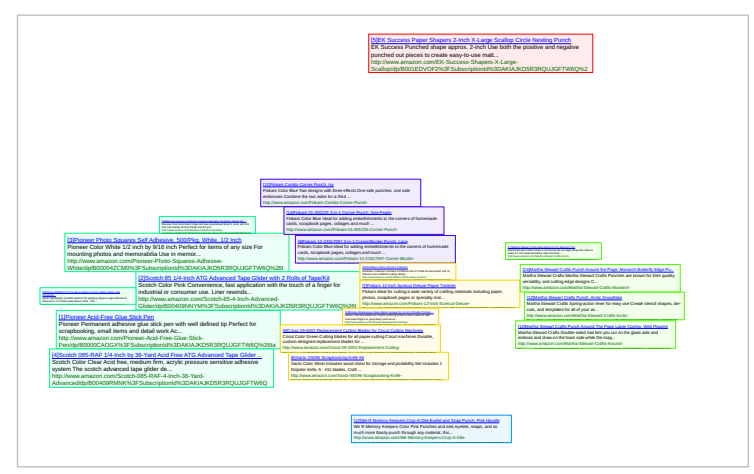

(c) $E=\frac{1}{2}\left(E_{O}+E_{N}\right)$

Figura 3.4: a) Layout sem otimização; b) Energia de sobreposição $E_{O}$ só; c) ambas energias $E_{O}$ e $E_{N}$ combinadas $(\alpha=0.5)$.

Seja $L$ a matriz $n \times n$ com entradas $l_{i j}$ dada por:

$$
l_{i j}=\left\{\begin{array}{cl}
-1 /|i| & \text { se } j \neq i \text { e } \overline{i j} \text { é uma aresta de } \mathrm{G} \\
1 & \text { se } j=i \\
0 & \text { caso contrário }
\end{array}\right.
$$

onde $|i|$ é a valência do nó $i$.

Denotando por $\vec{x}^{0}$ e $\vec{y}^{0}$ os vetores de coordenadas $x$ e $y$ dos nós de $G$ (recordar que $\vec{x}^{0}$ e $\vec{y}^{0}$ são resultantes da projeção multidimensional) definimos os vetores diferenciáveis $\vec{\delta}_{x}$ e $\vec{\delta}_{y}$ como:

$$
\vec{\delta}_{x}=L \vec{x}^{0}, \quad \vec{\delta}_{y}=L \vec{y}^{0} .
$$

Note que os componentes de $\vec{\delta}_{x}$ e $\vec{\delta}_{y}$ são dadas respectivamente por:

$$
x_{i}^{0}-\frac{1}{\left|N_{i}\right|} \sum_{j \in N_{i}} x_{j}^{0}, \quad y_{i}^{0}-\frac{1}{\left|N_{i}\right|} \sum_{j \in N_{i}} y_{j}^{0}
$$


Em menos termos matemáticos, $\vec{\delta}_{x}$ e $\vec{\delta}_{y}$ medem quanto cada nó desvia-se da média dos seus vizinhos. Portanto, podemos definir a energia da vizinhança como:

$$
E_{N}=\frac{n^{2}}{2\left(\left\|\vec{\delta}_{x}\right\|^{2}+\left\|\vec{\delta}_{y}\right\|^{2}\right)}\left(\left\|L \vec{x}-w \vec{\delta}_{x}\right\|^{2}+\left\|L \vec{y}-w \vec{\delta}_{y}\right\|^{2}\right) .
$$

Não é difícil perceber que $E_{N}$ será mínima quando as relações de vizinhança são preservados durante a otimização. A variável $w$ é adicionado na otimização para garantir que qualquer escala dos pontos é um mínimo de energia de vizinhança ( $w$ é otimizado junto com $\vec{x}$ e $\vec{y}$ ).

O fator de normalização $\frac{n^{2}}{2}\left(\left\|\vec{\delta}_{x}\right\|_{2}^{2}+\left\|\vec{\delta}_{y}\right\|_{2}^{2}\right)^{-1}$ é necessário para assegurar que o intervalo de valores de $E_{N}$ está na mesma ordem de magnitude que $E_{O}$, fazendo assim que ambos termos desempenham funções similares (controlado pelo parâmetro $\alpha$ ) na energia total $E$.

A Figura 3.4 ilustra o resultado de aplicar a otimização a partir dos snippets projetados 3.4(a). A Figura 3.4(b) mostra o layout obtido quando só a energia de sobreposição é otimizada, enquanto que a Figura 3.4(c) mostra o resultado da otimização com ambos termos da energia igualmente equilibrados.

\subsection{Aspectos Computacionais e Outros Detalhes}

Os limites relacionados com os tamanhos das janelas de visualização são impostos como restrições para a minimização da energia (3.3). Isto é necessário pois, para um número $K$ positivo suficientemente grande, os vetores de coordenadas $\vec{x}=K \vec{x}^{0}$ e $\vec{y}=K \vec{y}^{0}$ correspondem ao minimizador global de $E$, pois nenhuma sobreposição deve acontecer e os diferenciais são preservados. No entanto, a solução mínima dada por escalonamento não é desejável porque é propenso a espalhar os snippets muito, resultando em visualizações desagradáveis e inúteis.

Portanto, denotando os limites horizontal e vertical da janela de visualização por $x_{\min }, x_{\max }$ e $y_{\min }, y_{\max }$ o problema de minimização torna-se:

$$
\begin{array}{ll}
\min & (1-\alpha) E_{O}+\alpha E_{N} \\
\text { s.t.: } & x_{\text {min }} \leq x_{i} \leq x_{\text {max }}-h_{i}, \quad i=1, \ldots, n \\
& y_{\text {min }} \leq y_{i} \leq y_{\text {max }}-v_{i}, \quad i=1, \ldots, n .
\end{array}
$$

o qual garante que todos os retângulos se encontram dentro da janela de visualização, assim é prevenido o efeito de escalonamento exagerado. 
A minimização é realizada por um método de otimização local convergente globalmente, chamado de Method of Moving Asymptotes (Svanberg, 2002), disponibilizado para seu uso na biblioteca livre de otimização não-linear $N L o p t^{6}$.

\subsubsection{Reduzindo espaços vazios}

A fim de reduzir os espaços em branco (vazios) entre os grupos de snippets no layout final, foi implementada uma versão simplificada da estrategia Seam Carving Wu et al. (2011), amplamente conhecida na área de processamento de imagens. A ideia consiste em particionar as regiões em branco (regiões sem ocupação de snippets) da janela de visualização em uma grade retilínea como ilustra a Figura 3.5(a), As costuras (seams) são criadas pelo colapso das células vazias da grade da esquerda para direita e de acima para baixo. Uma célula é colapsada se e somente se todos os snippets dos clusters afetados pelo colapso podem ser deslocados horizontalmente ou verticalmente. Tal mecanismo é executado rapidamente e evidentemente preserva os clusters. Algumas estratégias mais sofisticadas de carving são capazes de remover ainda mais espaços em branco existentes, mas essas técnicas são computacionalmente custosas e tendem a afetar as estruturas de vizinhança. O esquema descrito acima é computacionalmente eficiente, e resulta em layouts agradáveis que preservam os clusters inteiramente.

\subsection{Interação}

Uma das vantagens do ProjSnippet, é a exploração interativa dos resultado recuperados a partir de uma consulta textual na web. A Figura 3.6(a) mostra a janela principal que o ProjSnippet usa para mostrar os snippets. Na barra do lado esquerdo podem se encontrar algumas ferramentas que apóiam na exploração como zoom in e out, seleção de snippets, exportar a formato .pdf o mapa atual, mudar aleatoriamente as posições dos snippets, entre outras.

Quando o cursor do mouse é posicionado sobre alguns dos snippets, ele é ressaltado aumentando seu tamanho para melhorar a inspeção do seu conteúdo. Depois de alguns segundos (4 seg. aprox.) o sistema assume que o usuário possui algum interesse no conteúdo daquele resultado, assim uma pré-visualização da página web que o snippet representa é mostrada embaixo dele a fim de fornecer mais informação para que o usuário saiba se é o que ele procura. Se o usuário faz duplo clique no snippet, a página web será carregada no navegador de uso predeterminado. Uma vez que o usuário tira o cursor do snippet, o tamanho dele volta ao original. A Figura 3.6 ilustra esta interação.

\footnotetext{
${ }^{6}$ NLopt está disponível em http://ab-initio.mit.edu/wiki/index.php/NLopt
} 


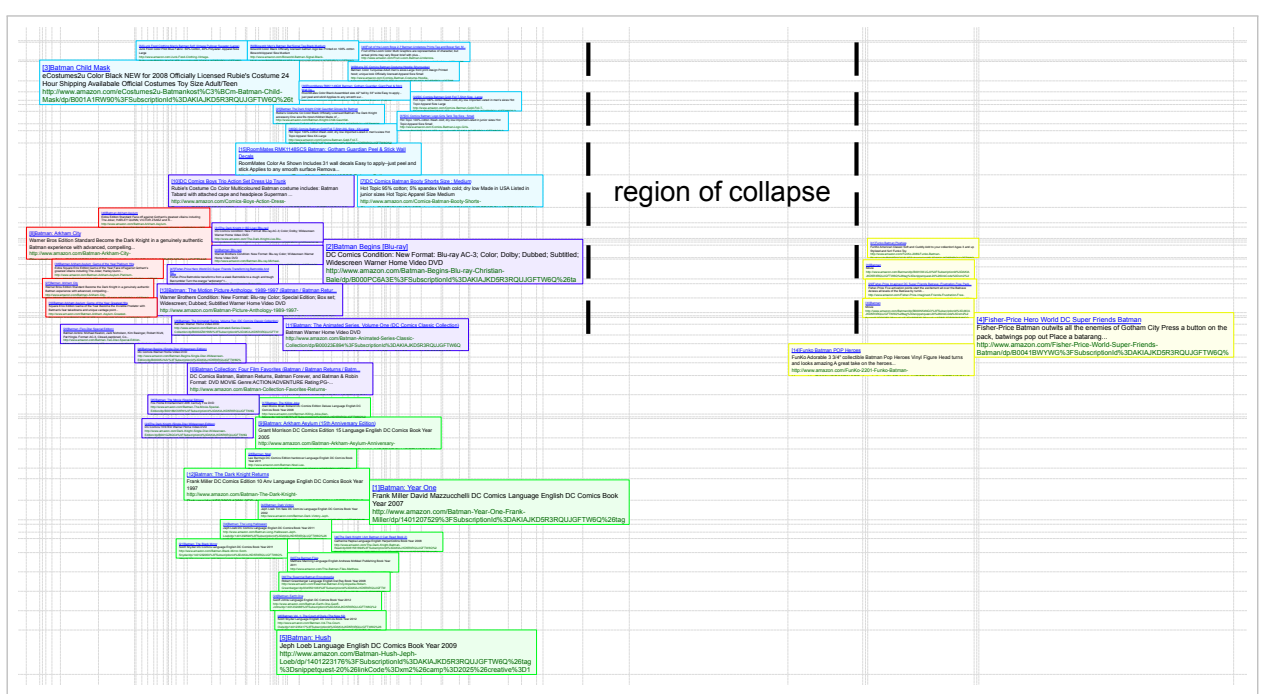

(a) Grade retilínea para aplicar carving.

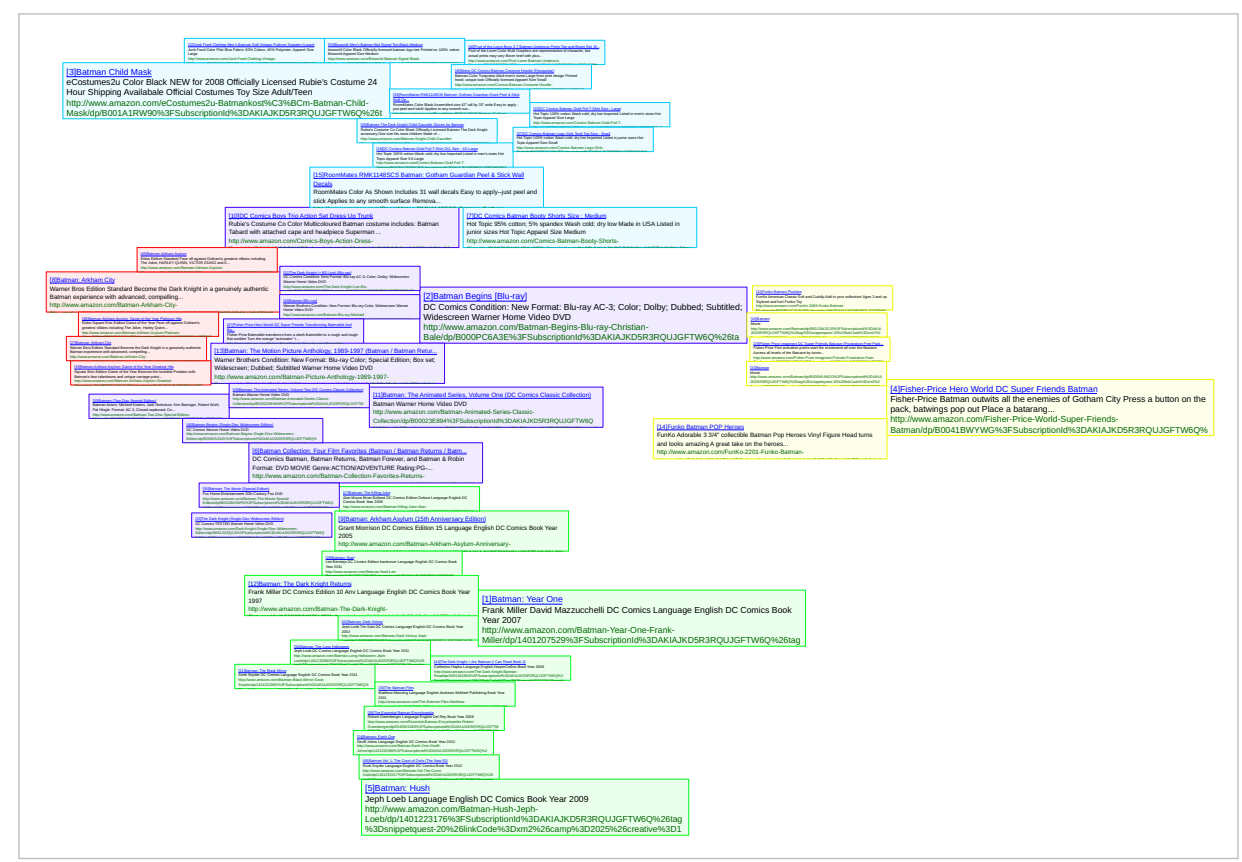

(b) Usando estrategia carving.

Figura 3.5: Reduzindo os espaços sem uso com o mecanismo carving.

\subsection{Resultados}

Essa seção apresenta alguns resultados para ilustrar o desempenho da abordagem proposta sob dados obtidos em tempo real da web. Todos os exemplos foram gerados usando Intel $\AA$ Core ${ }^{\mathrm{TM}}$ i7 CPU 920 2.66GHz com 8GB de RAM. O algoritmo de clustering $k$-means ++ foi aplicado com o proposito de colorir os retângulos para ressaltar visualmente os grupos de snippets si- 


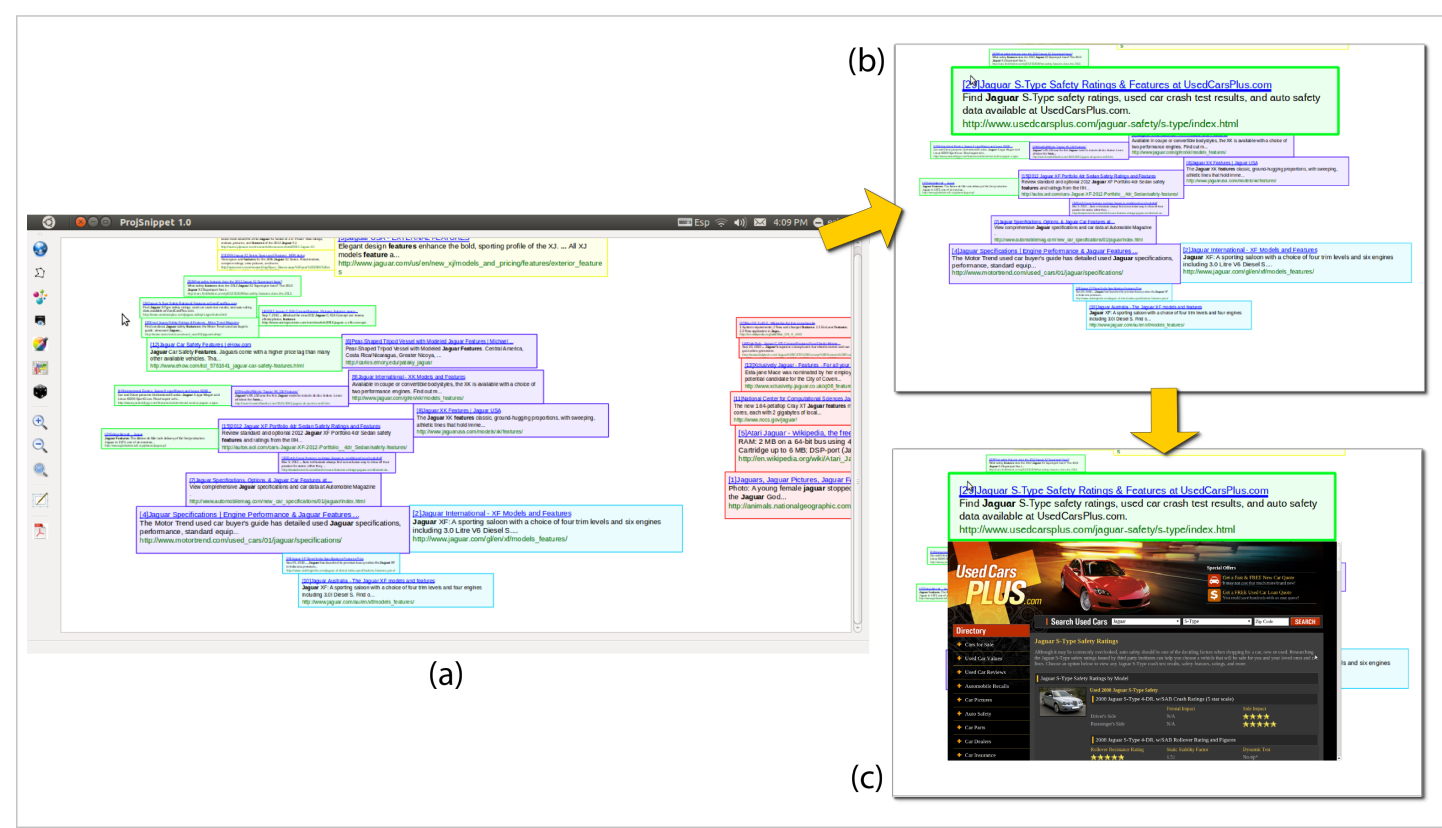

Figura 3.6: Exploração interativa do ProjSnippet: (a) Janela de visualização mostrando alguns resultados da pesquisa, (b) quando o cursor do mouse é posicionado sobre um dos snippets, ele é ressaltado aumentando suas dimensões a fim de fornecer uma melhor leitura, (c) depois de alguns segundos uma pré-visualização do conteúdo da página web é mostrada embaixo do snippet.

milares, além de fornecer uma segregação visual para facilitar a exploração dos resultados. O processo de otimização foi realizado com $\alpha=0.3$ (valor padrão na aplicação).

O primeiro exemplo ilustra o resultado ao consultar os termos "jaguar features" no motor de busca de Google. A Figura 3.7(a) visualiza a primeira pagina de resultados, listando o ranking dos 10 primeiros snippets, enquanto que a Figura 3.7(b) mostra a visualização de 64 snippets fornecida por ProjSnippet, fornecendo portanto a visualização das primeiras 6 paginas de Google. Inspecionando a visualização pode-se notar que os snippets do lado esquerdo (grupos ciano, vermelho, azul e amarelo) são todos referentes à marca de carros Jaguar com especificidades diferentes nos modelos, enquanto que os snippets verdes concentrados no lado direito referem-se a uma variedade de tópicos. Entre esses podemos encontrar algumas referencias ao mundo animal ( 3 instancias), e alguns modelos de supercomputadores chamados Jaguar (2 instancias). Vermos também referencias a uma versão do sistema operacional MacOs, a um jogo de vídeo, uma marca de piscinas, um modelo de aeronave e alguns outros tipos de objetos. Concentrando-se no lado esquerdo do resultado, podemos identificar que a maioria dos resultados no grupo azul são referentes à marca de carro, enquanto que os outros grupos referem-se principalmente a um modelo em especifico, a saber, os snippets em amarelo referem-se ao modelo XK, os snippets em ciano ao modelo XJ, e os snippets em vermelho ao modelo XF, com 


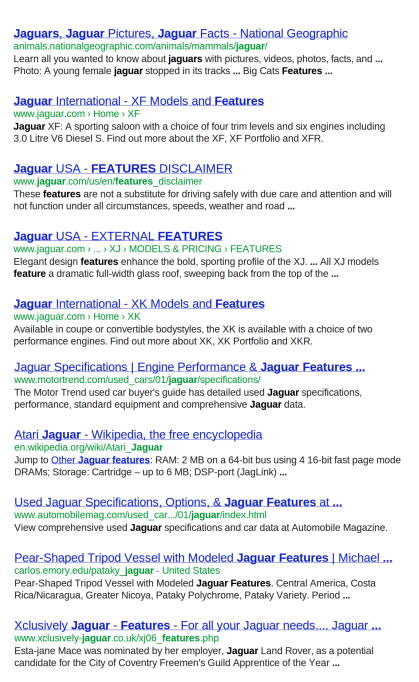

(a) Primeira página de Google

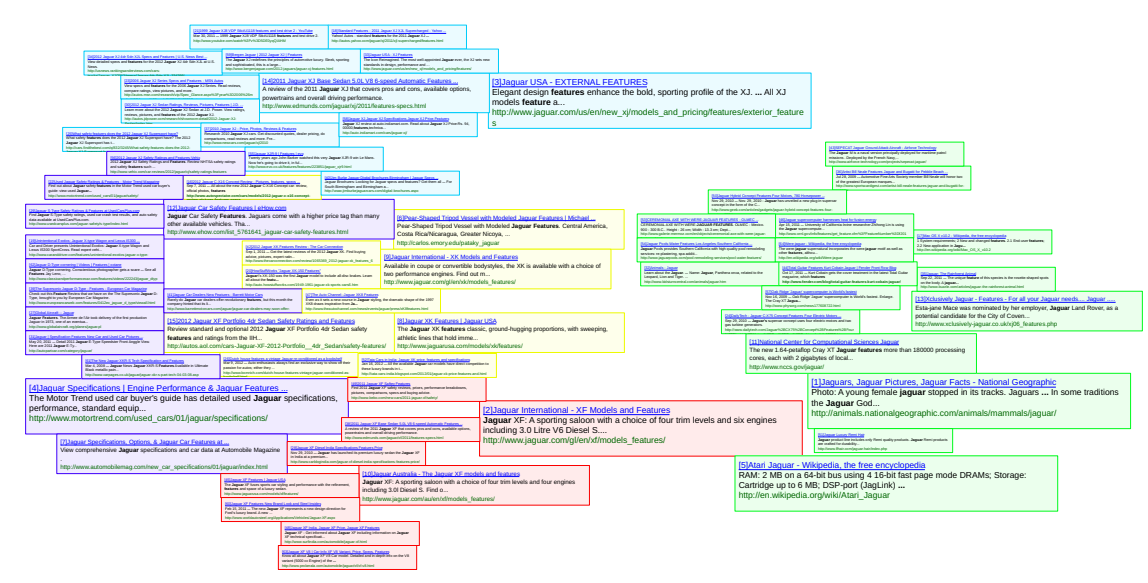

(b) ProjSnippet mostrando 64 snippets (mais de 6 páginas de Google)

Figura 3.7: Comparação entre a saída de Google e ProjSnippet.

algumas exceções e.g. um snippet do grupo amarelo refere-se ao modelo XF e um do grupo azul refere-se ao modelo XJ. Ainda assim em geral, o layout final faz um bom trabalho representando a visão global dos resultados da pesquisa, em termos de agrupamento de resultados similares. Note que tal variedade de tópicos e sub-tópicos é difícil de ser analisada com uma visualização baseada em lista como a fornecida por Google, a qual apresenta de fato só a marca de carros, o animal e o jogo de vídeo como tópicos na primeira pagina.

A Figura 3.8 apresenta visualizações a partir do motor de busca de Amazon, a fim de ilustrar o potencial de ProjSnippet no cenário de pesquisas de produtos em lojas online. Os testes a seguir consideram o conteúdo dos campos título, autor, marca, cor, edição, língua de publicação, característica, fabricante, grupo de produtos, tamanho, garantia, e o ano de publicação para criar o modelo de espaço vetorial, sem considerar o resto dos campos oferecidos pela Amazon Web Service ${ }^{7}$.

Na Figura 3.8(a) mostramos uma consulta com os termos "scrapbooking" na categoria "Office Products", da qual 50 produtos foram devolvidos e visualizados. Em geral, o layout final reflete a organização global dos produtos pela marca e funcionalidade. A maioria dos snippets do grupo laranja refere-se a modelos de furadeiras da mesma marca, EK Success. Também têm alguns snippets que referem-se a um removedor de adesivo e uma cantoneira arredondada, todos da mesma marca que as furadeiras. O grupo vermelho inclui apenas produtos da marca Fiskars, como furadeiras ou cantoneiras. O grupo verde amarelado à direita exibe produtos

\footnotetext{
${ }^{7}$ http://aws.amazon.com/
} 
da marca Martha Stewart Crafts, incluindo principalmente os modelos de furadeiras. O grupo verde de snippets do lado esquerdo é mais variado em conteúdo, inclui diversos produtos e marcas. Ainda assim, a maioria refere-se a diferentes tipos de colas e produtos relacionados: planadores de fita, recargas de fita, cola e ocorrências variadas de adesivos, como adesivos do bebê. $\mathrm{O}$ grupo verde também inclui uma referência a cartolina e uma referência para um rack de armazenamento de artesanatos. Os outros dois grupos restantes identificados pelo algoritmo de clustering são ambos muito pequenos. Os dois snippets em cima em azul, e o lado esquerdo do grupo amarelo referem-se a uma furadeira e um pad de papel. Os três snippets na parte inferior do grupo ciano referem-se a modelos de furadeira da mesma marca e um conjunto de canetas.

A Figura 3.8(b) mostra os 50 resultados obtidos depois de consultar os termos "pyrotechnics supplies" na categoria "All". O grupo vermelho a esquerda refere-se a desenhos de camisas para cachorros com a impressão de uma frase que contém o termo "pyrotechnics", com a exceção do snippet maior que refere-se a um fusível a prova de água (waterproof fuse). Abaixo do grupo vermelho, está o grupo azul composto por dois snippets referindo-se a uma marca nomeada Fireworx de papel colorido. Mais abaixo está o grupo ciano, onde a maioria dos snippets referem-se a manuais técnicos do Exército dos EUA (US Army) na pirotecnia militar. Novamente, existe uma exceção que faz referência ao abastecimento de etiquetas. O grupo verde na parte superior-direita da área, refere-se principalmente a abastecimento de químicos, mas também inclui duas referências a um livro e uma referência a um brinquedo. Finalmente, o grupo amarelo contém material didático, principalmente livros, mas também de vídeo, em matéria de segurança, abordando temas como estratégia de proteção, táticas e combate a incêndios. Uma exceção é a referência a um jogo de vídeo. O agrupamento nesta visualização é muito uniforme no conteúdo, i.e. os grupos estão claramente separados por tópico, com exceção de alguns itens incomuns, como as etiquetas ou o jogo de vídeo.

Na Figura 3.9 apresenta 60 resultados recuperados depois de emitir a consulta "wave applications" no motor de busca Bing, dividido em 6 grupos diferentes. O grupo amarelo em cima refere-se a aplicações para celulares da marca Samsung. No grupo ciano, embaixo do vermelho, os resultados referem-se à ferramenta on-line Google Wave. O grupo azul turquesa do lado direito refere-se a revistas de física, especificamente de eletromagnetismo. O grupo azul está composto por 2 snippets com o mesmo conteúdo, ambos referem-se a aplicações para piscinas. O grupo verde na parte baixa da janela, refere-se a softwares de simulação numérica. Por último, no grande grupo vermelho da esquerda foram agrupados todos os snippets que não tem nenhuma relação semântica com os outros grupos bem definidos.

O usuário pode interagir com as visualizações navegando diretamente entre os snippets para inspecionar os resultados agrupados da mesma forma como ele faz usando a metáfora con- 
vencional baseada em lista. Além disso, os exemplos mostrados ilustram claramente que as visualizações do ProjSnippet, são capazes de representar muitos snippets ao mesmo tempo de uma maneira clara e organizada.

\subsubsection{O efeito do parâmetro $\alpha$ (alfa)}

O efeito da variação do parâmetro $\alpha$ na Equação 3.3 é ilustrado na Figura 3.10, que mostra o layout após a otimização (sem a aplicação da estratégia carving) dos resultados recuperados na consulta dos termos "wave applications". Na Figura 3.10(a) só a energia de sobreposição foi considerada $(\alpha=0)$. Não existe sobreposição entre os snippets, mas a relação de vizinhança não foi preservada e os snippets foram muito espalhados. Inspecionando as Figuras $3.10(\mathrm{~b}) 3.10(\mathrm{c})$ e $3.10(\mathrm{~d})$ pode-se notar que os snippets semelhantes vão se aproximando com o aumento do valor de $\alpha$. Observe que, mesmo para grandes valores de $\alpha$ (por exemplo $\alpha=0.8$ na Figura 3.10(d) os snippets não se sobrepõem indevidamente, mostrando a robustez de ProjSnippet com respeito a $\alpha$. Nenhum deslocamento ocorre se $\alpha=1$, pois o resultado da projeção é claramente um minimizador da energia da vizinhança $\left(E_{N}\right)$.

A tabela 3.1 mostra os valores da energia após a otimização, e os tempos computacionais (em segundos) para os exemplos apresentados nessa seção. Observe que a estratégia de minimização faz um bom trabalho em tempos admissíveis.

Tabela 3.1: Resultados da otimização.

\begin{tabular}{|c|c|c|c|c|c|c|}
\hline Consulta & $n$ & $k$ & $E_{O}$ & $E_{N}$ & $E$ & Tempo (s) \\
\hline \hline Pyrotechnics supplies & 50 & 5 & $4.54^{-7}$ & $1.97^{-4}$ & $5.93^{-5}$ & 0.24 \\
\hline Scrapbooking supplies & 50 & 7 & $1.71^{-7}$ & $5.09^{-4}$ & $5.11^{-5}$ & 0.23 \\
\hline Jaguar features & 64 & 5 & $3.97^{-7}$ & $1.91^{-4}$ & $5.76^{-4}$ & 0.27 \\
\hline Wave applications & 60 & 6 & $5.38^{-6}$ & $8.53^{-4}$ & $3.44^{-4}$ & 1.12 \\
\hline Batman & 50 & 5 & $2.79^{-8}$ & $4.86^{-5}$ & $2.19^{-5}$ & 0.26 \\
\hline
\end{tabular}




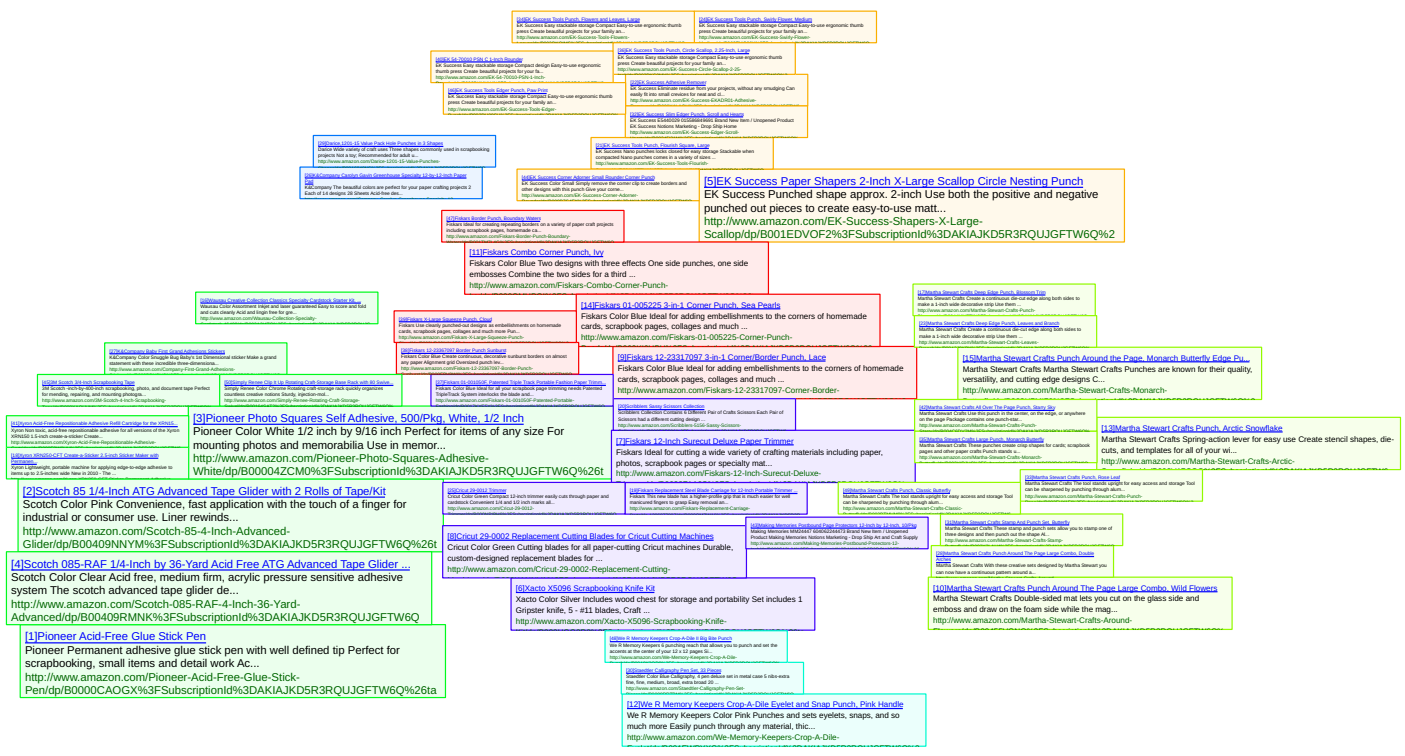

(a) 'scrapbooking supplies' (50 snippets)

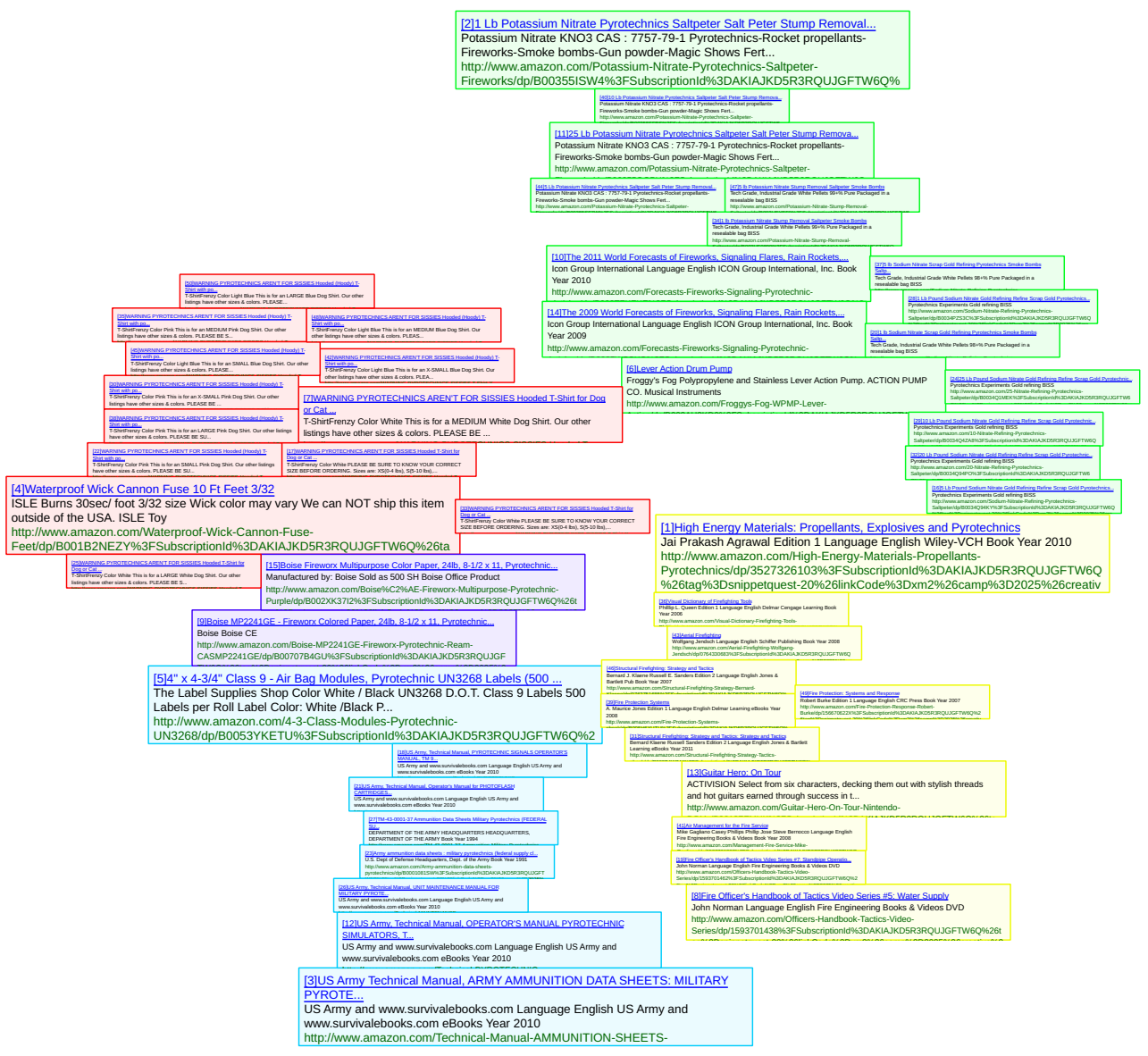

(b) 'pyrotechnics supplies' (50 snippets)

Figura 3.8: Procurando "scrapbooking supplies" (a) and "pyrothecnique supplies" (b) em Amazon. 


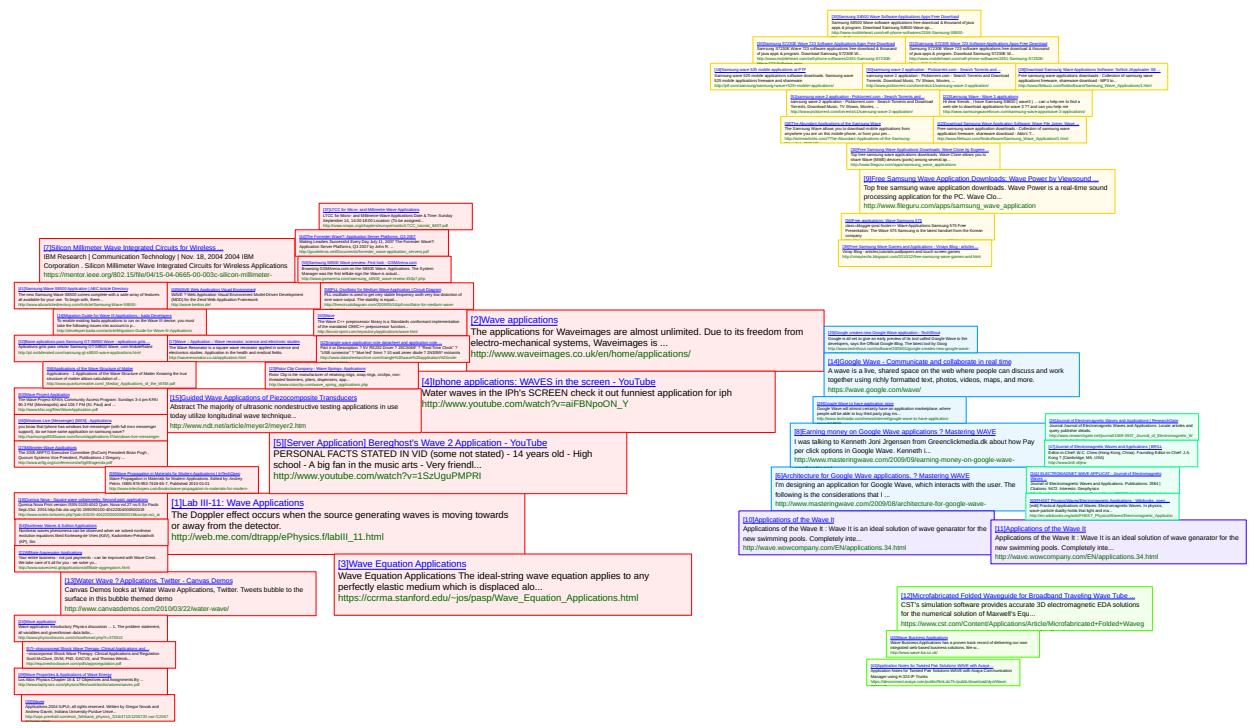

Figura 3.9: Procurando "wave applications" em Bing.

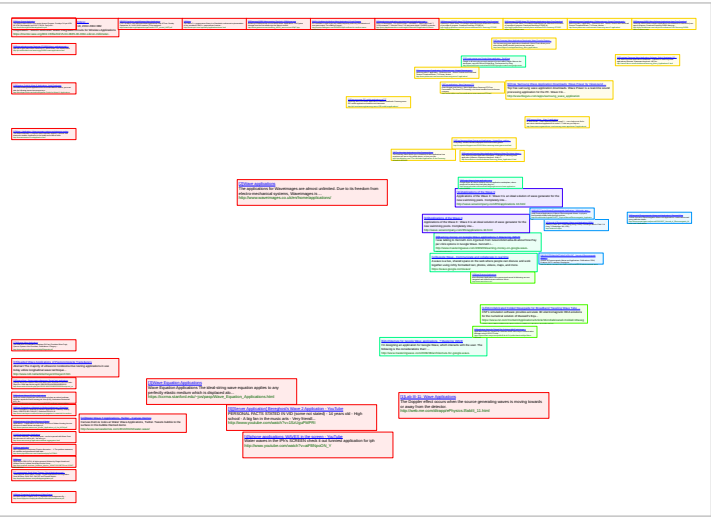

(a) $\alpha=0.0$

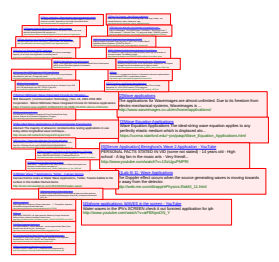

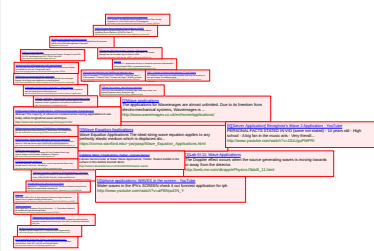

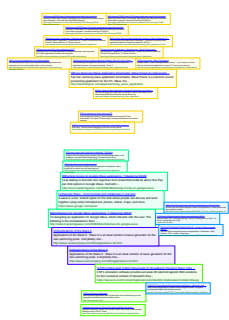

(b) $\alpha=0.2$
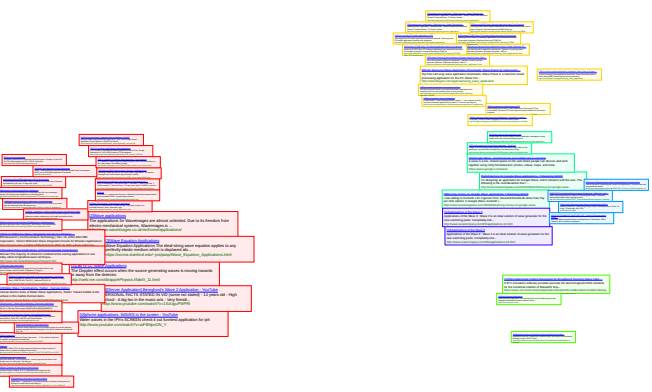

(c) $\alpha=0.5$

Figura 3.10: Efeito da variação do parâmetro $\alpha$. 


\section{Estudo Comparativo: Avaliação e Resultados}

Este capítulo tem como finalidade comparar os resultados obtidos pelo ProjSnippet com técnicas correlatas no contexto de heurística para remoção de sobreposições. Na primeira seção é apresentada uma breve descrição das técnicas empregadas em nossas comparações. Na segunda seção são definidas as métricas de avaliação que empregamos para mensurar o desempenho das técnicas envolvidas. Finalmente, na ultima seção são apresentados e discutidos os resultados obtidos pelas técnicas usadas em nosso estudo comparativo.

\subsection{Heurísticas para a Remoção de Sobreposição}

\subsubsection{VPSC}

Dwyer et al. (2005) propuseram um algoritmo para remoção de sobreposições em grafos baseado em propriedades ortogonais do mesmo. Essencialmente tal algoritmo é composto por dois passos elementares: o primeiro impõe restrições de separação para os nós do grafo enquanto o segundo visa encontrar uma solução que englobe todas as restrições inicialmente impostas no sentido de gerar resultados "o mais próximo possível"do layout inicial. Após a geração das restrições envolvendo cada par de nós, almeja-se solucionar, para cada dimensão, o seguinte problema de otimização Dwyer et al. (2005): 
Variable Placement with Separation Constraints (VPSC): Dadas $n$ variáveis $v_{1}, \ldots, v_{n}$ com pesos $w_{i} \geq 0$, um valor previamente definido $d_{i}$ para cada uma das variável supracitadas e um conjunto de restrições de separação C sobre essas variáveis, encontrar os valores ideias para as variáveis envolvidas de forma a minimizar a seguinte função objetivo: $\sum_{i=1}^{n} w_{i} \times\left(v_{i}-d_{i}\right)^{2}$, sujeito a $C$.

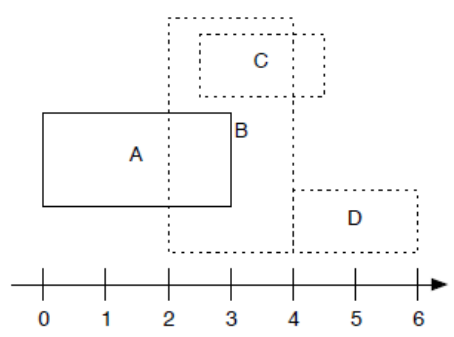

(a)

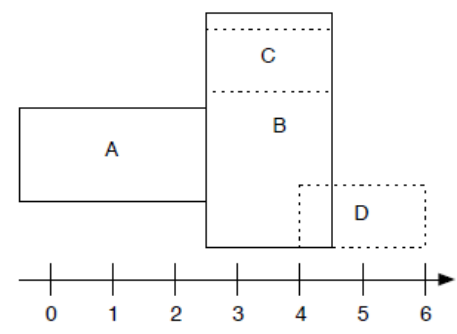

(b)

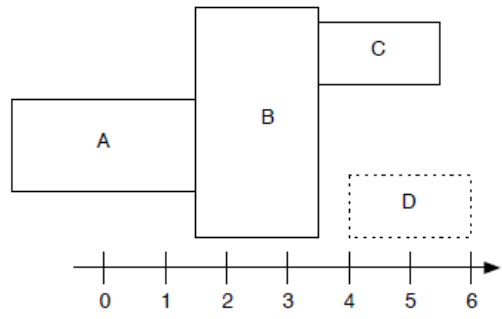

(c)

Figura 4.1: Exemplo de solução ótima usando o algoritmo VPSC. Os nós são ordenados de forma ascendente (a), onde cada um é computado (b,c) para produzir um layout livre de sobreposições de modo a respeitar as restrições de separação inicialmente impostas (extraído de Dwyer et al. (2005)).

A Figura 4.1 mostra o processo de remoção de 4 nós no formato retangular. No caso das soluções produzidas pelo VPSC é importante mencionar que, dependendo da ordenação dos nós no grafo, é possível que não exista uma solução plenamente ótima para o problema.

\subsubsection{PRISM}

Proximity Stress Model (PRISM), é uma algoritmo proposto por Gansner e Hu (2008) para a remoção de sobreposições que busca preservar as relações de proximidade por meio de um grafo de proximidade gerado partir de uma triangulação de Delaunay sobre os nós do grafo base. O fator de sobreposição entre dois nós do grafo é calculado por:

$$
t_{i j}=\max \left(\min \left(\frac{h w_{i}+h w_{j}}{x_{i}-x_{j}}, \frac{h h_{i}+h h_{j}}{y_{i}-y_{j}}\right), 1\right)
$$

onde $h w_{i}$ e $h h_{i}$ são a metade do comprimento e da altura do nó $i$ respectivamente. No caso de não existir uma sobreposição, $t_{i j}$ assume o valor unitário. Caso contrário, a sobreposição pode ser removida por meio do aumento do tamanho do fator de sobreposição $t_{i j}$ relativo à aresta que liga os nós sob análise. 
Desta forma, o principal objetivo da PRISM é minimizar a seguinte função de stress:

$$
\sum_{(i, j) \in A_{p}} w_{i j}\left(\left\|x_{i}-x_{j}\right\|-d_{i j}\right)^{2}
$$

onde $A_{p}$ é o conjunto de arestas do grafo de proximidade e $d_{i j}$ é a distância ideal entre os nós $i$ e $j$. Assim, o fator de sobreposição pode ser computado pela seguinte equação algébrica:

$$
s_{i j}=\min \left(t_{i j}, s_{\max }\right)
$$

onde $s_{\max }$ é o número de sobreposições que podem ser removidas em uma iteração. No caso de existir ainda nós sobrepostos, um algoritmo de varredura é aplicado para encontrar e adicionar as sobreposições restantes no grafo de proximidade. Finalmente, o processo é, então, repetido até que o algoritmo de varredura não encontre mais sobreposições remanescentes.

\subsubsection{Wordle/ManiWordle}

Wordle (Viegas et al., 2009) é um gerador de nuvens de palavras para web que visa corrigir problemas tipográficos comuns em outras visualizações envolvendo nuvens, como uso de filas de texto ordenadas alfabeticamente, justaposição de diferentes tipos e tamanhos de fontes com remoção de espaços em branco, variedade de fontes associadas ao navegador web, etc.

O layout base do Wordle é construído pela execução do seguinte algoritmo:

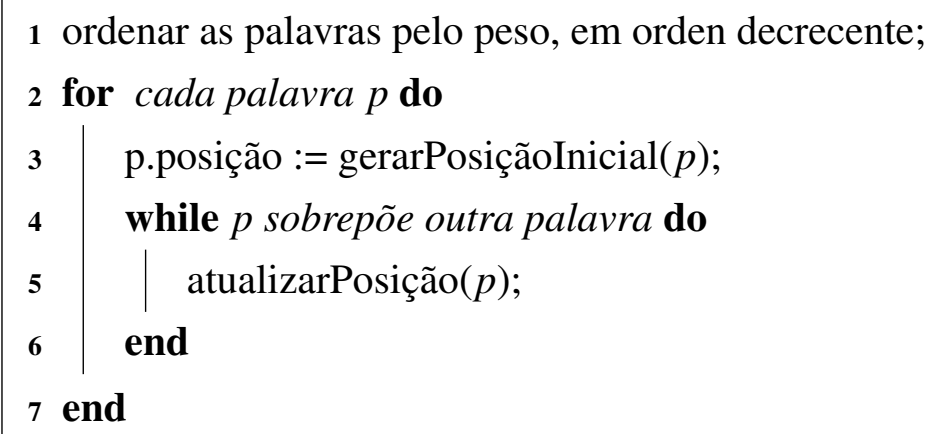

Algoritmo 1: Geração do layout (Wordle)

Enquanto o comando "gerarPosiçãoInicial" escolhe um ponto aleatório dentro da distribuição desejada (por exemplo, ordenada alfabeticamente), o "atualizarPosição" move a palavra na forma de uma espiral com um raio crescente, orbitando até encontrar a posição ideal para remover as sobreposições. Mais tarde, Koh et al. (2010) propuseram uma versão denominada 
Manipulating Wordle (ManiWordle), que permite ao usuário interagir com a posição dos pontos. Além disso, os autores incorporaram no pipeline de processamento da técnica algumas melhorias no sentido de melhorar a performance do algoritmo original.

\subsubsection{Voronoi}

O algoritmo de Lloyd (Lloyd, 2006) (chamado também de iteração de Voronoi) é uma técnica amplamente conhecida em computação gráfica para o relaxamento de distribuições pontuais. Tal técnica parte inicialmente do cálculo da região de Voronoi ${ }^{1}$ para cada ponto. Na sequência, o centróide de cada uma dessas regiões é determinado por uma dada métrica. Assim, cada ponto gerado é, então, movimentado na direção do centróide anteriormente computado. Estes passos devem ser aplicados até que o algoritmo atinja a convergência numérica. Aplicado no problema de remoção de sobreposições, o algoritmo pode ser descrito de forma sucinta através dos seguintes passos:

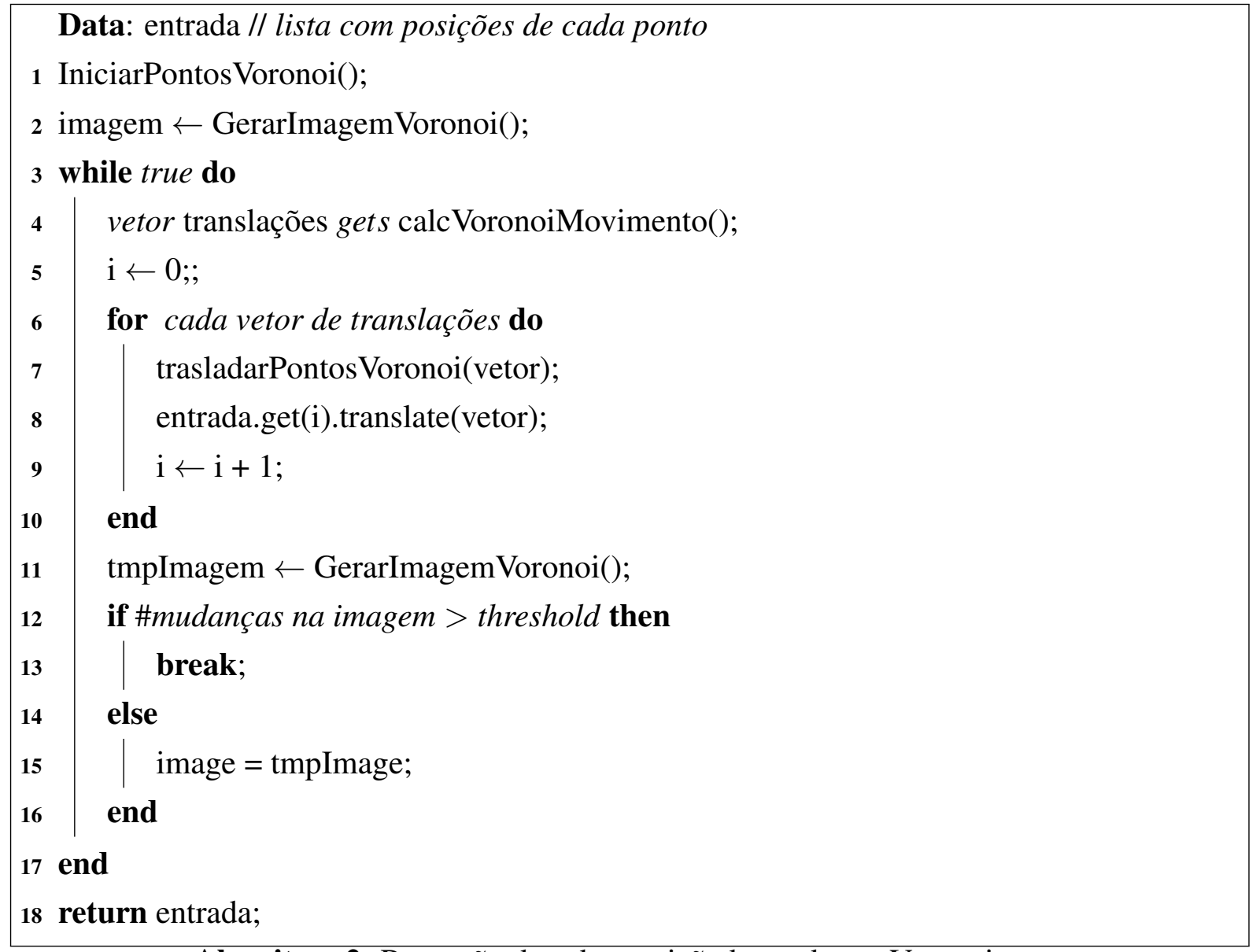

Algoritmo 2: Remoção de sobreposição baseada em Voronoi

\footnotetext{
${ }^{1}$ A região de Voronoi de um conjunto de pontos é a região em que nenhum outro ponto a ser gerado será mais próximo a ela
} 
Embora esse algoritmo é computacionalmente mais custoso, o layout resultante fica sempre livre de sobreposição. Por outro lado, as relações de vizinhança são fortemente alteradas no processo de atualização de posições.

\subsection{Métodos de Avaliação Quantitativa}

\subsubsection{Medida de distância Euclidiana}

A medida da distância Euclidiana é uma métrica simples que calcula a distância média provinda de cada instância de $L$ para $L^{\prime}$. Em outras palavras: a ideia da métrica Euclidiana é indicar numericamente se houve alterações bruscas entre as instâncias do layout inicial e final. Assim, a média da distância Euclidiana pode ser calculada pela seguinte fórmula:

$$
M_{E D}=\frac{1}{|P|} \sum_{1 \leq i \leq|P|} d\left(p_{i}, p_{i}^{\prime}\right)
$$

onde $|P|$ representa o numero de pontos e $d\left(p_{i}, p_{i}^{\prime}\right)$ é a distância Euclidiana entre a posição $p_{i}$ no layout inicial e a nova posição $p_{i}^{\prime}$ no novo layout. Aqui, a distância Euclidiana é computada pela fórmula convencional como segue:

$$
d\left(p, p^{\prime}\right)=\sqrt{\left(x^{\prime}-x\right)^{2}+\left(y^{\prime}-y\right)^{2}}
$$

\subsubsection{Similaridade no layout}

Uma das formas mais simples de calcular a semelhança entre dois layouts é medir a distância entre todos os seus pares de vértices. De fato, se ambos forem similares, as distâncias deverão ser, então, similares. Isto é conhecido como a métrica de Frobenius no problema de localização de sensores. Sendo o cálculo de todas essas distâncias uma tarefa computacionalmente cara no caso de layouts dotados de muitos vértices, Gansner e Hu (2008) propuseram, então, uma métrica baseada apenas no processamento das arestas de um determinado grafo de proximidade, o qual é construído usando a Triangulação de Delaunay. Sendo $x^{0}$ e $x$ o layout original e o final, respectivamente, e $E_{p}$ o conjunto de arestas da triangulação, a razão do comprimento da arestas do grafo de proximidade é computada por:

$$
r_{i j}=\frac{\left\|x_{i}-x_{j}\right\|}{\left\|x_{i}^{0}-x_{j}^{0}\right\|},\{i, j\} \in E_{p}
$$


Deste modo, a métrica de similaridade entre os layouts envolvidos é definida através da equação de desvio padrão normalizado

$$
\sigma_{\text {dist }}\left(x^{0}, x\right)=\frac{\sqrt{\frac{\sum_{\{i, j\} \in E_{p}}\left(r_{i j}-\bar{r}\right)^{2}}{\left|E_{p}\right|}}}{\bar{r}}
$$

onde a razão média $\bar{r}$ é dada por:

$$
\bar{r}=\frac{1}{\left|E_{p}\right|} \sum_{\{i, j\} \in E_{p}} r_{i j}
$$

\subsubsection{Incremento no tamanho}

Essa métrica é definida pela variação das áreas ocupadas por cada uma das instâncias envolvidas. Assim, dados os fechos convexos do layout inicial $F_{c}$ e do final $F_{c}^{\prime}$, a média de incremento é calculada por:

$$
s i=\frac{\operatorname{area}\left(F_{c}^{\prime}\right)}{\operatorname{area}\left(F_{c}\right)}
$$

Um ponto interessante a ser ressaltado é que, por meio dessa métrica, é possível determinar mudanças relativas no tamanho da visualização, além de medir seu grau de compacidade.

\subsubsection{Preservação de vizinhança}

Paulovich e Minghim (2008) propuseram uma interessante abordagem para avaliar layouts com base na preservação de vizinhanças. Tal avaliação é feita tomando os $k$ vizinhos mais próximos de cada ponto na representação original, e verificando qual proporção destes foi preservada na representação final.

A Figura 4.2 ilustra os passos da técnica proposta em Paulovich e Minghim(2008). Inicialmente, Tomou-se os 5 pontos vizinhos (em vermelho) mais próximos do ponto $p_{i}$ (em verde). Em seguida, é possível notar que 3 dos pontos inicialmente escolhidos não fazem parte do conjunto inicial de vizinhos. Logo, concluí-se que apenas $40 \%$ da vizinhança com respeito a este ponto foi preservada nesse novo layout. 


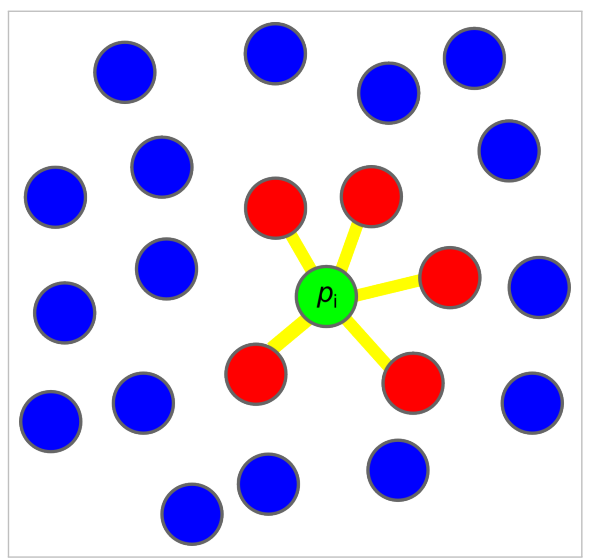

(a) Layout original

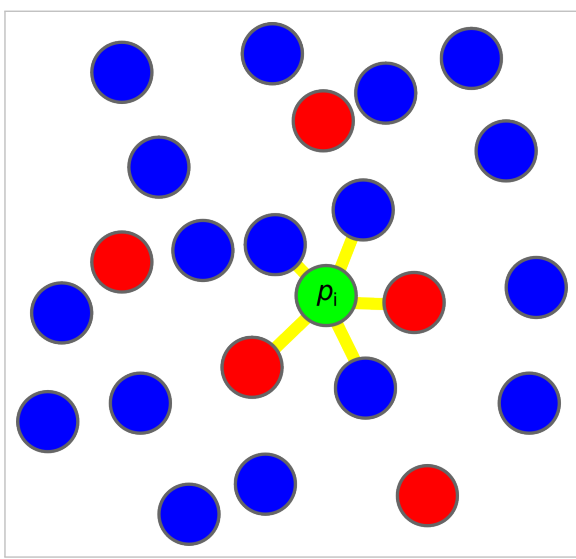

(b) Layout atualizado

Figura 4.2: Ilustração da medida de preservação de vizinhança

\subsection{Comparações e Resultados}

\subsubsection{Conjunto de dados 1: "pyrotechnics supplies"}

O conjunto de dados "pyrotechnics supplies" foi inicialmente classificado em 5 grupos, onde cada um dos 50 snippets da configuração inicial possuem, ao menos, uma sobreposição com os demais. A Figura 4.3(a) apresenta o layout a ser otimizado enquanto que a Figura 4.3(b) traz o resultado obtido pelo ProjSnippet. Pode-se observar que o resultado traz todos clusters completamente preservados em um layout bastante compacto. Por outro lado, pode-se perceber que o resultado produzido pela técnica PRISM (Figura 4.3(c)) espalha consideravelmente os snippets tornando a configuração visual final totalmente dispersa. Já no resultado em espiral obtido pela Wordle (Figura 4.3(f)], pode-se notar que não houve sobreposições envolvendo quaisquer pares de snippets, porém, devido a técnica não empregar nenhum critério de preservação semântica entre os snippets, não foi possível detectar nenhum dos agrupamentos previamente definidos. A Figura 4.3(e) mostra o layout após aplicar a técnica VPSC. Pode ser constatado as vizinhanças foram integralmente preservadas, embora tal técnica não apresente nenhum critério específico para atingir tal preservação. No entanto, o grupo em amarelo foi dividido por um snippet do grupo ciano na parte inferior do layout. Além disso, o layout final apresentou um alongamento vertical na disposição dos snippets. Finalmente, o método baseado em Voronoi (Figura 4.3(d)) mostra um layout livre de sobreposições, porém, totalmente disperso em termos de preservação de vizinhança e compacidade.

A Figura 4.4 apresenta os resultados obtidos através da aplicação das métricas de avaliação anteriormente descritas nos layouts acima. Considerando a métrica da média da distância Eu- 
clidiana, nossa técnica foi a que alcançou o melhor desempenho, seguido pela técnica VPSC. Podemos, assim, constatar que o ProjSnippet usou a menor distância para otimizar os snippets no layout final. No caso do incremento do tamanho entre o layout original e final, ProjSnippet, VPSC e Wordle obtiveram resultados similares, no entanto, a técnica Voronoi e PRISM mostram um alto incremento no layout resultante. Além disso, VPSC, PRISM e ProjSnippet produziram layouts mais similares com relação ao original em comparação com os resultados gerados pelas técnicas de Voronoi e Wordle. A relação de vizinhança entre os snippets foi melhor preservada pelos métodos PRISM, VPSC e ProjSnippet tal como sugere a Figura 4.4(d).

Através dos resultados obtidos pelas métricas aplicadas aos layouts resultantes, construímos vetores que representam as técnicas descritas como pontos em alta dimensão. Adicionamos, também, 3 pontos sintéticos (gerados manualmente) com os resultados do melhor, intermediário e pior caso considerando cada uma das métricas usadas, na intenção de avaliar o desempenho das técnicas envolvidas. Todos os pontos foram, então, projetados no espaço bi-dimensional usando a técnica de projeção multidimensional Local Affine Multidimensional Projection (LAMP) (Joia et al., 2011a) (vide Figura 4.5). Como pode-se observar, o ProjSnippet ficou mais próximo do melhor caso quando comparada com as demais técnicas. Na tabela da Figura 4.5 são mostradas as distâncias em detalhe entre as técnicas avaliadas e os casos gerados.

\subsubsection{Conjunto de dados 2: "scrapbooking supplies"}

O conjunto de dados "scrapbooking supplies" contém 50 snippets que foram classificados em 7 grupos. Os resultados obtidos pelas heurísticas para a remoção de sobreposição são apresentados na Figura 4.6. A Figura 4.6(a) apresenta o layout a ser processado. Os resultados do Wordle (Figura 4.6(f)] e Voronoi (Figura 4.6(d)), como no exemplo anterior, evidenciam uma transformação do layout na intenção de evitar as sobreposições entre os snippets envolvidos. O layout gerado pelo PRISM (Figura 4.6(c) traz uma distribuição semelhante à original, mas contendo muitos espaços em branco. Já o resultado obtido pelo VPSC apresenta um layout livre de sobreposições, no entanto ele dividiu um dos grupos definidos no layout inicial (o cluster de cor roxa). Por outro lado, o resultado obtido pelo ProjSnippet (Figura 4.6(b)] é apresentado sem a utilização da otimização do operador Seam Carving (vida capitulo anterior para maiores detalhes). Aqui a finalidade é analisar a abordagem proposta exclusivamente no contexto de heurística para a remoção de sobreposições. Como mostrado na Figura 4.6(b), o resultado é um layout livre de sobreposições e relativamente compacto, o qual preserva a forma do layout original.

A Figura 4.7 apresenta os resultados obtidos pelas métricas quantitativas quando aplicadas aos layouts produzidos pelas técnicas sob investigação. Com relação à métrica da média da dis- 
tância Euclidiana, o ProjSnippet obteve um ótimo resultado, seguido pelo VPSC. Novamente, os layouts que possuem o menor incremento no tamanho são ProjSnippet, VPSC e Wordle. Neste caso, o PRISM gerou um layout bem similar ao original enquanto que o resultado produzido pelo Wordle apresentou baixíssima similaridade. Quanto à avaliação da preservação de vizinhança, os melhores resultados foram produzidos pela PRISM, ProjSnippet e VPSC, respetivamente.

Para finalizar, a projeção de cada um dos resultados numéricos produzidos pelas técnicas avaliadas é apresentada na Figura 4.8. A exemplo do caso anterior, o ProjSnippet foi a técnica que se aproximou do resultado sintético ideal (com uma distância de 9.480 entre eles), seguido pelo VPSC (distância de 16.12) e o Wordle (distância de 75.80).

\subsubsection{Conjunto de dados 3: "jaguar features"}

O conjunto de dados "jaguar features" contém 64 snippets que foram classificados em 5 grupos. Os resultados obtidos pelas heurísticas de remoção de sobreposições são apresentados na Figura 4.9. Neste caso, a Figura 4.9(a) traz o layout a ser otimizado. Os resultados produzidos pelo Wordle (Figura 4.9(f) e Voronoi (Figura 4.9(d)] mostram os layouts sem sobreposições, entretanto, apresentam uma forte alteração na estrutura do layout de entrada. O layout gerado pelo PRISM (Figura 4.9(c) evidencia uma grande similaridade com relação ao layout original, mas apresenta uma dissipação bastante acentuada entre os clusters. O VPSC (Figura 4.9(e)) produziu um layout bem ordenado de uma forma mais geral, mas separou erroneamente os snippets de dois dos clusters processados (o roxo e o amarelo). Finalmente, a Figura 4.9(b) traz o resultado obtido pelo ProjSnippet. Apenas um único snippet ficou ligeiramente desalocado de seu grupo de origem.

A Figura 4.10 relaciona os resultados obtidos pelas métricas de avaliação nos layouts gerados pelos métodos aqui apresentados. No caso da métrica da média da distância Euclidiana e no incremento do tamanho, o ProjSnippet obteve o melhor resultado. Já em relação à similaridade do layout, o melhor resultado foi obtido pelos métodos PRISM e VPSC, seguido do ProjSnippet, Voronoi e Wordle, respetivamente. O resultado da avaliação da preservação da vizinhança mostra uma estreita diferença entre PRISM, VPSC e ProjSnippet.

Quanto a projeção baseada nos resultados das métricas (Figura 4.11), a projeção multidimensional relativa ao ProjSnippet se aproximou novamente do melhor caso (com uma distância de 11.01), seguido pelo VPSC (distância de 64.56) e do Wordle (distância de 138.3). 


\subsubsection{Conjunto de dados 4: "wave applications"}

O conjunto de dados "wave applications" é composto por 60 snippets os quais foram classificados em 5 clusters. Os resultados obtidos pelas heurísticas de remoção de sobreposições no referido dataset, bem como o resultado produzido pela técnica proposta são apresentados na Figura 4.12, onde a Figura 4.12(a) traz o layout a ser otimizado. O VPSC (Figura 4.12(e) conduz a um layout livre de sobreposição, mas excessivamente alongado verticalmente, gerando uma subdivisão dos 60 snippets em dois clusters separados por um grande espaço em branco sem uso. Por outro lado, o ProjSnippet (Figura 4.12(b) gerou um resultado bastante harmonioso, onde todos os clusters ficaram completamente preservados em um layout relativamente compacto. É importante destacar que no resultado mostrado não foi utilizado a otimização do operador Seam Carving para compactar ainda mais o layout na intenção de reduzir os espaços vazios. Os resultados do PRISM (Figura 4.12(c)), do Wordle (Figura 4.12(f)) e da técnica baseada em Voronoi (Figura 4.12(d)) apresentam o mesmo comportamento dos casos anteriores.

A Figura 4.13 mostra os resultados obtidos pelas métricas de avaliação nos layouts apresentados na Figura 4.12. Na média da distância Euclidiana e no incremento do tamanho, o ProjSnippet obteve uma ampla vantagem no desempenho, seguido do VPSC. No incremento da área, os melhores resultados foram obtidos pelo Wordle, ProjSnippet e VPSC. A exemplo do caso anterior, o resultado da avaliação da preservação da vizinhança mostra uma igualdade técnica entre PRISM, VPSC e ProjSnippet.

A projeção baseada nos resultados das métricas consideradas acima é apresentada na Figura 4.14. Novamente, o ProjSnippet foi projetado mais proximo do melhor caso (com uma distância de 13.00), seguido pelo VPSC (distância de 44.71) e do Wordle (distância de 105.9).

\subsubsection{Conjunto de dados 5: "batman"}

O conjunto de dados "batman" possui 60 snippets os quais foram inicialmente clusterizados em 5 grupos distintos, sendo a Figura 4.15(a) layout de entrada a ser otimizado neste caso. Tanto o ProjSnippet (Figura 4.15(b) quanto o VPSC (Figura 4.15(e)) apresentam um resultado contendo um snippet no grupo roxo, separado do cluster de origem por outro snippet do grupo vermelho. No entanto, o ProjSnippet apresentou um layout muito mais compacto (mesmo sem o uso do operador Seam Carving, a exemplo deste experimento) e similar ao layout original em comparação com o resultado gerado pelo VPSC. Os resultados do PRISM (Figura 4.15(c)), do Wordle (Figura 4.15(f)] e do Voronoi (Figura 4.15(d)] mostraram o mesmo comportamento dos casos anteriores. 
A Figura 4.16 mostra os resultados obtidos pelo uso das métricas de avaliação quantitativa nos layouts gerados pelas técnicas aqui investigadas. Com relação à métrica da média da distância Euclidiana, o ProjSnippet obteve, mais uma vez, o melhor desempenho. No incremento do tamanho, o melhores resultados quantitativos foram obtidos pela nossa abordagem e a técnica Wordle. Quanto à métrica que mensura a similaridade do layout, tanto o PRISM quanto o ProjSnippet buscaram preservar melhor a estrutura do layout de entrada.

A exemplo dos casos anteriores, A Figura 4.17 apresenta a análise quantitativa via projeção dos resultados métricos descritos no parágrafo acima. Seguindo a tendência observada nos exemplos anteriores, a projeção dos resultados do ProjSnippet foi a que mais se aproximou do caso ideal (com uma distância de 15.05), seguido do VPSC (distância de 20.83) e do Wordle (distância de 44.40). 


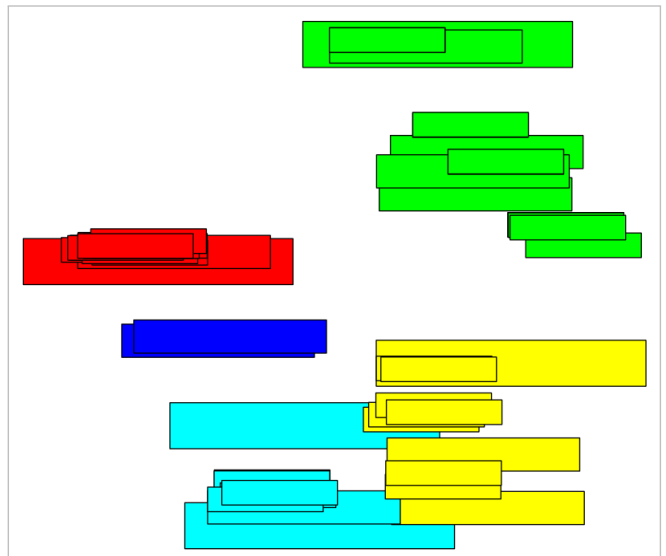

(a) Original

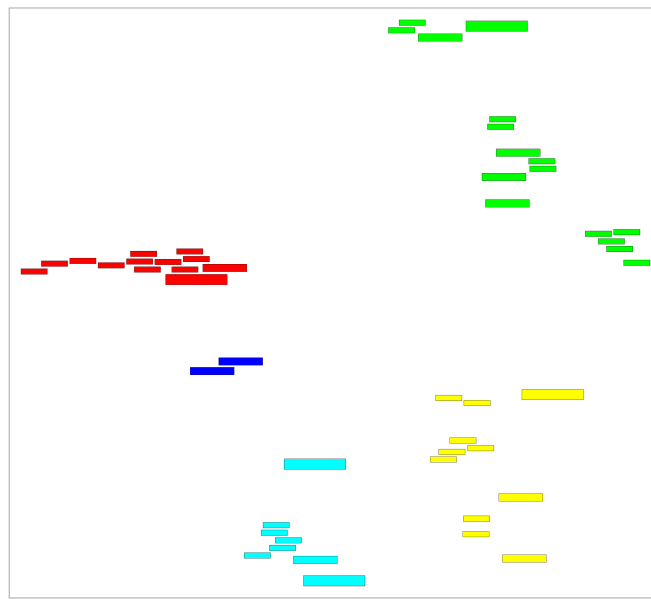

(c) PRISM

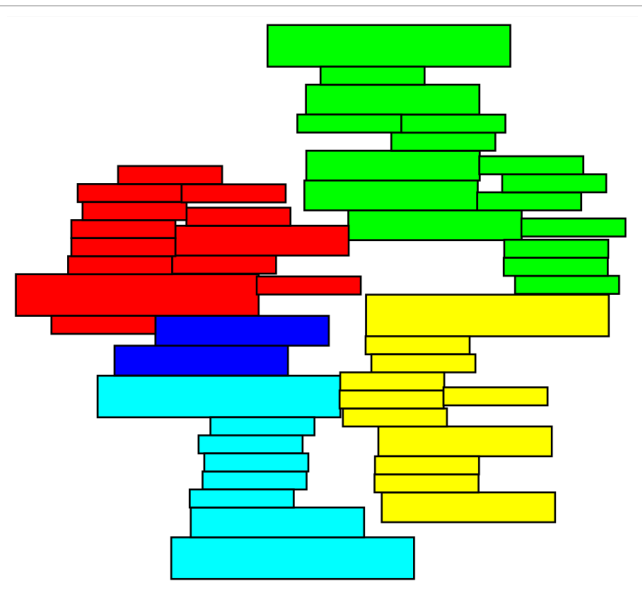

(b) ProjSnippet

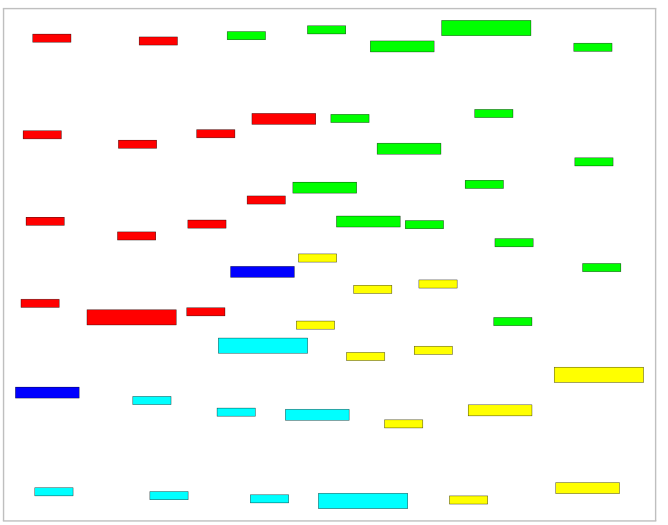

(d) Voronoi

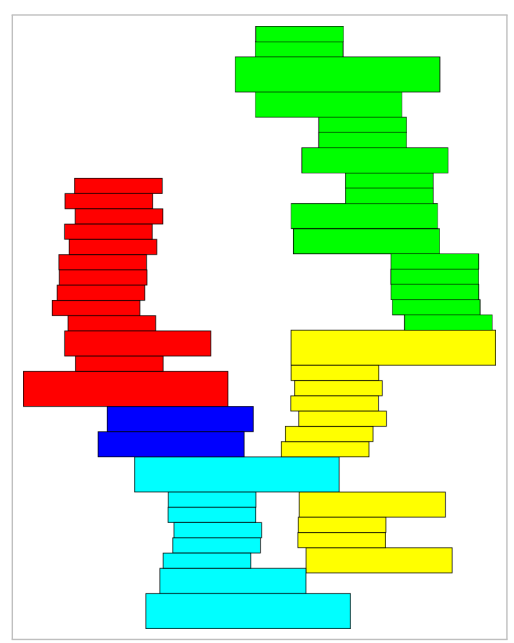

(e) VPSC

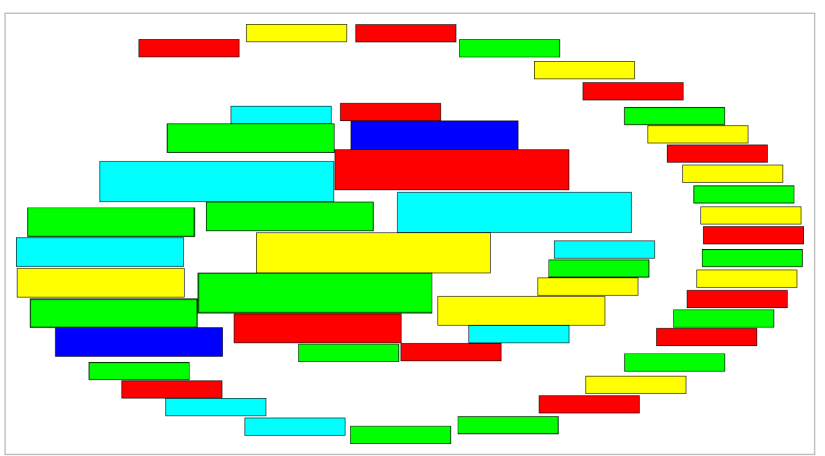

(f) Wordle

Figura 4.3: Layouts obtidos pelos métodos aqui comparados (conjunto de dados “pyrotechnics supplies"). 


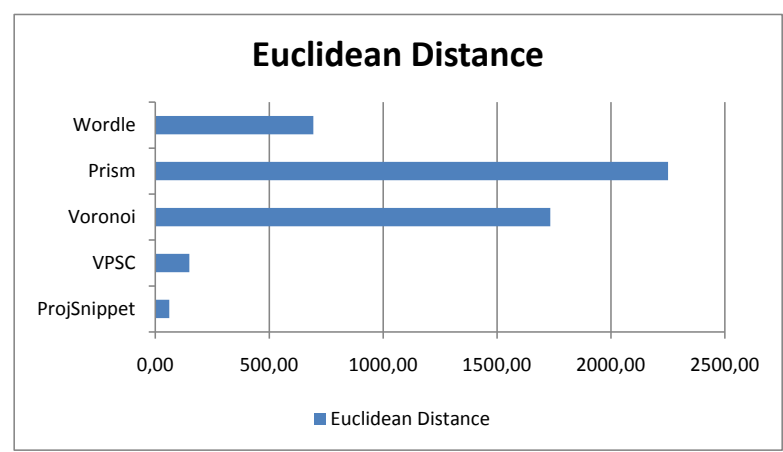

(a)

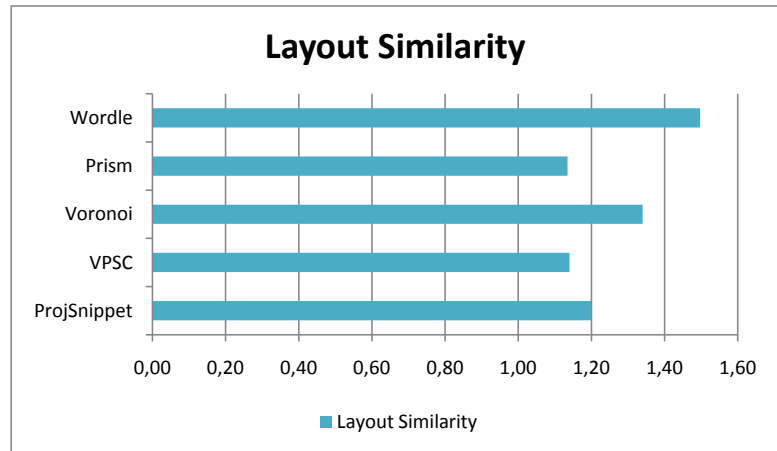

(c)

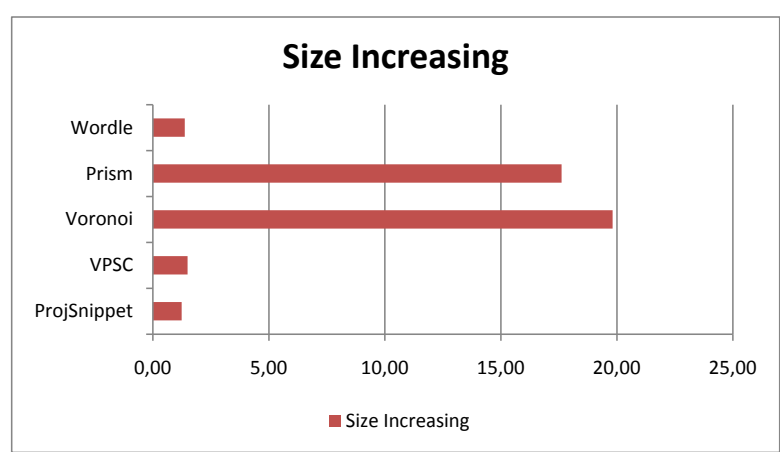

(b)

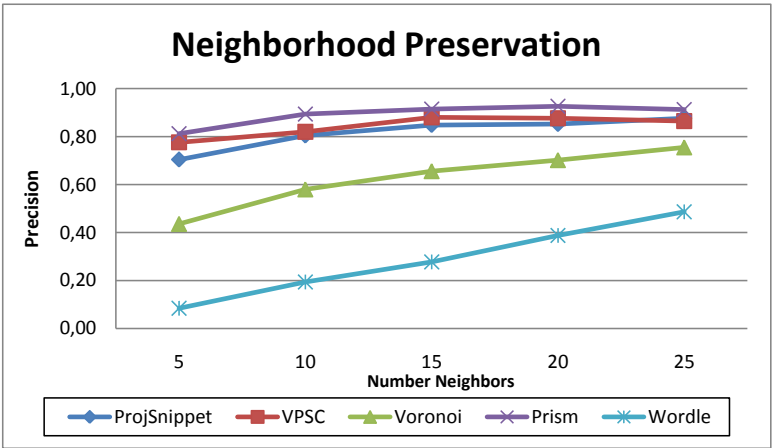

(d)

Figura 4.4: Resultados obtidos pelas métricas quantitativas aplicadas às técnicas de remoção de sobreposição aqui avaliadas (conjunto de dados "pyrotechnics supplies").

\begin{tabular}{|c|c|c|c|c|}
\hline \multicolumn{5}{|l|}{$=$ o[worst } \\
\hline \multirow{4}{*}{ DPRISM } & & Best & Average & Worst \\
\hline & ProjSnippet & 5.862 & 92.77 & 285.1 \\
\hline & VPSC & 13.75 & 86.66 & 279.4 \\
\hline & Voronoi & 121.5 & 90.21 & 195.2 \\
\hline \multirow[t]{2}{*}{. Voronoil } & PRISM & 194.4 & 184.4 & 101.2 \\
\hline & Wordle & 56.36 & 40.59 & 282.9 \\
\hline
\end{tabular}

Figura 4.5: Projeção multidimensional e tabela de distâncias sobre os resultados obtidos para o conjunto de dados "pyrotechnics supplies". 


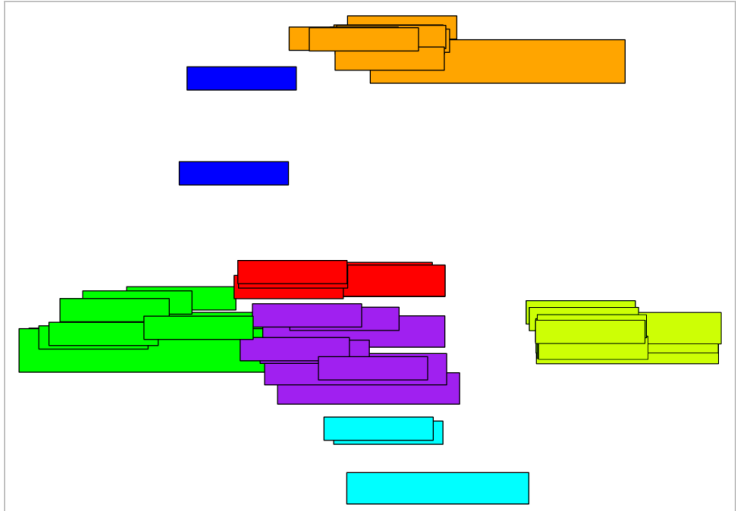

(a) Original

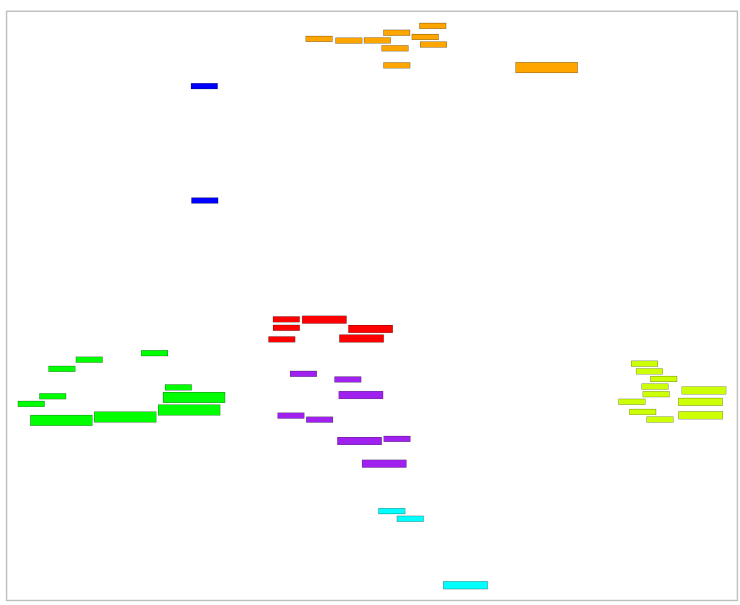

(c) PRISM

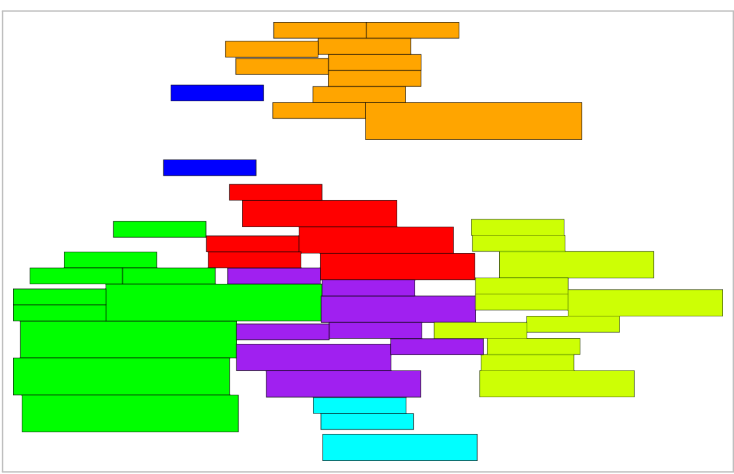

(b) ProjSnippet

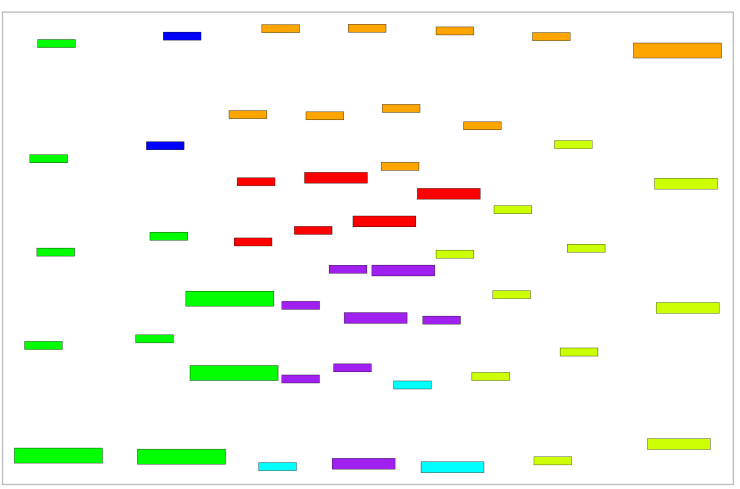

(d) Voronoi

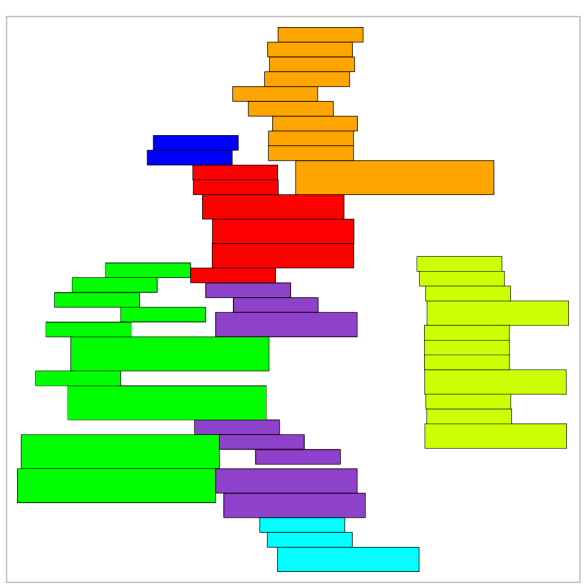

(e) VPSC

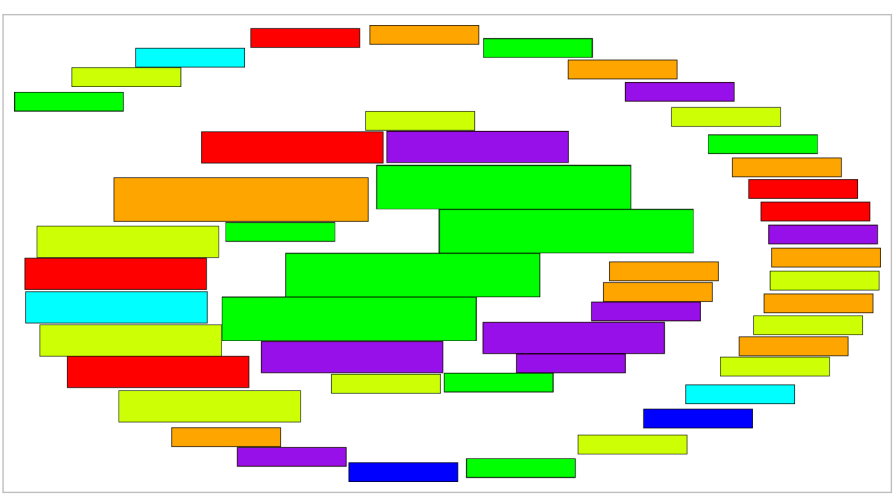

(f) Wordle

Figura 4.6: Layouts obtidos pelos métodos aqui comparados (conjunto de dados "scrapbooking supplies"). 


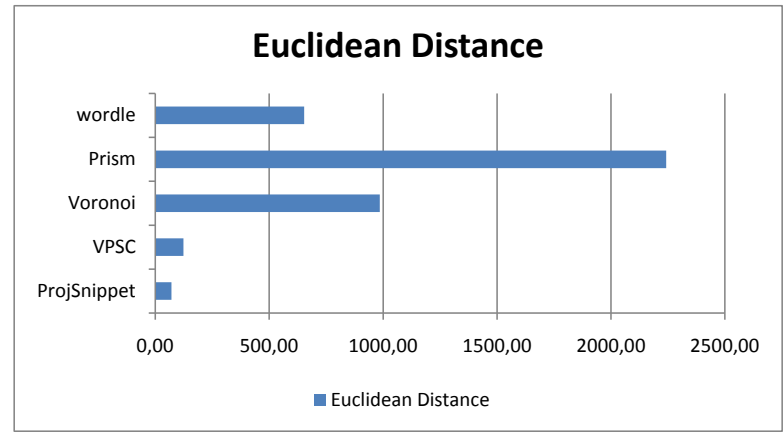

(a)

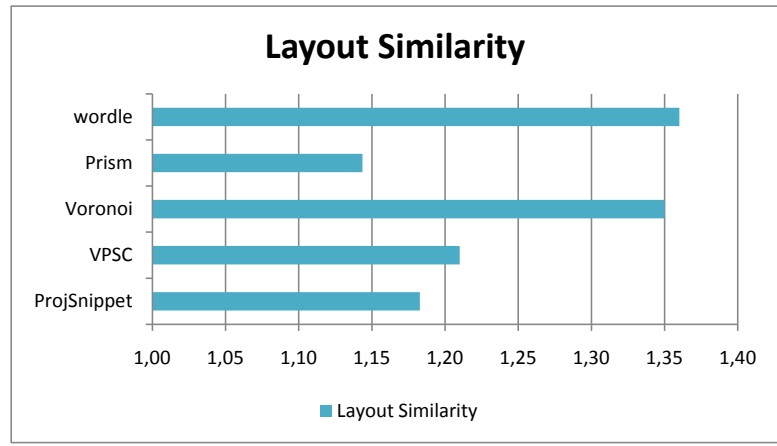

(c)

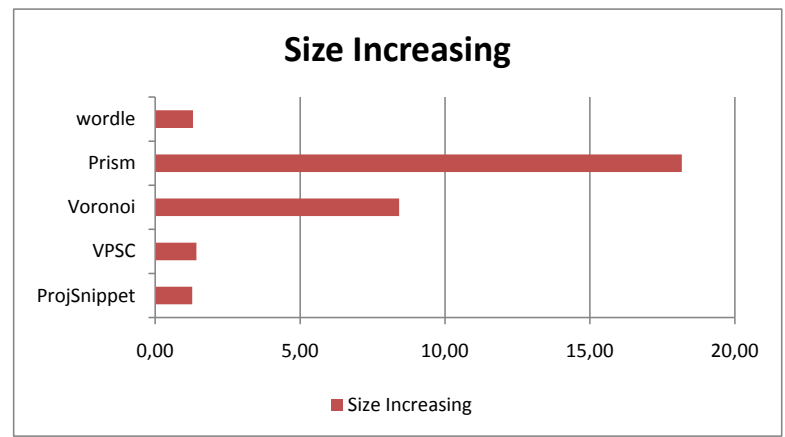

(b)

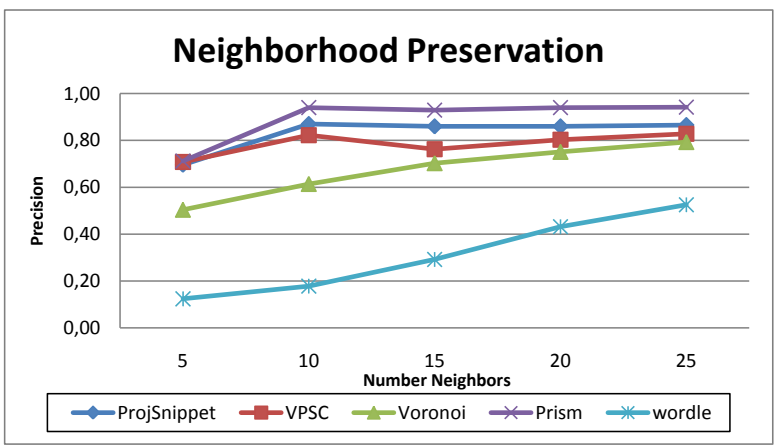

(d)

Figura 4.7: Resultados obtidos pelas métricas quantitativas aplicadas às técnicas de remoção de sobreposição aqui avaliadas ("scrapbooking supplies").

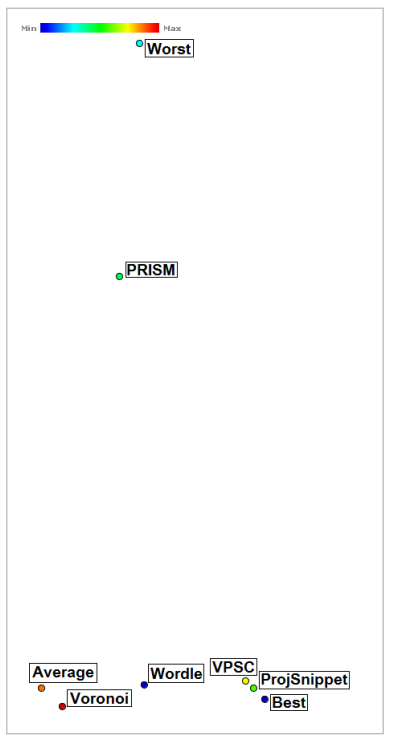

\begin{tabular}{l|c|c|c}
\hline & Best & Average & Worst \\
\hline ProjSnippet & 9.480 & 133.2 & 385.6 \\
VPSC & 16.12 & 128.0 & 380.6 \\
Voronoi & 127.0 & 17.21 & 393.0 \\
PRISM & 264.5 & 246.7 & 137.7 \\
Wordle & 75.80 & 64.70 & 376.9 \\
\hline
\end{tabular}

Figura 4.8: Projeção multidimensional e tabela de distâncias sobre os resultados obtidos para o conjunto de dados "scrapbooking supplies". 


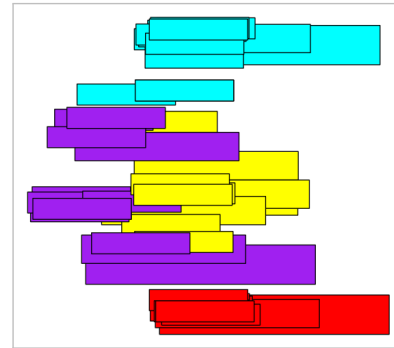

(a) Original

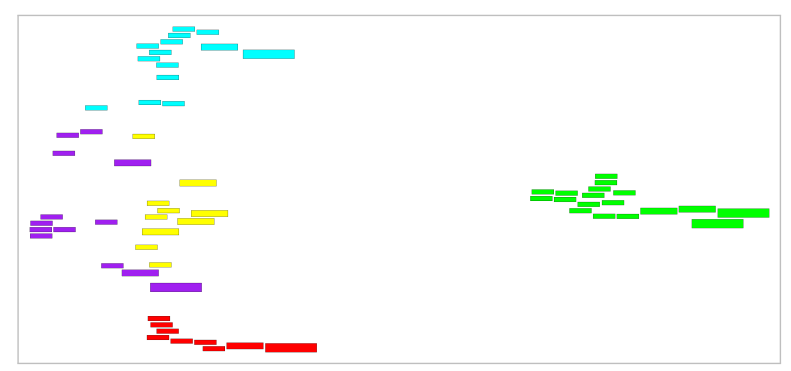

(c) PRISM

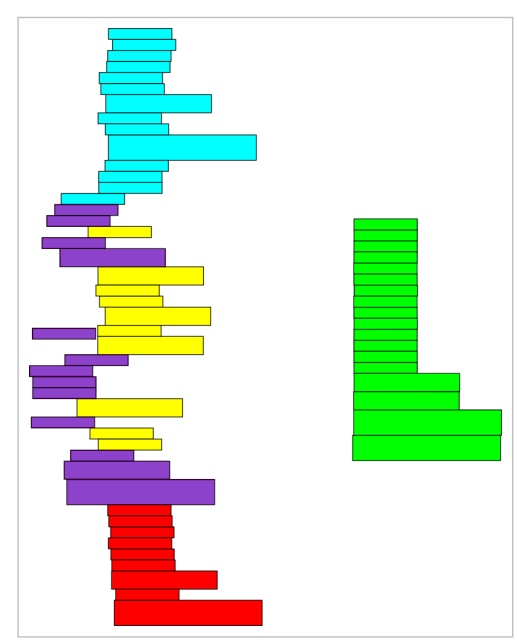

(e) VPSC

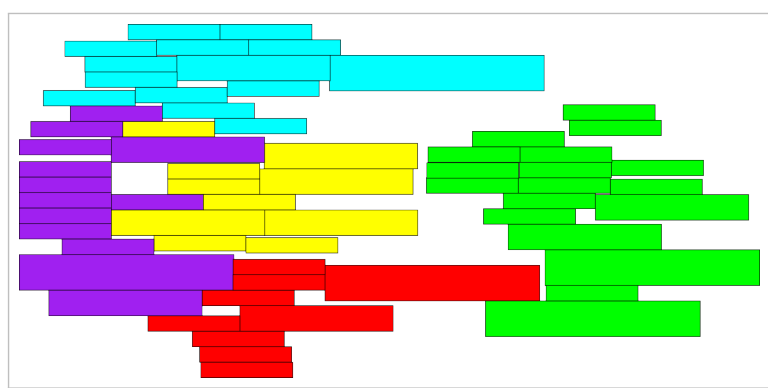

(b) ProjSnippet

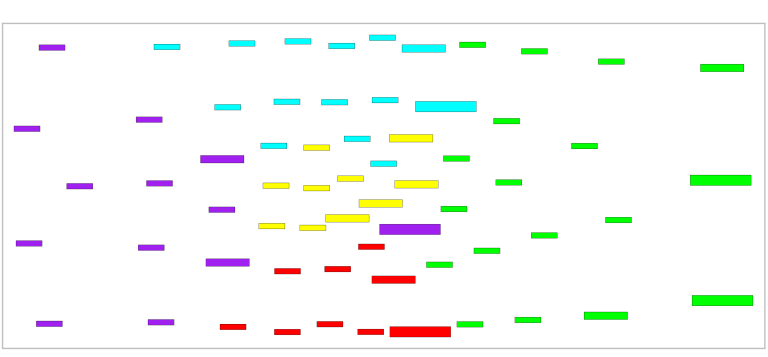

(d) Voronoi

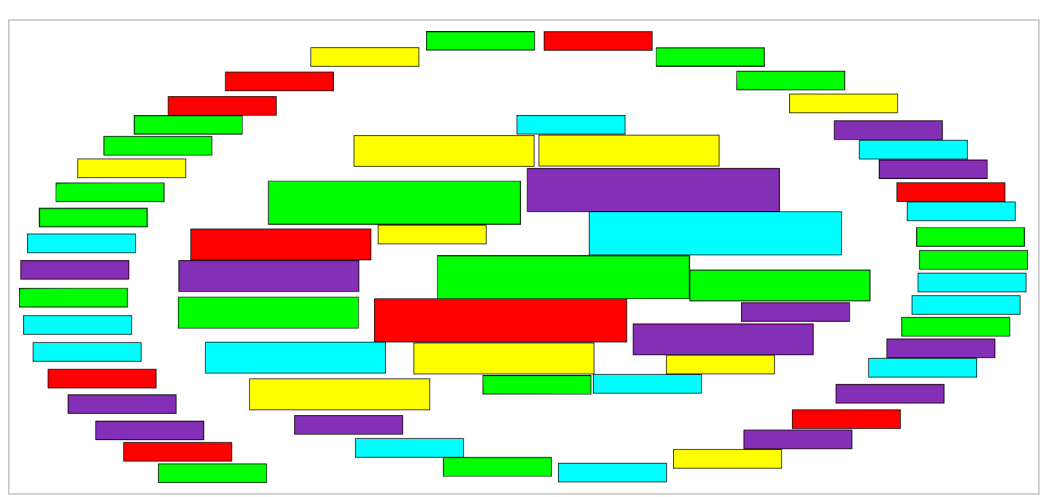

(f) Wordle

Figura 4.9: Layouts obtidos pelos métodos comparados (conjunto de dados “jaguar features"). 


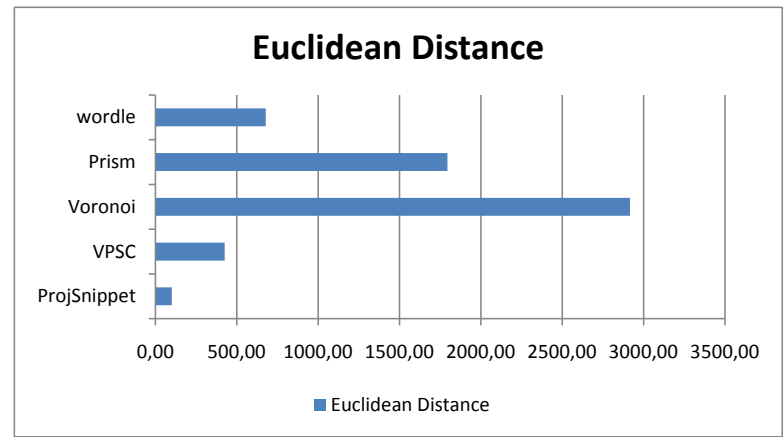

(a)

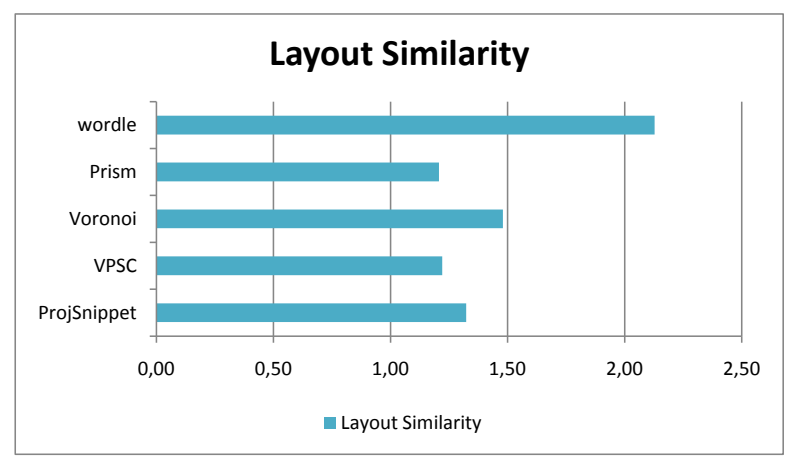

(c)

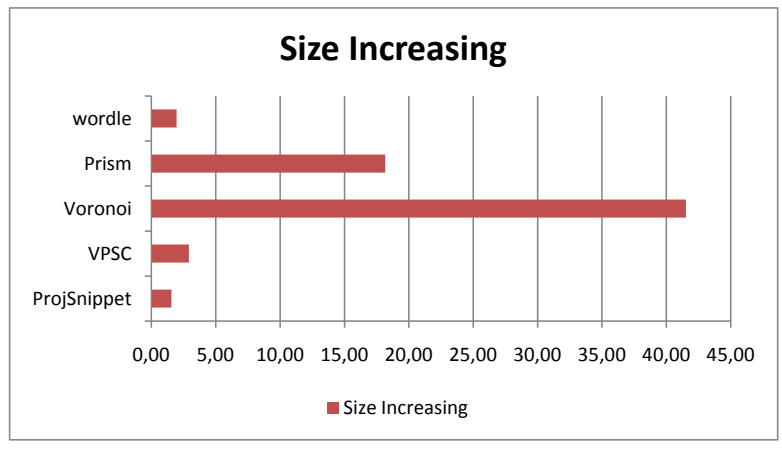

(b)

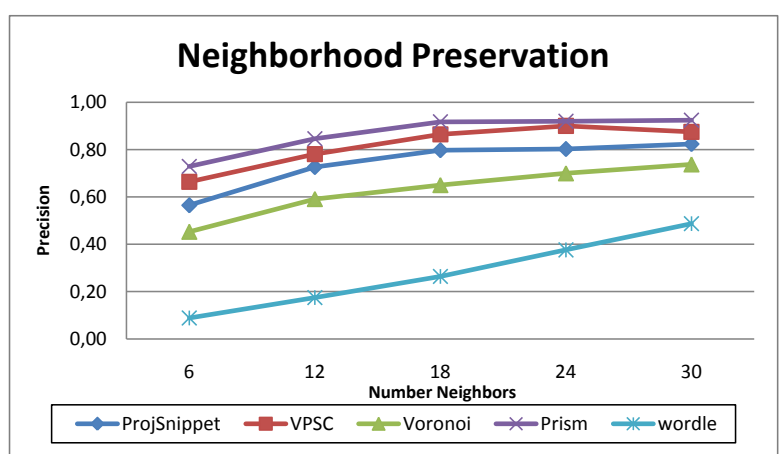

(d)

Figura 4.10: Resultados obtidos pelas métricas quantitativas aplicadas às técnicas de remoção de sobreposição aqui avaliadas (conjunto de dados "jaguar features").

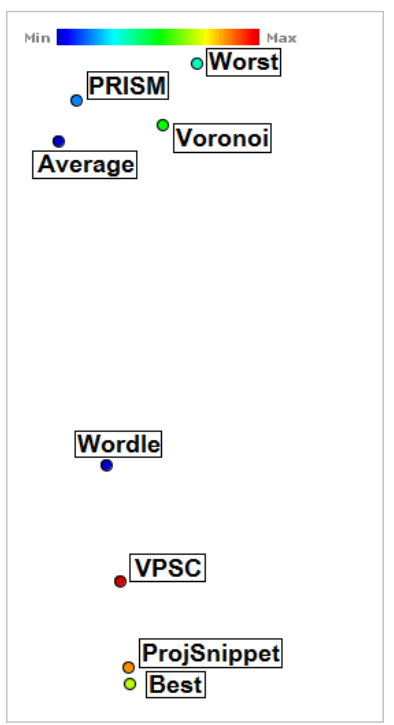

\begin{tabular}{l|c|c|c}
\hline & Best & Average & Worst \\
\hline ProjSnippet & 11.01 & 334.5 & 382.6 \\
VPSC & 64.56 & 281.0 & 330.9 \\
Voronoi & 352.2 & 80.06 & 46.93 \\
PRISM & 368.4 & 28.96 & 94.61 \\
Wordle & 138.3 & 207.2 & 262.2 \\
\hline
\end{tabular}

Figura 4.11: Projeção multidimensional e tabela de distâncias sobre os resultados obtidos para o conjunto de dados "jaguar features". 


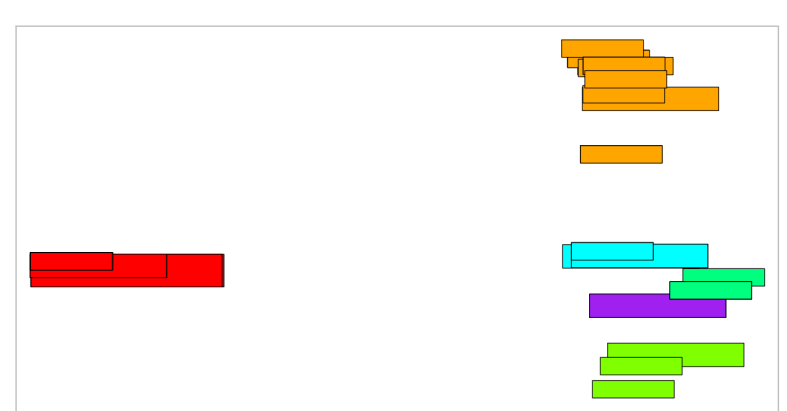

(a) Original

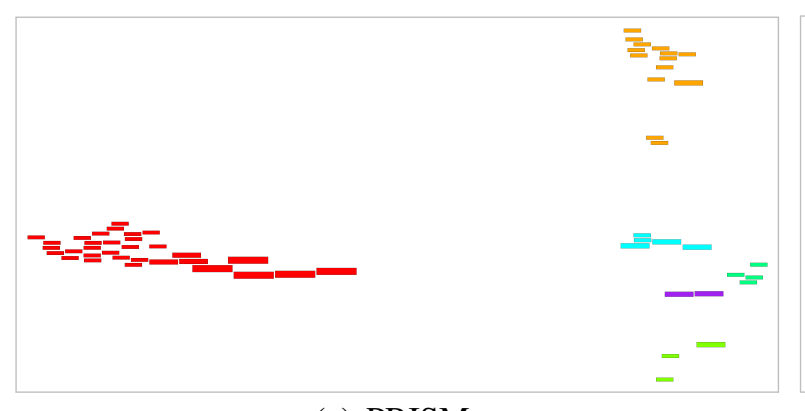

(c) PRISM

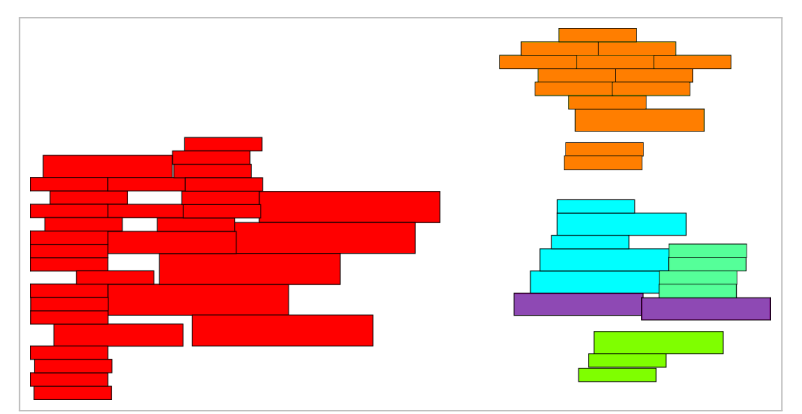

(b) ProjSnippet

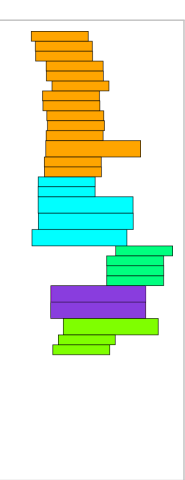

(e) VPSC

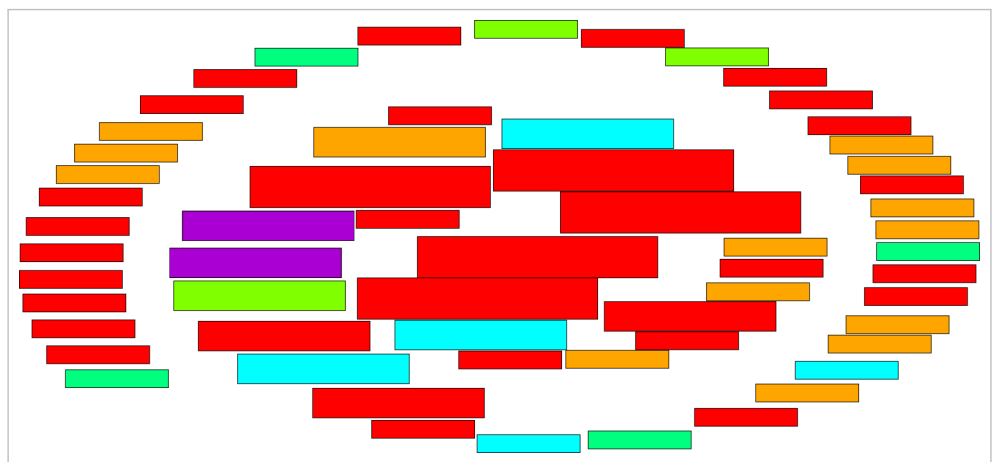

(f) Wordle

Figura 4.12: Layouts obtidos pelos métodos aqui comparados (conjunto de dados "wave applications"). 


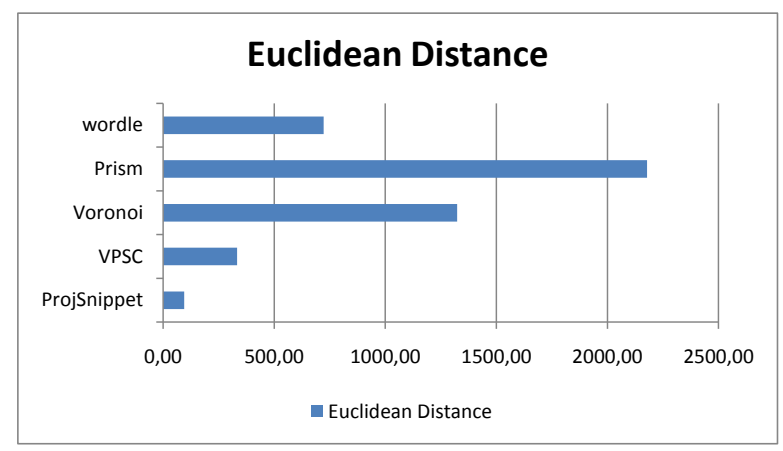

(a)

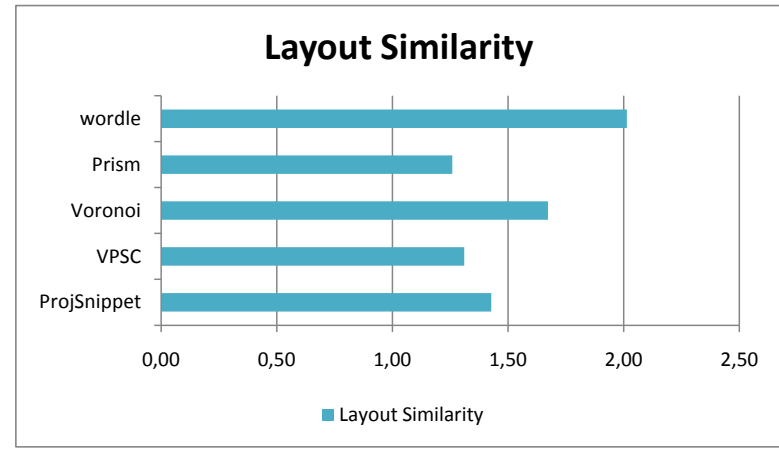

(c)

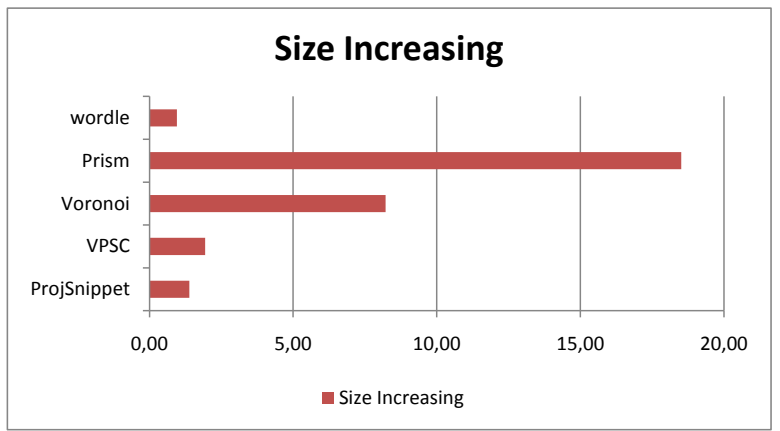

(b)

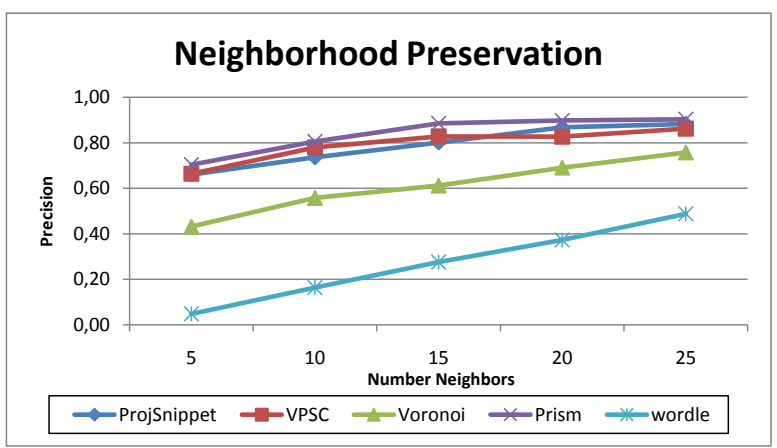

(d)

Figura 4.13: Resultados obtidos pelas métricas quantitativas aplicadas às técnicas de remoção de sobreposição aqui avaliadas (conjunto de dados "wave applications").

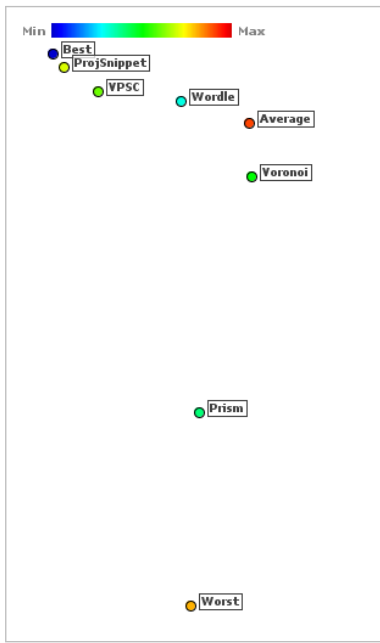

\begin{tabular}{l|c|c|c}
\hline & Best & Average & Worst \\
\hline ProjSnippet & 13.00 & 150.7 & 393.0 \\
VPSC & 44.71 & 120.5 & 370.2 \\
Voronoi & 178.4 & 37.10 & 307.1 \\
PRISM & 278.2 & 207.7 & 136.6 \\
Wordle & 105.9 & 55.98 & 356.5 \\
\hline
\end{tabular}

Figura 4.14: Projeção multidimensional e tabela de distâncias sobre os resultados obtidos para o conjunto de dados "wave applications". 


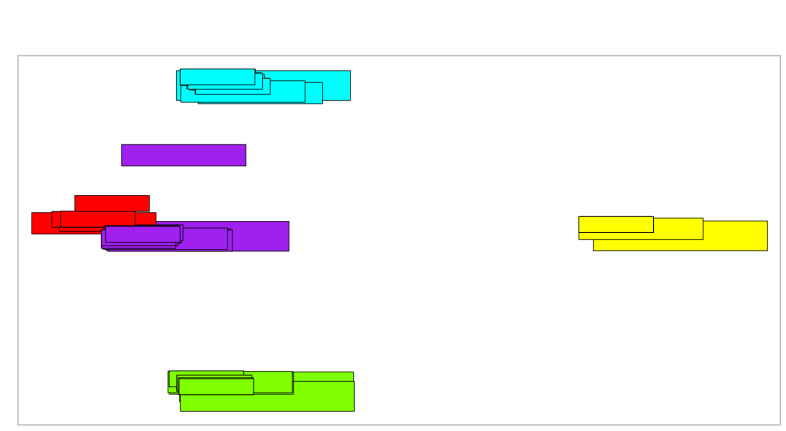

(a) Original

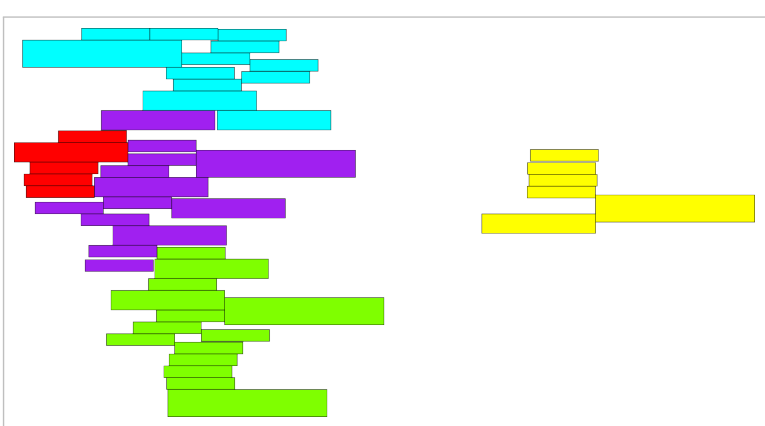

(b) ProjSnippet

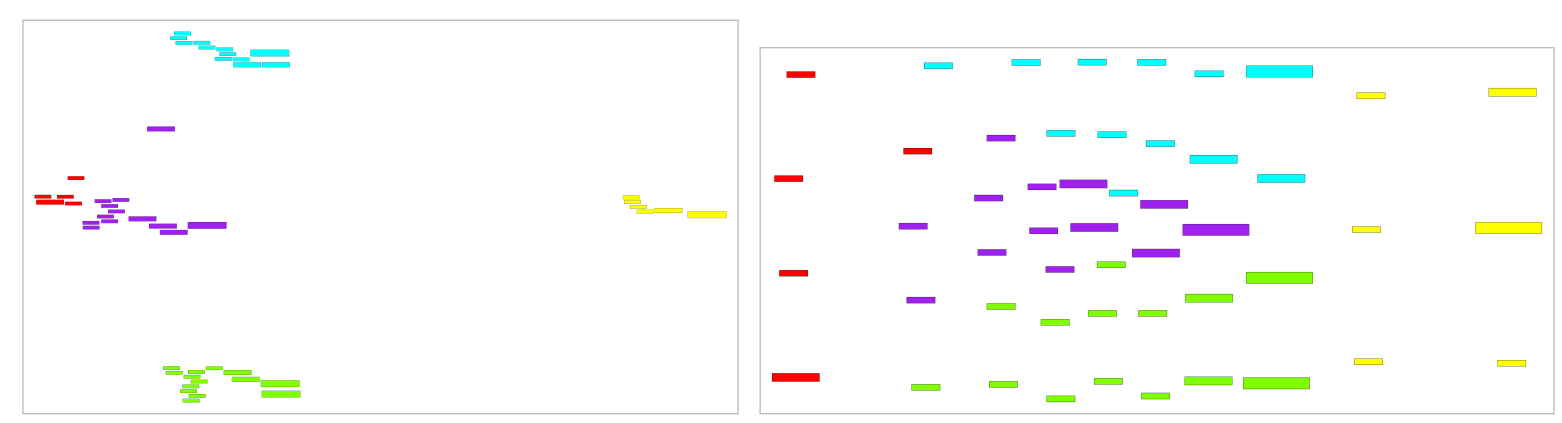

(c) PRISM

(d) Voronoi

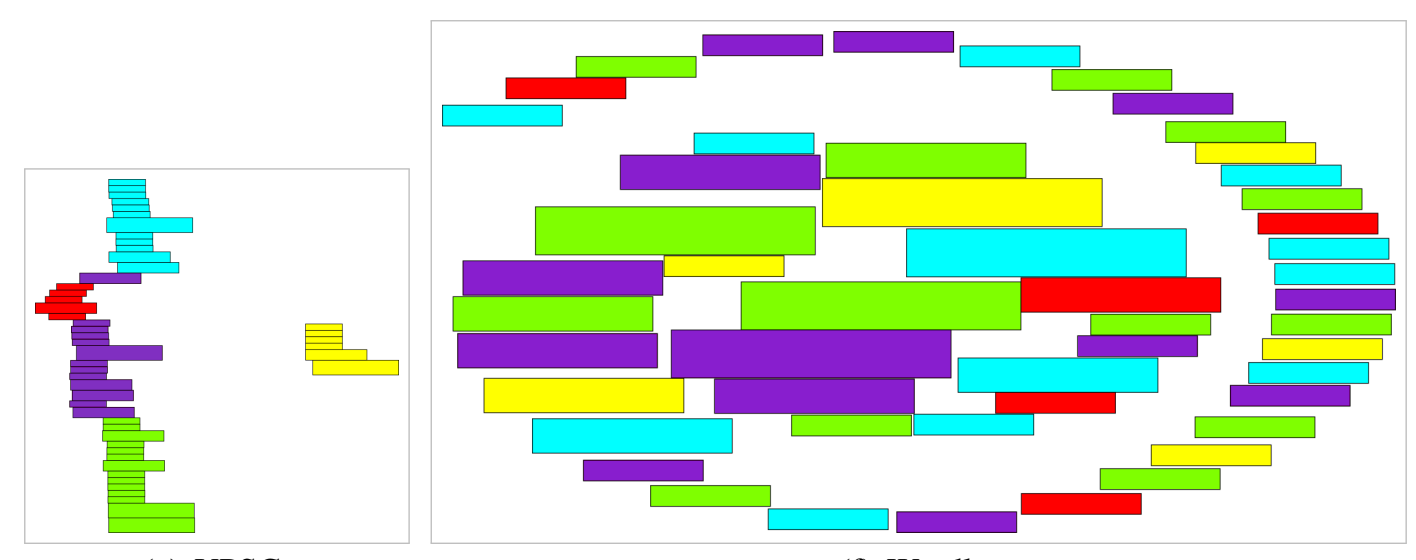

(e) VPSC

(f) Wordle

Figura 4.15: Layouts obtidos pelos métodos comparados (conjunto de dados “batman”). 


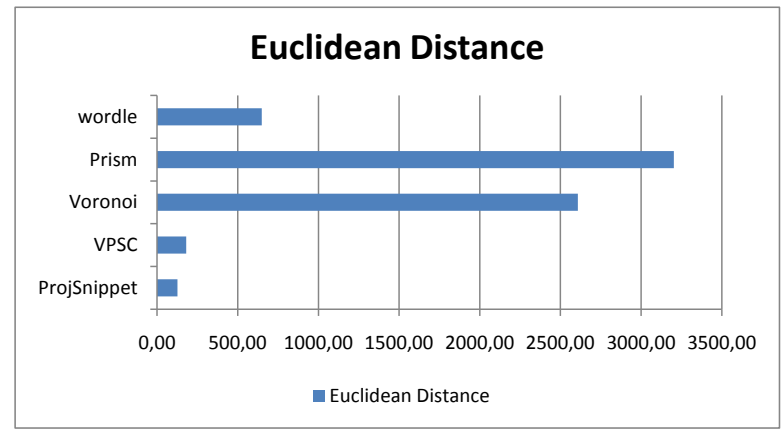

(a)

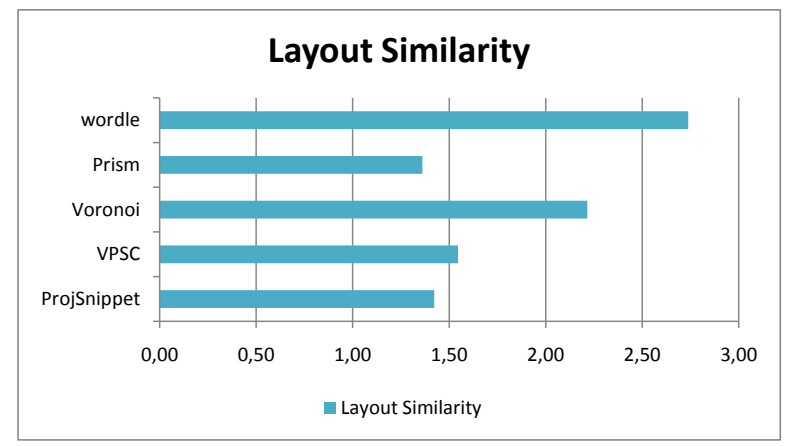

(c)

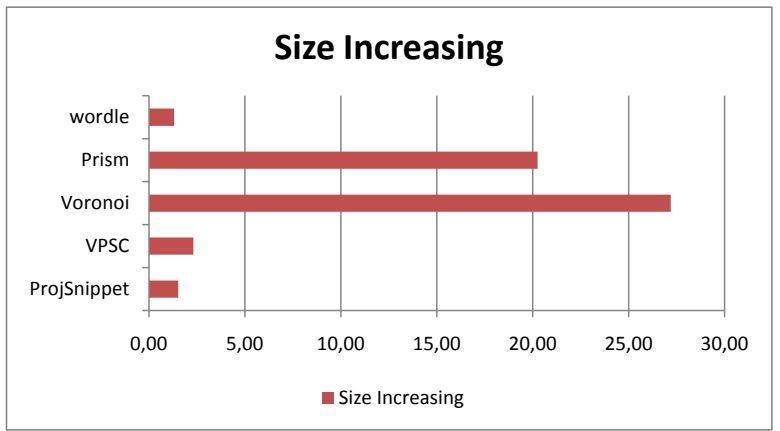

(b)

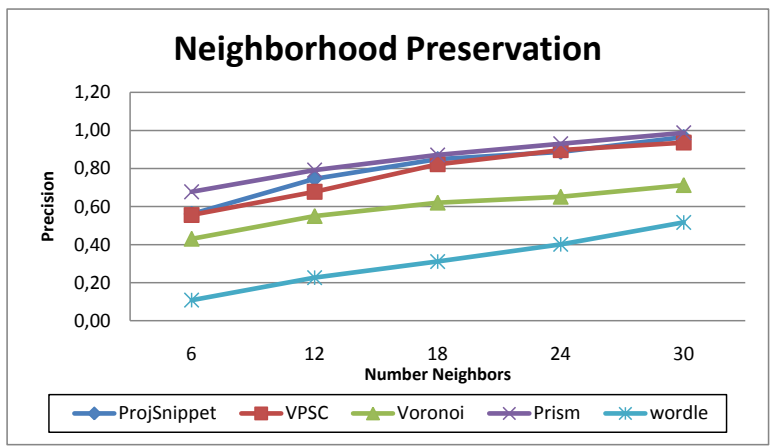

(d)

Figura 4.16: Resultados obtidos pelas métricas quantitativas aplicadas às técnicas de remoção de sobreposição aqui avaliadas (conjunto de dados "batman").

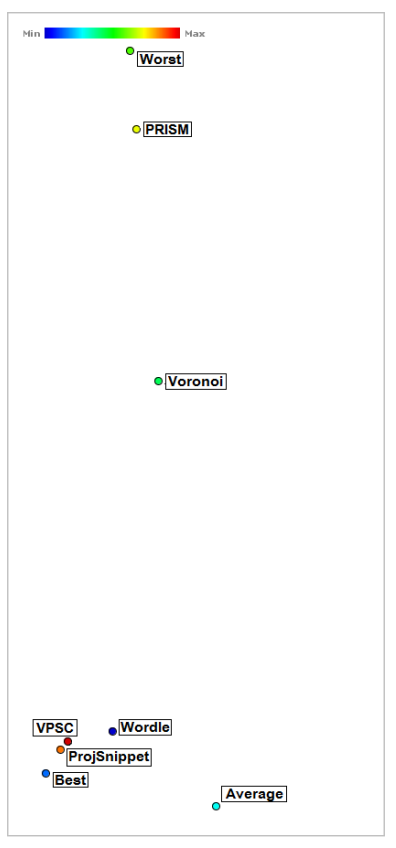

\begin{tabular}{l|c|c|c}
\hline & Best & Average & Worst \\
\hline ProjSnippet & 15.05 & 94.34 & 362.8 \\
VPSC & 20.83 & 92.20 & 358.1 \\
Voronoi & 212.4 & 221.8 & 171.4 \\
PRISM & 336.1 & 352.3 & 40.83 \\
Wordle & 44.40 & 70.94 & 351.6 \\
\hline
\end{tabular}

Figura 4.17: Projeção multidimensional e tabela de distâncias sobre os resultados obtidos para o conjunto de dados "batman". 


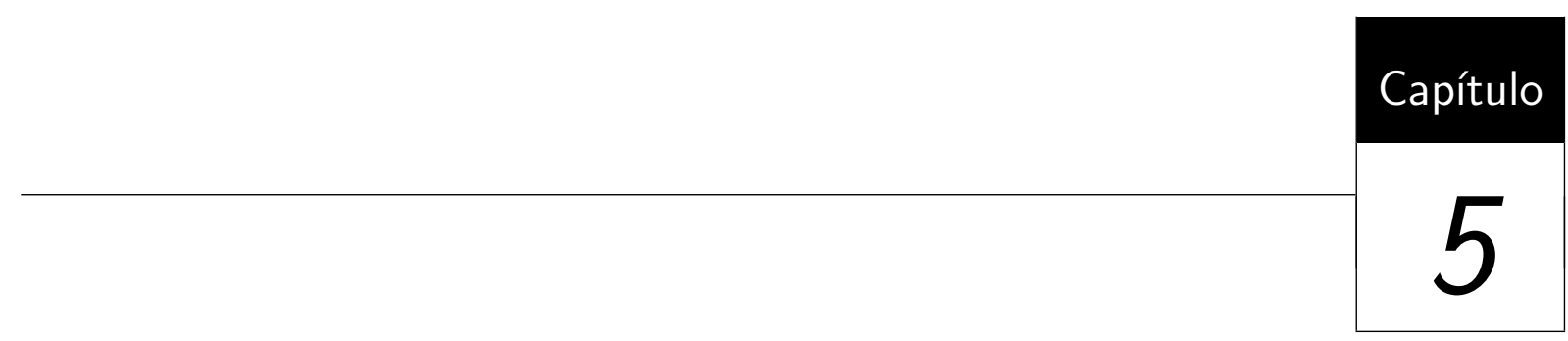

Conclusões

Neste capítulo são apresentadas as principais contribuições desta dissertação no contexto de visualização de resultados de buscas textuais, bem como algumas de suas limitações. Além disso, são apresentadas algumas ideias para trabalhos futuros no sentido de dar continuidade à abordagem proposta.

\subsection{Contribuições}

As principais contribuições deste trabalho de mestrado podem ser sucintamente sumarizadas tal como segue.

- Um novo método (denominado aqui por ProjSnippet) para exibir os resultados de consultas textuais que combina snippets textuais com um interativo layout baseado em projeção multidimensional a fim de gerar uma simples e intuitiva visualização bi-dimensional dos resultados de busca. Nossa abordagem busca representar uma coleção de resultados de busca de modo a destacar os grupos de documentos de mesma similaridade preservando, desta forma, o paradigma textual de snippets, uma característica ausente nos métodos existentes do estado da arte de visualização textual de snippets.

- O layout do ProjSnippet conta com um novo funcional de energia que considera tanto a relação de vizinhança entre os snippets como também sua sobreposição no espaço visual. 
Cabe destacar que este trabalho explora a projeção multidimensional não como uma ferramenta final de visualização, mas sim como um instrumento para a construção de visualizações interativas. Na verdade, o uso de projeções multidimensionais a fim de investigar visualizações alternativas também pode levar à novas possibilidades de sua utilização em uma infinidade de ferramentas de visualização destinadas a amparar aplicações complexas em diferentes domínios do conhecimento.

\subsection{Limitações}

Em algumas situações mais críticas, o layout visual do ProjSnippet pode ser afetado tanto pelo tamanho da tela quanto pelo número de snippets expostos simultaneamente. Os exemplos representativos anteriormente apresentados foram gerados em monitores de tamanho ligeiramente superior ao tamanho convencional. Assim, tais exemplos puderam ser facilmente interpretados uma vez que o conteúdo textual pode ser facilmente identificado. Além disso, a possibilidade de visualizar a pré-visualização de páginas web ajuda os usuários a melhor verificar o conteúdo de cada documento da coleção. Obviamente, a legibilidade poderá ser prejudicada em monitores pequenos. Neste caso, é aconselhável que o usuário defina uma quantidade não muito elevada de snippets a serem apresentados na tela. Encontrar um número ideal de snippets a serem visualizados não é uma tarefa tão simples, uma vez que há muitas variáveis envolvidas no pipeline de visualização tais como a resolução da tela e o tipo de pesquisa que está sendo realizada.

Os exemplos apresentados indicam que fazer o pré-processamento só sobre o texto resumido a partir dos snippets traz resultados bastante satisfatórios. As entidades similares ficam bem agrupadas, embora podemos observar alguns poucos "outliers" nos clusters. Nesse sentido, a relação semântica dentro dos clusters pode ser melhorada se conteúdos adicionais forem utilizados no pipeline de processamento do ProjSnippet como, por exemplo, conteúdos intrínseco extraídos de cada um dos documentos coletados. Nesse caso, é importante mencionar que tal estratégia poderia ser utilizada para gerar os vetores de entrada para o nosso algoritmo de agrupamento, porém, isso certamente levaria a um custo computacional mais elevado. Além disso, o esforço extra não produziria necessariamente melhores resultados, pois o agrupamento do texto é intrinsecamente difuso. Em muitas situações, pode-se facilmente justificar a atribuição de um documento à vários grupos se um processo de agrupamento com base no conteúdo foi realizado manualmente.

O pré-processamento requerido pelo ProjSnippet é muito simples, mas algumas questões complicadas permanecem. Um deles é que não é simples para definir valores adequados para os cortes superiores e inferiores do Luhn em casos onde pouca informação está disponível, como 
é o caso aqui. Este problema merece uma investigação mais aprofundada. Em nosso estudo, usualmente é empregado um valor de três no corte inferior, e no corte superior não é definido valor nenhum, mas os termos que aparecem na consulta são removidos a partir da representação vetorial.

O agrupamento no espaço visual irá produzir bons resultados, enquanto a técnica de projeção faz um bom trabalho na preservação de vizinhanças relevantes. Este fato aconteceu na maioria de nossos experimentos, incluindo os mostrados aqui. No entanto, se este não é o caso, a visualização de grupos pode ser enganosa. Os usuários podem interagir com a escolha do parâmetro $k$ para alterar o número de grupos enquanto se observa a visualização, a fim de investigar alternativas.

\subsection{Trabalhos Futuros}

Após a pesquisa, desenvolvimento e avaliação dessa técnica de visualização, neste período algumas ideias foram propostas no sentido de consolidar a base para trabalhos futuros. Dentre elas destacam-se:

- Processamento multimodal em novos recursos da web: Nesse caso, a técnica deverá visualizar snippets que representam páginas na web. Seria interessante iniciar com o estudo de buscas de diferentes tipos de dados na web (imagens, vídeos, etc) e processá-los de maneira multimodal, baseado não só no conteúdo textual (titulo, descrição, metadata), mas sim no próprio contexto desses recursos extraindo, assim, mais características representativas de cada instância. Esse aporte poderia favorecer os resultados no processo de projetar os dados no espaço visual.

- Otimização baseada no operador Seam Carving: A estratégia baseada no operador Seam Carving mostra um desempenho altamente aplicável no contexto de remoção de espaços em branco em visualizações. Assim, um estudo mais detalhado de como empregálo de forma a preservar as relações semânticas tal como proposto em $\mathrm{Wu}$ et al. (2011), poderá levar a uma abordagem muito eficiente na visualização da informação. Uma implementação preliminar foi desenvolvida, no contexto de buscas de vídeos usando o motor de pesquisa de Youtube, como apresenta a Figura 5.1. Nesse primeiro experimento o processamento foi feito usando só o conteúdo textual do vídeo e removendo os espaços em branco com o operador Seam Carving, além de aplicar algumas outras operações para evitar a sobreposição de snippets e fazer o clustering de resultados. O resultado preliminar mostrou-se bastante competitivo dentro desse contexto. 


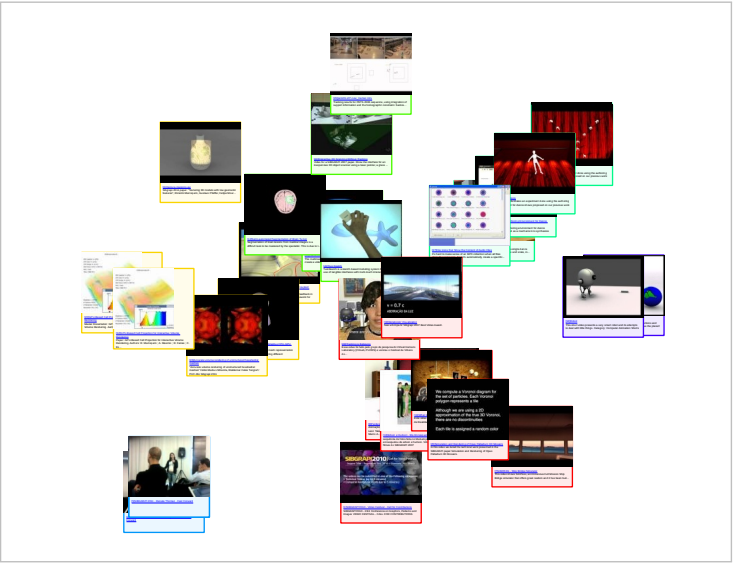

(a) Projeção multidimensional

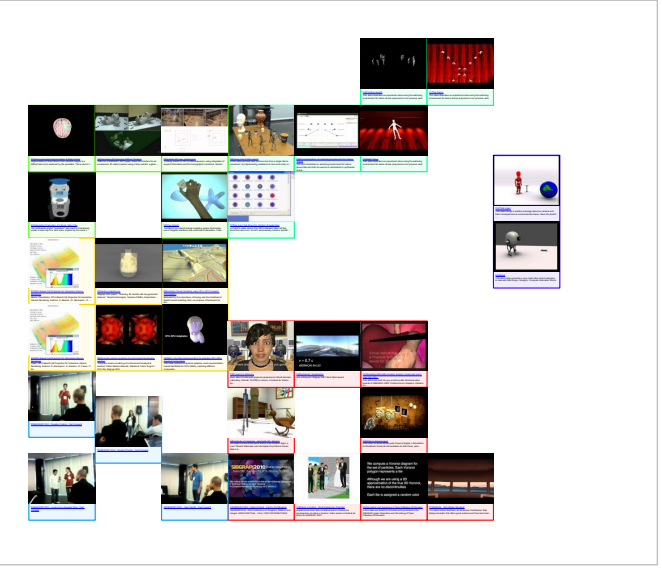

(b) Resultado da otimização

Figura 5.1: Resultados preliminares de uma abordagem baseada inteiramente no operador Seam Carving. São mostrados 37 vídeos resultantes da pesquisa do termo "sibgrapi" no motor de busca de Youtube. As cores ilustram os diferentes grupos reconhecidos após a aplicação de um algoritmo de clustering. A primeira vista pode-se notar que a semelhança entre os resultados de cada grupo fica bastante clara e evidente.

- Refinamento interativo da busca: Durante a exploração é importante fornecer ao usuário o maior conhecimento possível sobre o domínio de dados explorado e dirigir a busca interativa sempre no sentido de auxiliar o usuário. Uma estratégia de navegação que permita refinar interativamente a busca de acordo com a informação prévia que o usuário tem dos dados que está procurando poderia levar a uma ferramenta fortemente recomendável e útil na exploração dos dados.

- Estudo de novas ferramentas interativas: a necessidade de novos instrumentos de apoio à analise de dados é sempre algo útil e necessário ainda mais dependendo, principalmente, do tipo de dado que está se analisando. No caso de dados da Web, um estudo de novas formas de apresentação/visualização da informação tal como o país de procedência, a procedência do servidor de armazenamento, a quantidade de visitas do recurso pode trazer resultados promissores no futuro no contexto de visualização da informação. 


\section{Referências Bibliográficas}

Arivazhagan, S.; Ganesan, L.; Priyal, S. P. Texture classification using Gabor wavelets based rotation invariant features. Pattern Recognition Letters, v. 27, p. 1976-1982, 2006.

Arthur, D.; VAssilvitskit, S. k-means++: the advantages of careful seeding. In: Proceedings of the eighteenth annual ACM-SIAM symposium on Discrete algorithms, SODA '07, Philadelphia, PA, USA: Society for Industrial and Applied Mathematics, 2007, p. 1027-1035 (SODA '07, ).

Disponível em http://dl.acm.org/citation.cfm?id=1283383.1283494

AVIDAn, S.; ShAmir, A. Seam carving for content-aware image resizing. ACM Transactions on Graphics, v. 26, n. 3, 2007.

Disponível em http://doi.acm.org/10.1145/1276377.1276390

BAKer, C. F.; Fillmore, C. J.; Lowe, J. B. The Berkeley FrameNet Project. In: Proceedings of the 36th Annual Meeting of the Association for Computational Linguistics and 17th International Conference on Computational Linguistics, Stroudsburg, PA, USA: Association for Computational Linguistics, 1998, p. 86-90.

Disponível em http://dx.doi.org/10.3115/980845.980860

Bertin, J. Semiology of graphics. University of Wisconsin Press, 1983.

Disponível em http://books.google.com.br/books?id=ruZQAAAAMAAJ

Chakrabarti, S. Mining the Web: Discovering Knowledge from Hypertext Data. MorganKauffman, 2002.

Disponível em http://www.cse.iitb.ac.in/ ${ }^{\sim}$ soumen/mining-the-web/ 
Collins, C.; Penn, G.; Carpendale, S. Bubble Sets: Revealing Set Relations with Isocontours over Existing Visualizations. IEEE Transactions on Visualization and Computer Graphics, v. 15, n. 6, p. $1009-1016,2009$.

Cox, T.; Cox, M. Multidimensional Scaling. London: Chapman and Hall, 1994.

Cui, W.; Wu, Y.; LiU, S.; WeI, F.; Zhou, M.; Qu, H. Context-Preserving, Dynamic Word Cloud Visualization. IEEE Computer Graphics and Applications, v. 30, n. 6, p. 42 -53, 2010.

Deselaers, T.; Keysers, D.; Ney, H. Features for Image Retrieval: An Experimental Comparison. Information Retrieval, v. 11, p. 77-107, 2008.

Dörk, M.; Carpendale, S.; Collins, C.; Williamson, C. VisGets: Coordinated Visualizations for Web-based Information Exploration and Discovery. IEEE Transactions on Visualization and Computer Graphics, v. 14, n. 6, p. 1205-1212, 2008.

Dwyer, T.; Marriott, K.; Stuckey, P. J. Fast Node Overlap Removal. In: Graph Drawing, 2005, p. 153-164.

Fayyad, U.; Piatetsky-Shapiro, G.; Smyth, P. From Data Mining to Knowledge Discovery in Databases. AI Magazine, v. 17, p. 37-54, 1996.

Fellbaum, C. WordNet: An Electronical Lexical Database. Cambridge, MA: The MIT Press, 1998.

FEw, S. Information Dashboard Design: The Effective Visual Communication of Data. 1st ed. USA: O'Reilly, 2006.

Few, S. Now You See It: Simple Visualization Techniques for Quantitative Analysis. 1st ed. USA: Analytics Press, 2009.

Gansner, E. R.; Hu, Y. Efficient Node Overlap Removal Using a Proximity Stress Model. In: Graph Drawing, 2008, p. 206-217.

GÜtlein, M.; Frank, E.; HAll, M.; KARWATH, A. Large-scale attribute selection using wrappers. In: Proceedings of IEEE Symposium on Computational Intelligence and Data Mining, IEEE, 2009, p. 332-339.

Hearst, M. Search User Interfaces. Search User Interfaces. Cambridge University Press, 2009.

Disponível em http://books.google.com.br/books?id=dKDnq79R4R8C 
Hearst, M. A. TileBars: visualization of term distribution information in full text information access. In: Proceedings of the SIGCHI conference on Human factors in computing systems, New York, NY, USA: ACM Press/Addison-Wesley Publishing Co., 1995, p. 59-66. Disponível em http://dx.doi.org/10.1145/223904.223912

Hightower, R. R.; Ring, L. T.; Helfman, J. I.; Bederson, B. B.; Hollan, J. D. Graphical multiscale Web histories: a study of padprints. In: Proceedings of the 11th annual ACM symposium on User interface software and technology, New York, NY, USA: ACM, 1998, p. 58-65.

Disponível em http://doi.acm.org/10.1145/276627.276634

Hoeber, O.; YAng, X. D. A Comparative User Study of Web Search Interfaces: HotMap, Concept Highlighter, and Google. In: International Conference on Web Intelligence, 2006. WI 2006. IEEE/WIC/ACM, 2006a, p. 866-874.

Hoeber, O.; YAng, X. D. Interactive Web Information Retrieval Using WordBars. In: Proceedings of the 2006 IEEE/WIC/ACM International Conference on Web Intelligence, Washington, DC, USA: IEEE Computer Society, 2006b, p. 875-882.

Disponível em http://dx.doi.org/10.1109/WI.2006.103

JHAVERI, N.; RÄIHÄ, K.-J. The advantages of a cross-session web workspace. In: $C H I$ '05 extended abstracts on Human factors in computing systems, New York, NY, USA: ACM, 2005, p. 1949-1952.

Disponível em http://doi.acm.org/10.1145/1056808.1057064

JiAO, B.; YANG, L.; XU, J.; WU, F. Visual summarization of web pages. In: Proceedings of the 33rd international ACM SIGIR conference on Research and development in information retrieval, New York, NY, USA: ACM, 2010, p. 499-506.

Disponível em http://doi.acm.org/10.1145/1835449.1835533

Joia, P.; Coimbra, D.; Cuminato, J. A.; Paulovich, F. V.; Nonato, L. G. Local Affine Multidimensional Projection. IEEE Transactions on Visualization and Computer Graphics, v. 17, n. 12, p. 2563-2571, 2011a.

Disponível em http://dblp.uni-trier.de/db/journals/tvcg/tvcg17.html\# JoiaCCPN11

Joia, P.; Gomez Nieto, E.; Botelho, G.; Batista Neto, J.; Paiva, A.; Nonato, L. G. Projection-based Image Retrieval using Class-Specific Metrics. In: LEWINER, T.; TORRES, 
R., eds. XXIV Conference on Graphics, Patterns and Images, Maceió, AL, 2011b.

Disponível em http://www.im.ufal.br/evento/sibgrapi2011/

KEIM, D. A. Information Visualization and Visual Data Mining. IEEE Transactions on Visualization and Computer Graphics, v. 8, n. 1, p. 1-8, 2002.

Disponível em http://dx.doi.org/10.1109/2945.981847

KoH, K.; LeE, B.; KIM, B.; SeO, J. ManiWordle: Providing Flexible Control over Wordle. IEEE Transactions on Visualization and Computer Graphics, v. 16, p. 1190-1197, 2010.

Kumar, D. A.; Esther, J. Article: Comparative Study on CBIR based by Color Histogram, Gabor and Wavelet Transform. International Journal of Computer Applications, v. 17, n. 3, p. 37-44, published by Foundation of Computer Science, 2011.

Kuo, B. Y.-L.; Hentrich, T.; Good, B. M. .; Wilkinson, M. D. Tag clouds for summarizing web search results. In: Proceedings of the 16th international conference on World Wide Web, New York, NY, USA: ACM, 2007, p. 1203-1204.

Disponível em http://doi.acm.org/10.1145/1242572.1242766

Landwehr, N.; Hall, M.; Frank, E. Logistic Model Trees. Machine Learning, v. 59, p. 161-205, 2005.

Disponível em http://dx.doi.org/10.1007/s10994-005-0466-3

Liere, R.; LeEuw, W. GraphSplatting: Visualizing Graphs as Continuous Fields. IEEE Transactions on Visualization and Computer Graphics, v. 9, n. 2, p. 206-212, 2003.

Disponível em http://dx.doi.org/10.1109/TVCG.2003.1196007

LIU, B. Web Data Mining: Exploring Hyperlinks, Contents, and Usage Data (Data-Centric Systems and Applications). Secaucus, NJ, USA: Springer-Verlag New York, Inc., 2006.

LLOYD, S. Least squares quantization in PCM. IEEE Transactions on Information Theory, v. 28, n. 2, p. 129-137, 2006.

Disponível em http://dx.doi.org/10.1109/TIT.1982.1056489

Luhn, H. P. The automatic creation of literature abstracts. IBM Journal of Research and Development, v. 2, n. 2, p. 159-165, 1958.

Disponível em http://dx.doi.org/10.1147/rd.22.0159

Maheshwary, P.; Srivastav, N. Retrieving Similar Image Using Color Moment Feature Detector and K-Means Clustering of Remote Sensing Images. In: Proceedings of the 2008 International Conference on Computer and Electrical Engineering, 2008, p. 821-824. 
Nguyen, T.; Zhang, J. A Novel Visualization Model for Web Search Results. IEEE Transactions on Visualization and Computer Graphics, v. 12, n. 5, p. 981-988, 2006.

Disponível em http://dx.doi.org/10.1109/TVCG.2006.111

NizameE, M.; ShoJib, M. Visualizing the web search results with web search visualization using scatter plot. In: Web Society (SWS), 2010 IEEE 2 nd Symposium on, 2010, p. 5 -10.

Paulovich, F.; Minghim, R. HiPP: A Novel Hierarchical Point Placement Strategy and its Application to the Exploration of Document Collections. IEEE Transactions on Visualization and Computer Graphics, v. 14, n. 6, p. 1229 -1236, 2008.

Paulovich, F. V.; Minghim, R. Text Map Explorer: a Tool to Create and Explore Document Maps. International Conference on Information Visualisation, v. 0, p. 245-251, 2006.

Paulovich, F. V.; Nonato, L. G.; Minghim, R.; Levkowitz, H. Least Square Projection: A Fast High-Precision Multidimensional Projection Technique and Its Application to Document Mapping. IEEE Transactions on Visualization and Computer Graphics, v. 14, p. 564-575, 2008a.

Paulovich, F. V.; Oliveira, M. C. F.; Minghim, R. The Projection Explorer: A Flexible Tool for Projection-based Multidimensional Visualization. In: Proceedings of the XX Brazilian Symposium on Computer Graphics and Image Processing, Washington, DC, USA: IEEE Computer Society, 2007, p. 27-36.

Disponível em http://portal.acm.org/citation.cfm?id=1306881.1307555

Paulovich, F. V.; Pinho, R.; Botha, C. P.; Heiss, A.; Minghim, R. PEx-WeB: Content-based Visualization of Web Search Results. In: Proceedings of the 12th International Conference on Information Visualization, Los Alamitos, CA, USA: IEEE Computer Society, 2008b, p. 208-214.

Paulovich, F. V.; Toledo, F. M. B.; Telles, G. P.; Minghim, R.; Nonato, L. G. Semantic Wordification of Document Collections. Computer Graphics Forum, v. 31, n. 3, p. 1145-1153, 2012.

Disponível em http://diglib.eg.org/EG/CGF/volume31/issue3/ v31i3pp1145-1153.pdf

Porter, M. F. An algorithm for suffix stripping San Francisco, CA, USA: Morgan Kaufmann Publishers Inc., p. 313-316, 1997.

Disponível em http://portal .acm.org/citation. cfm?id=275537.275705 
Reiterer, H.; Mussler, G.; MAnn, T. M.; HAndschuh, S. INSYDER - an information assistant for business intelligence. In: Proceedings of the 23rd annual international ACM SIGIR conference on Research and development in information retrieval, New York, NY, USA: ACM, 2000, p. 112-119.

Disponível em http://doi.acm.org/10.1145/345508.345559

REITERER, H.; TUlliUs, G.; MANN, T. M. INSYDER: a content-based visual-informationseeking system for the Web. International Journal on Digital Libraries, v. 5, p. 25-41, 2005. Disponível em http://dx.doi.org/10.1007/s00799-004-0111-y

Sallaberry, A.; Zaidi, F.; PICH, C.; MelançOn, G. Interactive visualization and navigation of web search results revealing community structures and bridges. In: Proceedings of Graphics Interface 2010, Toronto, Ont., Canada, Canada: Canadian Information Processing Society, 2010, p. 105-112.

Disponível em http://dl.acm.org/citation.cfm?id=1839214.1839234

SAlton, G.; Wong, A.; YAng, C. S. A vector space model for automatic indexing. Communications of the ACM, v. 18, n. 11, p. 613-620, 1975.

Disponível em http://doi.acm.org/10.1145/361219.361220

SPOERRI, A. RankSpiral: Toward Enhancing Search Results Visualizations. In: Proceedings of the IEEE Symposium on Information Visualization, Washington, DC, USA: IEEE Computer Society, 2004, p. p18.

Disponível em http://dx.doi.org/10.1109/INFOVIS.2004.56

Steinbach, M.; Karypis, G.; Kumar, V. A Comparison of Document Clustering Techniques. KDD workshop on text mining, v. 400, n. X, p. 1-2, 2000.

Disponível em http://ieeexplore.ieee.org/lpdocs/epic03/wrapper.htm? arnumber $=4721382$

SvAnBerg, K. A Class of Globally Convergent Optimization Methods Based on Conservative Convex Separable Approximations. SIAM Journal on Optimization, v. 12, n. 2, p. 555-573, 2002.

Disponível em http://link.aip.org/link/?SJE/12/555/1

Teevan, J.; Cutrell, E.; Fisher, D.; Drucker, S. M.; Ramos, G.; André, P.; Hu, C. Visual snippets: summarizing web pages for search and revisitation. In: Proceedings of the 27th international conference on Human factors in computing systems, New York, NY, 
USA: ACM, 2009, p. 2023-2032.

Disponível em http://doi.acm.org/10.1145/1518701.1519008

Tejada, E.; Minghim, R.; Nonato, L. G. On improved projection techniques to support visual exploration of multidimensional data sets. Information Visualization, v. 2, n. 4, p. 218-231, 2003.

Disponível em http://dx.doi.org/10.1057/palgrave.ivs.9500054

Theodoridis, S.; Koutroumbas, K. Pattern Recognition. 4th ed. Academic Press, 2009.

Treisman, A. Preattentive processing in vision. Computer Vision, Graphics, and Image Processing, v. 31, n. 2, p. $156-177,1985$.

Disponível em http://www.sciencedirect.com/science/article/pii/ S0734189X85800049

TUFTE, E. R. The visual display of quantitative information. Cheshire, CT, USA: Graphics Press, 1986.

Viegas, F. B.; Wattenberg, M.; Feinberg, J. Participatory Visualization with Wordle. IEEE Transactions on Visualization and Computer Graphics, v. 15, p. 1137-1144, 2009.

WARE, C. Information Visualization: Perception for Design. The Morgan Kaufmann Series in Interactive Technologies. Morgan Kaufman, 2004.

Disponível em http://books.google.com.br/books?id=ZmG_FiqqyqgC

Wong, P. C. Guest Editor's Introduction: Visual Data Mining. IEEE Computer Graphics and Applications, v. 19, p. 20-21, 1999.

Woodruff, A.; Faulring, A.; Rosenholtz, R.; Morrsion, J.; Pirolli, P. Using thumbnails to search the Web. In: Proceedings of the SIGCHI conference on Human factors in computing systems, New York, NY, USA: ACM, 2001, p. 198-205.

Disponível em http://doi.acm.org/10.1145/365024.365098

Wu, Y.; Provan, T.; Wei, F.; LiU, S.; MA, K.-L. Semantic-Preserving Word Clouds by Seam Carving. Computer Graphics Forum, v. 30, n. 3, p. 741-750, 2011.

Disponível em http://dx.doi.org/10.1111/j.1467-8659.2011.01923.x

YaO, J. T.; Hoeber, O.; YAng, X. D. Supporting Web Search with Visualization Springer London, p. 183-214, 2010. 